LABOR INCOME DYNAMICS AT BUSINESS-CYCLE FREQUENCIES:

IMPLICATIONS FOR PORTFOLIO CHOICE

Anthony W. Lynch

Sinan Tan

Working Paper 11010 
NBER WORKING PAPER SERIES

\title{
LABOR INCOME DYNAMICS AT BUSINESS-CYCLE FREQUENCIES: IMPLICATIONS FOR PORTFOLIO CHOICE
}

\author{
Anthony W. Lynch \\ Sinan Tan \\ Working Paper 11010 \\ http://www.nber.org/papers/w11010
NATIONAL BUREAU OF ECONOMIC RESEARCH
1050 Massachusetts Avenue
Cambridge, MA 02138
December 2004

The authors would like to thank Ned Elton, Marti Gruber, Joel Hasbrouck, Lasse Pedersen, Matt Richardson, Jessica Wachter and participants in the Monday NYU Finance Seminar and the NYU Macro-finance Reading Group for helpful comments and suggestions. All remaining errors are of course the authors' responsibility. The views expressed herein are those of the author(s) and do not necessarily reflect the views of the National Bureau of Economic Research.

(C) 2004 by Anthony W. Lynch and Sinan Tan. All rights reserved. Short sections of text, not to exceed two paragraphs, may be quoted without explicit permission provided that full credit, including $\odot$ notice, is given to the source. 
Labor Income Dynamics at Business-Cycle Frequencies: Implications for Portfolio Choice Anthony W. Lynch and Sinan Tan

NBER Working Paper No. 11010

December 2004

JEL No. G11, G12

\section{ABSTRACT}

A large recent literature has focused on multiperiod portfolio choice with labor income, and while the models are elaborate along several dimensions, they all assume that the joint distribution of shocks to labor income and asset returns is i.i.d.. Calibrating this joint distribution to U.S. data, these papers obtain three results not found empirically for U.S. households: young agents choose a higher stock allocation than old agents; young agents choose a higher stock allocation when poor than when rich; and, young agents always hold some stock. This paper asks whether allowing the conditional joint distribution to depend on the business cycle can allow the model to generate equity holdings that better match those of U.S. households, while keeping the unconditional distribution the same as in the data. Calibrating the business-cycle variation in the first two moments of labor income growth to U.S. data leads to large reductions in stock holdings by young agents with low wealthincome ratios. The reductions are so large that young, poor agents now hold less stock than both young, rich agents and old agents, and also hold no stock a large fraction of the time. Our results suggest that the predictability of labor-income growth at a business-cycle frequency plays an important role in a young agent's decision-making about her portfolio's stock holding.

Anthony W. Lynch

Stern School of Business

New York University

44 West Fourth Sreet

Suite 9-190

New York, NY 10012-1126

and NBER

alynch@stern.nyu.edu
Sinan Tan

Stern School of Business

New York University

44 West Fourth Sreet

Suite 9-190

New York, NY 10012-1126

stan@stern.nyu.edu 


\section{Introduction}

A large recent literature has focused on multiperiod portfolio choice with labor income, and while the models are elaborate along several dimensions, they all assume that the joint distribution of shocks to labor income and asset returns is i.i.d.. ${ }^{1}$ Calibrating this joint distribution to U.S. data, these papers obtain three results not found empirically for U.S. households: young agents choose a higher stock allocation than old agents; young agents choose a higher stock allocation when poor than when rich; and, young agents always hold some stock. ${ }^{2,3}$ This paper asks whether allowing the conditional joint distribution to depend on the business cycle can allow the model to generate equity holdings that better match those of U.S. households, while keeping the unconditional distribution the same as in the data. Calibrating the business-cycle variation in the first two moments of labor income growth to U.S. data leads to large reductions in stock holdings by young agents with low wealth-income ratios. The reductions are so large that young, poor agents now hold less stock than both young, rich agents and old agents, and also hold no stock a large fraction of the time. Our results suggest that the predictability of labor-income growth at a business-cycle frequency plays an important role in a young agent's decision-making about her portfolio's stock holding.

Enriching labor-income dynamics along this dimension can be motivated by recent evidence that the first and second moments labor income growth are predictable at business-cycle frequencies. In a recent paper, Storesletten, Telmer and Yaron (2004) using household-level labor-earnings data from PSID, estimate that standard deviation of shocks to permanent log labor income increases by around $75 \%$ as the macroeconomy moves from peak to trough. Further, economic intuition strongly suggests that labor income growth may be higher in good times than in bad. We esimate the magnitude of this effect by taking the changes in log aggregate labor income and covarying this series with the lagged value of the 12-month dividend yield on the value weighted NYSE index. When the aggregate labor income measure is either monthly earnings for the retail sales industry or the total private sector (both from the Bureau of Labor Statistics tables), the point estimate of this covariance is negative and strongly significant. If one subscribes to the view that dividend yield is counter-cyclical, this point estimate implies that the change in log aggregate labor income is

\footnotetext{
${ }^{1}$ See Zeldes (1989), Heaton and Lucas (1997), Davis and Willen (2000a), Viceira (2001), Cocco, Gomes and Maenhout (2002), and Gomes and Michaelides (2003).

${ }^{2}$ These findings are robust to the presence of reasonable transactions costs in the stock market (see Heaton and Lucas, 1997) but possibly not habit formation preferences. Polkovnichenko (2003) finds that additive habit formation preferences can induce lower stock holdings as the agent's wealth-income ratio declines.

${ }^{3}$ The empirical papers that report contradictory stock holding patterns by U.S. households include Friend and Blume (1975), Poterba (1993), Bertaut (1994), Blume and Zeldes (1994), Heaton and Lucas (1999) and VissingJorgensen (2002).
} 
pro-cyclical, which is consistent with intuition. Moreover, if one assumes that log individual labor income growth consists of an aggregate component, log aggregate labor income growth, plus an idiosyncratic component uncorrelated with the business cycle, then this covariance point estimate is also a point estimate of the covariance of log individual labor income growth with lagged dividend yield. Calibrating the volatility of permanent labor income growth to individual data, the resulting correlations with lagged dividend yield are around $-2 \%$ or $-3 \%$. While the magnitude seems small, the effect on portfolio allocations could be large, much in the same way that return predictability regressions with low R-squareds can still induce large hedging demands for stock.

Both the pro-cyclical behavior of mean labor income growth (state-dependent mean channel)and the counter-cyclical behavior of labor-income volatility (state-dependent volatility channel) can generate negative hedging demands for stocks and therefore more realistic stock holding implications. The intuition is as follows. Merton (1973) shows that for CRRA investors with risk aversion greater than 1, positive correlation between return and future investment opportunities leads to reductions in stock holdings by young investors. Empirically, realized stock return is low when the economy enters a recession. But in recessions expected income growth is low and volatility of income growth is high. So a low stock return this period means low expected income growth and high volatility of income growth in the next period and future periods. Thus, stock returns and future "labor income" opportunities are positively correlated. Therefore business-cycle variation in the first two moments of income growth causes reductions in stock holdings by young investors. Moreover, these reductions are more pronounced for poor young investors, for whom future labor income is more important. ${ }^{4}$

A third channel by which labor income reduces an agent's allocation to stock has also been discussed in the literature. ${ }^{5}$ Positive conditional correlation between today's realized return and today's labor growth innovation can also reduce equity holdings (the return correlation channel). This is a diversification-like channel and is available even when stock return and labor income growth are i.i.d. processes. Consequently, it is a channel that is quite distinct from the other two we are considering. Moreover, the contemporaneous correlation between returns and labor income growth

\footnotetext{
${ }^{4}$ Note that these negative hedging demands can be regarded as the flipside of the effect of mean stock return predictability on portfolio allocation. Since expected stock returns are positively related to dividend yield (see, for example, Fama and French, 1988 and 1989), the negative correlation between today's dividend yield innovation and today's return shock also means that today's stock returns are high when expected future stock returns are low, which induces a positive hedging demand for stock. This is one of the key results from the recent literature exploring portfolio choices by a multiperiod agent in the persence of return predictability: see, for example, Campbell and Viceira (1998), Barberis (2000) and Balduzzi and Lynch (1999).

${ }^{5}$ See Davis and Willen (2000b), Michaelides (2003).
} 
appears to be small in the data. Davis and Willen (2000b) use individual level Current Population Survey data and consider the correlations between S\&P 500 returns and labor income shocks of synthetic individuals defined in terms of sex, birth cohort and educational attaintment. They find that these correlations are very close to zero or negative for all but the most educated group. Fama and Schwert (1977) report near zero correlations between the value weighted portfolio of NYSE stocks and measures of aggregate labor income. Botazzi et at. (1996) provide corroborating international evidence. This small unconditional correlation is an important stylized fact that likely restricts the ability of the return correlation channel to reduce equity holdings.

Our goal is to quantify the effects of these three labor-income channels on portfolio allocations by young investors. To do so, we formulate a dynamic life-cycle portfolio choice problem and calibrate the stock return and labor income processes to U.S. data. Simple VAR dynamics are used to incorporate all three mechanisms, with dividend yield, a counter-cyclical business-cycle variable, being used as the predictor for both labor-income growth and stock return. The VAR process for labor-income growth is initially assumed time-invariant over the agent's 20-year horizon. The statedependent mean and return correlation channels are incorporated by calibrating the covariance of labor income growth with stock return and lagged dividend yield respectively to that for aggregate monthly wages in the retail trade industry. When the second moment is allowed to be predictable, the ratio of the recession to boom innovation volatility for permanent labor income growth is matched to 1.75, the value reported in Storesletten, Telmer and Yaron (2004). At the same time, the unconditional volatility of permanent labor income growth itself is always matched to the $15 \%$ per annum reported in Gakidis (1997) based on PSID data for professionals and managers not self-employed under age 45.

Our results, for a power utility agent with risk aversion of 6 , indicate that presence of the the two business-cycle channels (the state-dependent mean and volatility channels) leads to significant reductions in the young poor agent's demand for stocks. Even in the presence of the return predictability that causes young agent's to increase stock holdings, the presence of the first two channels calibrated to data causes the agent's stock allocation to drop from near the boundary of $100 \%$ to an average allocation of less than $37 \%$ for a young agent's whose financial wealth is less than 30 times her monthly wage. The magnitude of the reduction is only increased by considering smaller wealth-income ratios. Adding the return-correlation channel has only a negligible incremental effect on allocations, consistent with the idea that the small empirical correlation between labor income growth and stock returns might hamper this channel's ability to affect stock allocations. However, 
both predictability channels are important. When financial wealth is 30 times the young agent's monthly labor income, the average stock allocation increases by an allocation of $29 \%$ when the mean channel is switched off and by an allocation of $39 \%$ when the volatility channel is switched off. Even so, it is the volatility channel's presence that causes the relation between average stock allocation and wealth-income ratio to flip from the negative relation in the theoretical literature to a positive one as in the data.

To examine stock allocations as a function of age, we conduct simulations that fix the agent's wealth-income ratio in her first month. With the ratio fixed at 1 so that financial wealth equals monthly labor income, the average stock allocation is a negative function of age when all three channels are switched off. Switching on the two business-cycle channels causes the function to become positive, consistent with the data. Turning to the non-participation results, all three channels switched off leads to participation in the stock market virtually all the time, irrespective of age or wealth-income ratio. Switching on the two business-cycle channels results in substantial non-participation by agents in their first month and the non-participation steadily declines as the agent gets older. For example, an agent with a wealth-income ratio of 1 in the first month decides not to participate in the stock market $70 \%$ of the time in the first month; and after ten years, this probability has declined to a fraction that is still above $20 \%$.

Adding a $10 \%$ temporary shock to per annum labor income growth, which translates to a $24.5 \%$ temporary shock to monthly growth, has virtually no effect on the agent's allocations. Thus, it appears that temporary shocks to labor income growth do not materially affect allocations, at least shocks of the magnitude documented for U.S. individuals.

The impact of an unemployment state on portfolio allocations is another question of interest. Carroll (1992) uses PSID data and finds that the probability of a near-zero income realization for a year is $0.05 \%$. We incorporate this by allowing a $0.05 \%$ chance each month of being in an unemployment state that pays only $10 \%$ of permanent labor income. This parameter choice implies that the average fraction of a year that the agent is unemployed in $0.05 \%$, which is also implied by the Carroll number. Somewhat surprisingly, the results are qualitatively similar to those without an unemployment state. Cocco, Gomes and Maenhout (2002) examine the effect of an unemployment state in a model with annual decision-making and they present simulation results that are suggestive, but not conclusive, that an $0.05 \%$ probability of being unemployed in any given year has a large effect on stock allocations, particularly early in life. But their model allows for a hump-shaped labor-income profile over the agent's life and perhaps more importantly, implies some 
degree of persistence in the unemployment state at a monthly frequency. To incorporate persistence into the unemployment state, we also consider a Markov regime switching model, with two states, employment and unemployment. By allowing the transaction matrix to be age-dependent, we are able to exactly replicate the transition dynamics used by Cocco, Gomes and Maenhout and assumed by Carroll. Making the unemployment state persistent lowers average stock allocations irrespective of which subset of channels is switched on, but the incremental effect of the channels on stock allocations largely remains the same.

The magnitude of the covariance with lagged dividend yield is lower for growth in total private sector earnings than for growth in retail trade earnings. Consequently, it is worthwhile checking whether the state-dependent mean channel continues to have a large effect when this series is used to calibrate the covariance. We find that the combined effect of the two business-cycle channels on average stock allocations in the first month is reduced but never by an amount greater than $12 \%$, with the largest reduction occurring when the young agent's wealth is 30 times her monthly labor income. But at this wealth-income ratio, switching off the state-dependent mean channel still increases the young agent's stock allocation by an amount of $20 \%$ (as opposed to an amount of $29 \%$ for retail trade) while switching off the state-dependent volatility increases the allocation by an amount of $35 \%$, which is quite close to the $39 \%$ reported for retail trade.

An agent's labor income profile is typically hump-shaped and she enjoys a period of retirement. We use a 3rd order polynomial to approximate the hump shaped life-cycle earnings profile, taking the parameter point estimates in Cocco, Gomes and Maenhaut (2002) for college graduates. The agent starts work at age 22 and retires at 65, receiving a lump sum payout equivalent to receiving 93.8\% of her retirement permanent income until death as reported in Cocco, Gomes and Maenhout (2002) for college graduates. The agent dies with probability 1 at age 100, and death probabilities are taken from the U.S. Life Tables, 2001, provided by the NCHS.

Introducing business cycle variation in the first two moments of permanent labor income growth causes the young poor lifecycle agent to reduce stock holdings even more aggressively than the young agent in the twenty-year flat profile case. For a young agent whose wealth is less than 30 times her monthly income, the average reduction is always more than $67 \%$ in the lifecycle case as opposed to only $52 \%$ in the twenty-year flat profile case. All the qualitative conclusions from the twenty-year flat profile case carry over to the more realistic lifecycle setting. The presence of the two business cycle channels causes the relation between stock allocation and wealth-income ratio to become positive for young agents and the relation between stock allocation and age to become 
positive for poor, young agents. The former result is again driven by the state-dependent volatility channel while both channels are important for the latter finding. The two business-cycle channels induce substantial non-participation in a setting where there would be almost none with all three channels switched off. When the two business-cycle channels are present, a 22-year old agent with no financial wealth decides not to participate in the stock market over $70 \%$ of the time in her first year, a substantial fraction of the time in the rest of her 20s and early 30s, and always some fraction of the time through until retirement. The hump-shape is having some effect since replacing it with a flat profile with the same monthly mean as in the twenty-year case causes the average reduction for a young agent whose wealth is less than 30 times her monthly income to never exceed $61 \%$. However, eliminating the lump sum payout upon retirement has almost no impact on the stock holding by the young agent, though it materially decreases the agent's stock allocation in the years just prior to retirement.

Two recent papers have considered the return correlation channel as a way to generate more reasonable equity holdings. Davis and Willen (2000a) consider a multiperiod CARA agent who has access to returns and labor income growth, and show that sizeable positive contemporaneous correlation between stock returns and labor income innovations induces the agent to hold considerably less stock than in the zero correlation case. A closely related paper, Michaelides (2003), allows stock returns to be predictable but keeps labor income growth i.i.d.. He briefly discusses how the positive correlation between the conditional shock to stock return and labor income can lead to negative hedging demands for stocks. While his labor income process is not state dependent, his permanent income innovation is allowed to be conditionally correlated with the innovation to the predictive business cycle variable and to returns. He discusses large negative hedging demands for the case of positive correlation between returns and the permanent labor income innovation, but he does not provide any supporting results.

The three channels we consider are also likely to affect the portfolio allocations of agent's who receive proprietary income rather than wage income. Heaton and Lucas (2000a) document a similar puzzle for individuals receiving proprietary income: the standard model produces stock holdings that are too high. The state-dependent mean and return correlation channels are incorporated by calibrating the covariance of labor income growth with stock return and lagged dividend yield respectively to that for aggregate monthly non-farm proprietary income from NIPA. When the second moment is allowed to be predictable, the ratio of the recession to boom innovation volatility for permanent labor income growth is, in the absence of a data estimate based on proprietary 
income, again matched to the Storesletten, Telmer and Yaron (2004) value of 1.75. At the same time, the unconditional volatility of permanent proprietary income growth itself is always matched to the $25 \%$ per annum used by Heaton and Lucas (2000b) based on annual Tax Model data. There is no temporary shock. The resulting $25 \%$ implied for per annum proprietary income growth volatility seems reasonable since Heaton and Lucas report median volatilities of $29 \%$ and $19 \%$ per annum respectively for proprietary and labor income, while our wage-earner calibration with temporary shocks implies a per annum volatility of $18 \%$. We find that business cycle variation in the first two moments of permanent proprietary income growth causes the young agent to drastically reduce her stock position. For young agents with wealth less than 30 times monthly income, the reduction in holding is always at least $60 \%$. Adding the return correlation channel has a negligible incremental effect, never more than $3 \%$, despite the larger covariance with return than the two labor income series.

Section 2 presents our formulation of the problem and describes the three channels through which we allow labor income to affect the stock holdings of young agents. while section 3 describes how the return and labor income processes are calibrated to the data. Section 4 discusses our results and section 5 concludes.

\section{Formulation and Solution of the Problem}

\subsection{Processes}

Following Carroll (1996) and (1997), labor income is specified to have both permanent and temporary components:

$$
\begin{array}{r}
y_{t+1}=y_{t+1}^{P}+\epsilon_{t+1}, \\
g_{t+1} \equiv y_{t+1}^{P}-y_{t}^{P}=\bar{g}+b_{g} d_{t}+u_{t+1},
\end{array}
$$

where $y_{t}$ is $\log$ labor income received at $\mathrm{t}, y_{t}^{P}$ is $\log$ permanent income at $\mathrm{t}, \epsilon_{t+1}$ is $\log$ temporary labor income at $\mathrm{t}, d_{t} \equiv \ln \left(1+D_{t}\right)$, and $\epsilon_{t}$ and $u_{t+1}$ are uncorrelated i.i.d. processes. $D$ is the mean reverting predictor to proxy for the business cycle, which we take to be the 12-month dividend yield on the value-weighted NYSE index. $\epsilon_{t}$ and $u_{t+1}$ contain no information about future returns $\left(R_{t+1}, R_{t+2}, \ldots\right)$ or about future $D$ values $\left(D_{t+1}, D_{t+2}, \ldots\right)$. We also specify a VAR for the $\log$ market return and dividend yield for which lagged didvidend yield is the only predictor:

$$
\begin{gathered}
r_{t+1}=a_{r}+b_{r} d_{t}+e_{t+1}, \\
d_{t+1}=a_{d}+b_{d} d_{t}+w_{t+1},
\end{gathered}
$$


where $r_{t+1} \equiv \ln \left(R_{t+1}\right)$ is the log market return, $a_{r}$ and $a_{d}$ are intercepts, $b_{r}$ and $b_{d}$ are coefficients and $[\mathrm{w} \mathrm{e} \mathrm{v}]$ is a vector of mean-zero, multivariate normal disturbances, with unconditional covariance matrix $\Sigma$, whose conditional covariance matrix might possibility depend on the state. Let $\sigma_{k j}$ be the unconditional covariance of $k$ with $j$ where $k, j$ can be $u$, $e$ or $w$. Similarly, let $\sigma_{k}$ be the unconditional standard deviation of $k$ where $k$ can be $u$, $e$ or $w$.

\subsection{Problem and Solution Technique}

With labor income, the law of motion for the investor's wealth, $W$, is given by

$$
\begin{aligned}
& W_{t+1}=\left(W_{t}+Y_{t}-c_{t}\right)\left[\alpha_{t}\left(R_{t+1}-R_{t}^{f}\right)+R_{t}^{f}\right] \\
& \text { for } t=1, \ldots, T-1 \text {, }
\end{aligned}
$$

where $Y_{t}$ is labor income received at time- $t$. At the terminal data $T, C_{T}=W_{T}+Y_{T}$ so the investor does receive labor income at the terminal date.

The law of motion for the investors wealth, $W$, can be rewritten as

$$
\begin{aligned}
& \Gamma_{t+1}=\left(\Gamma_{t}-\hat{\kappa}_{t}+\exp \left\{\epsilon_{t}\right\}\right) \exp \left\{-g_{t+1}\right\}\left[\alpha_{t}\left(R_{t+1}-R_{t}^{f}\right)+R_{t}^{f}\right] \\
& \text { for } t=1, \ldots, T-1 \text {. }
\end{aligned}
$$

where $\hat{\kappa}_{t} \equiv \frac{c_{t}}{Y_{t}^{P}}$. Eq.(6) is also the evolution equation for the state variable $\Gamma_{t}$.

We consider the optimal portfolio problem of a investor with a finite life of $T$ periods and utility over intermediate consumption. Preferences are time separable and exhibit constant relative risk aversion (CRRA):

$$
E\left[\sum_{t=1}^{T} \delta^{t} \frac{c_{t}^{1-\gamma}}{1-\gamma} \mid D_{1},\right],
$$

where $\gamma$ is the relative-risk-aversion coefficient, $\delta$ is the time-discount parameter and $\Gamma_{t}$ is the ratio of financial wealth at $t$ to lagged permanent labor income. Note that the expected lifetime utility depends on the state of the economy at time 1. Given this specification of the agent's problem with labor income, the value function at $t$ is homogenous in $Y_{t}^{P}$ and has an additional state variable: the ratio of financial wealth at $t$ to lagged permanent labor income $\Gamma_{t}$. Given our parametric assumptions, the Bellman equation faced by the investor is given by

$$
\begin{array}{r}
\frac{a\left(\Gamma_{t}, D_{t}, t\right)\left(Y_{t}^{P}\right)^{1-\gamma}}{1-\gamma}=E\left[\operatorname { m a x } _ { \hat { \kappa } ( \Gamma _ { t } , D _ { t } , \epsilon _ { t } , t ) , \alpha ( \Gamma _ { t } , D _ { t } , \epsilon _ { t } , t ) } \left\{\frac{\hat{\kappa}_{t}^{1-\gamma}\left(Y_{t}^{P}\right)^{1-\gamma}}{1-\gamma}\right.\right. \\
\left.\left.+\delta \frac{\left(Y_{t}^{P}\right)^{1-\gamma}}{1-\gamma} E\left[a\left(\Gamma_{t+1}, D_{t+1}, t+1\right)\left(\exp \left\{g_{t+1}\right\}\right)^{1-\gamma} \mid \Gamma_{t}, D_{t}, g_{t}, \epsilon_{t}\right]\right\} \mid \Gamma_{t}, D_{t},\right], \\
\text { for } t=1, \ldots, T-1,
\end{array}
$$


where $\alpha_{t} \equiv \alpha\left(\Gamma_{t}, D_{t}, \epsilon_{t}, t\right)$ and $\hat{\kappa}_{t} \equiv \hat{\kappa}\left(\Gamma_{t}, D_{t}, \epsilon_{t}, t\right)$. This recursion is solved by backward iteration starting with $t=T-1$ and $a(\Gamma, D, T)=\Gamma_{T}^{1-\gamma}$.

We also consider a version of the problem in which the agent retires at some time $S$ and thereafter receives no labor income through until the terminal date. Instead the agent receives a lump sum payout at time- $S$ which is some multiple of permanent labor income at time- $S$. So at the retirement date, the wealth evolution equation is:

$$
W_{S+1}=\left(W_{S}+Y_{S}^{P}\left(\eta_{S}+\exp \left\{\epsilon_{S}\right\}-c_{S}\right)\left[\alpha_{S}\left(R_{S+1}-R_{S}^{f}\right)+R_{S}^{f}\right]\right.
$$

The Bellman equation (8) also applies to this problem for $t=1, \ldots, S-1$ and it is solved by iterating back from $t=S-1$ with $a(\Gamma, D, S)=\hat{a(D}, T-S+1) \Gamma_{S}^{1-\gamma}$, where $\hat{a(t)} W_{t}^{1-\gamma}$ is the value function for the T-S period allocation problem with no labor income. To allow the agent's income process to be age-dependent, we sometimes allow the $\mu_{g}$ to be age-dependant. We also incorporate survival probabilities, with $\delta^{t}$ in (7) replaced by $p_{1, t} \delta^{t}$ and $\delta$ in (8) replaced by $p_{t, t+1} \delta$, where $p_{\tau, t}$ is the probability that the agent is still being alive at time- $t$ given that she is alive at time- $\tau$.

The holdings of both the risky and the riskless assets are always constrained to be non-negative. Compared to the standard portfolio choice problem, the presence of an additional state variable, the wealth to lagged permanent income ratio, considerably complicates the methodology needed to obtain accurate solutions in a manageable time-frame. Building on the numerical approach in Gourinchas and Parker (2002), we develop a new numerical methodology that allows the number of grid points to vary across ranges of the wealth-income ratio and chooses the number for each range to ensure that the resulting numerical errors in the policy functions are within prespecified bounds. The appendix contains a detailed description of the methodology employed.

\subsection{The Three Channels and Their Marginal Impact on Allocations}

The paper focuses on three channels through which labor income can affect the stock holdings of young agents and it is easy to describe them in the context of the VAR framework presented above in equations (2) to (4). The state-dependent mean channel (SDM) requires expected $g$ in this and future periods to depend on current $d$ in such a way that it is higher in expansions than in recessions. Since $d$ is countercyclical, this is equivalent to $b_{g}<0$. This channel is switched off by setting $b_{g}=0$. The state-dependent volatility channel (SDV) requires the conditional volatility of $g$ this period to depend on current $d$ so that it's higher in recessions than expansions. Following Storesletten, Telmer and Yaron (2004), we parameterize this by allowing the conditional volatility of $g$ to take two values, depending on the current $d$ value. In particular, since $d$ is countercyclical, 
we allow $\sigma\left[u_{t+1} \mid d_{t} \leq d^{*}\right]<\sigma\left[u_{t+1} \mid d_{t}>d^{*}\right]$ for $d^{*}$ the highest $d$ value for which the economy is still in an expansion. This channel is switched off by setting $\sigma\left[u_{t+1} \mid d_{t}\right]=\sigma_{u}$ for all $d_{t}$. The return correlation channel (CWR) requires a positive conditional covariance between $r$ and $g$ which means $\sigma_{u e}>0$. Setting $\sigma_{u e}=0$ switches off this channel.

It is easy to see that all pairwise combinations of these three channels switched on and off are implementable, resulting in 8 specifications: 1) All Effects: SDM, SDV, CWR; 2) SDM, SDV, no CWR; 3) SDM, no SDV, CWR; 4) no SDM, SDV, CWR; 5) no SDM, no SDV, CWR; 6) no SDM, SDV, no CWR; 7) no SDM, no SDV, CWR; 8) None: no SDM, no SDV, no CWR. Each of the three channels can be switched on when both, one, or none of the other channels is/are present. Thus, for each channel, there are 4 comparisons that generate 4 measures of that channel's incremental effect on stock holdings. The 4 comparisons hold all else constant, including return predictability, so that any change in stock holdings can only be due to the effect of the channel in question.

\section{Calibration}

We use the one-month Treasury-bill rate to obtain a proxy for the risk-free rate, we use the 12month dividend yield on the value-weighted NYSE index as a proxy for the predictive variable D. Aggregate labor income data is used to obtain point estimates of some moments of interest. Wage earnings data is from the Bureau of Labor Statistics website. We ues either Retail Trade which is series CEU4200000004 or Total Private which is series CEU0500000004. Proprietory income data is from Department of Commerce, Burea of Economic Analysis website. We use the Non Farm Proprietor's income series in NIPA table 2.6. All data is measured at a monthly frequency. The Retail Trade income data starts from January 1972, Total Private income data from January 1964, and Proprietary income data from January 1959. Return on the market and dividend yield start from January 1927. All data series end in December 2003. Income and return data are disinflated using a CPI measure, series CPIAUCNS, available from U.S. Department of Labor: Bureau of Labor Statistics. Per capita income values are generated by dividing all income series with a population measure, series POP, available from U.S. Department of Commerce: Census Bureau.

We estimate the VAR for the market return and dividend yield in (3) and (4). The data VAR for return and dividend yield is estimated using ordinary least squares (OLS) and discretized using a variation of Tauchen and Hussey's (1991) Gaussian quadrature method; the variation is designed to ensure that $d$ is the only state variable (see Balduzzi and Lynch (2000) for details). However, following and extending Lynch (2000), this study implements the discretization in a manner that 
produces exact matches for important moments for portfolio choice; in particular, we match the correlation between the innovations to return and dividend yield and the volatility of the innovation to return in each state to the unconditional volatility of the innovation and correlation between the innovations in the data. We choose 19 quadrature points for the dividend yield and 3 points for the stock-return innovations since Balduzzi and Lynch (1999) find that the resulting approximation is able to capture important dimensions of the return predictability in the data. Data point estimates and quadrature parameters are reported in Panel A of Table 1. The only parameter that the quadrature cannot match is the persistence parameter for dividend yield: the quadrature value is a little lower than the point estimate in the data. Stock return and dividend yield dynamics are always kept as in data and the same regardless of the subset of the three channels switched on.

Turning to the labor income process, the volatilities for log labor income are set to the baseline values in Viceira $(1997,2001)$ who describes these values as consistent with those obtained by Gakidis (1997) based on PSID data for professionals and managers not self-employed under age $45 .^{6}$ Viceira's baseline value for the standard deviation of the change in log permanent labor income is $15 \%$ per year and for the standard deviation of the log temporary shock is $10 \%$ per year. To get the monthly values, we utilize a loglinear approximation to the relate these monthly parameters to their annual counterparts while explicitly recognizing the predictive dynamics at monthly frequency. Or to assess the accuracy of the usual rules-of-thumb that get used to go from annual to monthly data, we just divide annual standard deviations by $\sqrt{1} 2$. As in Viceira, the multiplicative temporary shock $\exp \left\{\epsilon_{t}\right\}$ has a mean of 1 .

For the flat income profile cases, the mean growth of permanent labor income is also the baseline value in Viceira, $3 \%$ per annum. This translates into a monthly growth rate of $0.15 \%$. The agent's horizon is twenty years and she dies at the terminal date. For the age-dependent profile cases, we use a 3rd order polynomial to approximate the hump shaped life-cycle earnings profile as in Campbell and Cocco (2002). We use as parameters for the polynomial the point estimates in Cocco, Gomes and Maenhaut (2002) for college graduates. The agent starts work at age 22 and retires at 65 , receiving a lump sum payout equivalent to receiving $93.8 \%$ of her retirement permanent income until death as reported in Cocco, Gomes and Maenhout (2002) for college graduates. The agent dies with probability 1 at age 100, and death probabilities are taken from the U.S. Life Tables, 2001, provided by the NCHS.

\footnotetext{
${ }^{6}$ A number of papers (see, for example, Chamberlain and Hirano, 1997 and Carroll and Samwick, 1995) have estimated labor income parameters and a range of values are reported across these studies. However, the Gakidis values seem to lie within this range, which makes them reasonable to use.
} 
We also calibrate the three channels through which labor income affects portfolio allocations by young agents. Monthly aggregate labor income data is used to compute covariances between permanent labor income growth and lagged dividend yield and contemporaneous market return corresponding to the state-dependent mean and return correlation channels respectively. It is reasonable to use aggregate data to estimate covariance if the idiosyncratic component of individual labor income growth is uncorrelated with these two series. Aggregate labor income data is from the Bureau of Labor Statistics website. Retail Trade is series CEU4200000004. Total Private is series CEU0500000004. Proprietor's income data is from Department of Commerce, Bureau of Economic Analysis website. The series is the Non Farm Proprietor's income in NIPA table 2.6. In the base case using Retail Trade data, we calibrate the SDM channel by matching $b_{g}=\sigma_{g d_{-1}}$ to the point estimate for Retail Trade income growth covaried with lagged dividend yield. Given a per annum volatility for $g$ of $15 \%$, the $b_{g}$ value of $-0.1613 \%$ implies $\rho_{g d_{-1}}=-3.066 \%$ in the model, and a monthly volatility for $g$ of $5.26 \%$. When the SDM channel is switched off, $b_{g}$ is set equal to zero and $\sigma_{u}$ is adjusted to keep $\sigma_{g}$ equal to $5.26 \%$. To calibrate the CWR channel, the correlation of the return and permanent income growth shocks $\rho_{u e}$ is chosen so that $\sigma_{g r}$ matches the point estimate of covariance of aggregate Retail Trade wage income growth with stock return of $0.0901 \%{ }^{2}$. The sochosen $\rho_{u e}$ value is $0.48 \%$. Whenever the CWR channel is present, $\rho_{u e}$ conditional on the dividend yield state, is matched to this value, state by state. But when this channel is switched off, $\rho_{u e}$ is set to zero, state by state.

Turning to the state-dependent volatility channel, Storesletten, Telmer and Yaron (2004) find that the conditional volatility of permanent labor income growth is 1.75 higher in recessions than expansions, using NBER business-cycle cutoff to define the two. To incorporate this heteroscedasticity without increasing the state space, we need a way to define the two periods as function of the dividend yield state. Storesletten, Telmer and Yaron's business cycle specification implies a $68 \%$ probability of expansion and $32 \%$ probability of recession. We bifucate dividend yield variable to obtain recession and expansions states with the cutoff value chosen to match these unconditional probabilities. Interestingly, we obtain similar transition matrices to Storesletten, Telmer and Yaron for the two state transition probability matrix a yearly frequency. In particular, the probability of remaining in the expansion state is found to be $76 \%$ in the data and $82 \%$ in our calibration, values which are quite close to each other. There is more of a disparity for the probability of remaining in an expansion but $63 \%$ in the data and $50 \%$ for our calibration are still quite close. Further, we find that the Spearman correlation between our recession variable and NBER recessions is $64.4 \%$. 
In summary, our procedure for creating recession and expansion states has produced a two-state Markov chain which replicates key features of the expansion and recession states that Storesletten, Telmer and Yaron found in the data. When the SDV channel is switched on, the conditional volatility of $g$ in recession states is allowed to be 1.75 times its value in expansion states; otherwise the ratio is 1 .

We also allow for the possibility of an unemployment state. As a first pass, we allow the occurrence of the unemployment state to be an i.i.d. event by incorporating a $0.5 \%$ probability of being unemployed in a given month independent across months. By matching the expected duration of unemployment in a given year, this specification is consistent with Carroll's(1992) finding that half a percent of annual income realizations can be classified as near-zero using individual data. Using Carroll's definition of a near-zero income realization, we assume that the agent receives $10 \%$ of her permanent income in an unemployment month. To incorporate persistence into the unemployment state, we also consider a Markov regime switching model, with two states, employment and unemployment. By allowing the transaction matrix to be age-dependent, we are able to exactly replicate the transition dynamics assumed by Carroll: that is, that the agent is either employed or unemployed in each year of her life.

We also calibrate proprietary income since Heaton and Lucas (2000a) document a similar puzzle for individuals receiving proprietary income: the standard model produces stock holdings that are too high. The state-dependent mean and return correlation channels are incorporated by calibrating the covariance of labor income growth with stock return and lagged dividend yield respectively to that for aggregate monthly non-farm proprietary income from NIPA. When the second moment is allowed to be predictable, the ratio of the recession to boom innovation volatility for permanent labor income growth is, in the absence of a data estimate based on proprietary income, again matched to the Storesletten, Telmer and Yaron (2004) value of 1.75. At the same time, the unconditional volatility of permanent proprietary income growth itself is always matched to the $25 \%$ per annum used by Heaton and Lucas (2000b) based on annual Tax Model data. There is no temporary shock. The resulting $25 \%$ implied for per annum proprietary income growth volatility seems reasonable since Heaton and Lucas report median volatilities of $29 \%$ and $19 \%$ per annum respectively for proprietary and labor income, while our wage-earner calibration with temporary shocks implies a per annum volatility of $18 \%$.

Three aggregate labor income series are calibrated, as described above. And for each one, parameter values are reported in Panel B of Table 1 for the 8 associated quadrature approximations, 
each specification a possible combination of the three channels switched on and off. Panel B shows that for each set of 8 specifications, the mean and volatility of log monthly permanent labor income growth is kept constant across the 8 specifications. While the $b_{g}$ value in the data for the Retail Trade series implies a correlation between $g$ and lagged dividend yield of around $-3 \%$, the implied correlation for Total Private is still around $-1.9 \%$ and only drops to $-1.5 \%$ for the aggregate proprietary income series. Though the t-statistics are not reported, the $b_{g}$ estimates for the two labor income series are highly significant, using Newey-West covariances with either 3 or 12 lags. However, for the proprietary income series, the point estimate is again significant irrespective of the number of lags used, but only marginally so using 12 lags. The covariance with return point estimate implies a $\rho_{u e}$ value of $0.48 \%$ for the Retail Trade series and $-0.43 \%$ for Total Private which are both small. However, the implied $\rho_{u e}$ value for proprietary income is a much larger $1.21 \%$ which suggests that the CWR channel may have a larger effect in the proprietary income calibration than in the wage income calibrations. The negative sign for Total Private means that this channel is likely to increase stock holdings rather than decrease them.

\section{Results}

This section reports policy functions for the various problems described above. Simulation results are also reported.

\subsection{Twenty-year Flat-profile Labor Income Case}

Table 2 reports asset allocation and incremental effect results for the twenty-year flat profile labor income case. The agent has CRRA preferences with a coefficient of risk aversion of 6 for the first month of her 20 year horizon, and results are reported for a range of wealth to permanent income ratios from 0 to $\infty$. The mean monthly growth rate of permanent income is set to $3 \%$ p.a. based on Gakidis (1997). The volatility of the logarithmic monthly growth rate of permanent income $\sigma_{g}$, is obtained from its annual counterpart (fixed at $15 \%$ from Gakidis (1997)), accounting for the assumed dynamics of permanent income growth. There are no transitory shocks to income. Retail Trade Income (series CEU4200000004 by Bureau of Labor Statistics) is also used to calibrate labor income. The agent has access to the market portfolio and to a riskless bond. Panel A reports average stock holdings when all three and none of the channels are present. Panel B and C reports the incremental effects on stock holdings of switching on one of the three channels SDM, CWR or SDV. Each of these channels can be switched on when both, one, or none of the other channels 
are present and the four rows of each channel's subpanel report the incremental stock-holding reductions for these 4 cases. The calibration of the 8 problems needed to do the comparisons is detailed in section 3 above. Panel B reports average reductions in fractions of stock holdings using all states, Panel $\mathrm{C}$ does the same using only non binding states, states for which fractions of stock holdings for both cases are strictly between 0 and 1 .

Panel A shows that the simultaneous presence of all three channels leads to large reductions in average holdings for young agent's with low wealth-income ratios. At zero wealth, the average holding drops from $97.5 \%$ to $20.3 \%$ but even at a wealth-income ratio of 30 , the drop is still substantial, from $90.5 \%$ to $37 \%$. Almost all the reduction is due to the business cycle variation in the first two moments of permanent labor income growth. Panel B shows that the incremental effect of switching on the return correlation channel when the SDM and SDV channels are also on is never more than $1 \%$. In contrast, the reduction in stock holding is much smaller if either the SDM or SDV channels are switched off, suggesting that both are contributing to the reduced stock holding by young, low wealth-income agents. Panel B shows that for a young agent with a wealth to monthly income ratio of 30 , the average stock allocation increases by an allocation of $29 \%$ when the mean channel is switched off and by an allocation of $39 \%$ when the volatility channel is switched off.

Figure 1 plots stock holdings for first-period agents for a range of wealth to permanent income ratios from 0 to 500. Subfigure 1.a reports average stock holdings for the combinations of channels indicated in the legend. Subfigures b, c and d report the reductions in stock holdings induced by SDM, CWR and SDV channels, respectively. Subfigure 1.a shows that in the absence of all three channels, there is a negative realtion between average stock allocation and wealth-income ratio. Switching on the CWR or the SDM channel does not change the direction of this relation. However, when the SDV channel is switched on the relation becomes positive, which is the direction reported in the data. So while both the SDM and SDV channels have a considerable effect on the young agent's stock holdings, it is the SDV channel that changes the direction of the relation between stock holding and wealth-income ratio.

The incremental impacts reported in Panel $\mathrm{C}$ for states not at the boundaries are much larger than the incremental impacts reported in Panel B for all states. At low wealth income ratios, the agent's stock allocation is either $0 \%$ or $100 \%$ in almost every state. Even when just non-binding states are considered, the reductions due to the CWR channel are still less than $5 \%$ for wealth income ratios greater than 10 . 
Table 3 reports reports similar asset allocation results to those in Table 2, except the agent is in her last month of her 20 year horizon, not her first. Interestingly, Panel A shows that switching on the three channels has virtually no effect on allocations and the incremental effects reported in Panels $\mathrm{B}$ and $\mathrm{C}$ are virtually zero as well. This results indicate that the large effects on stock holdings reported in Table 2 caused by the state-dependent mean and volatility of permanent labor income growth are coming from the long horizon of the young agent. This is not surprising since the intuition that we present in the introduction for the reduced holdings very much relies on the young agent being able to rebalance many times before the terminal date.

The intuition for the reduction in stock holdings is as follows. With risk aversion greater than 1, positive correlation between stock return and future opportunity sets reduces the stock holding of a young agent relative to that of a myopic agent. Stock returns are low when the economy enters a recession (i.e dividend yield is high), so both lower mean labor income growth in bad states and higher volatility in bad states reduces the stock holding of a young agent. This mechanism is the flipside of the one by which return predictability affects the stock holdings of young agents with risk aversion greater than 1 . There, young agents hold more stock than myopic agents because of the negative correlation between stock return and future opportunity sets induced by the predictability.

The importance of horizon is confirmed by subfigures 3.a and 4.a which plot an agent's average stock allocations as a function of age, fixing the wealth to permanent income ratio at 1 and 100 respectively for her entire lifetime. These subfigures show that the average stock allocation is the same in the agent's last month of life irrespective of whether all, one business-cycle or none of the three channels are switched on. Rolling back though time from the terminal date when wealthincome is fixed at 1 each month (subfigure 3.a), we see that the average stock holdings weakly decreasing with age when none of the channels are switched on, but with at least the SDV or SDM channels switched on, the average stock allocation weakly increases for at least the first 16 years of life. In contrast, subfigure 6.a shows that when the wealth income ratio is increased to 100 and labor income is less important relative to financial wealth, the average stock allocation now decreases with age, irrespective of how many channels are switched on.

Another question of interest is how stock allocations vary over an agent's life. To address this question, subfigures 2.b and 2.b report analogous allocations to subfigures 2.a and 2.a but for agents with initial wealth to permanent income ratios of 1 and 100 respectively rather those values every period. Results are obtained via simulation and 500000 paths are simulated for each case of the 8 cases under consideration, and average allocations at each age are recorded. Initial dividend yield 
states are drawn from their unconditional distribution. These subfigures show that with all effects switched off, stock holding is counterfactually declining in age for an initial wealth-income ratio of 1 or 100 . However, once the two business-cycle channels are switched on, the relation becomes positive. Moreover, subfigure 2.b shows that when the wealth-income ratio is 1 , the SDV channel alone is enough to obtain the positive relation but SDM alone is not. In contrast subfigure 3.b shows that the two business-cycle effects are equally important with neither alone enough to make the relation positive.

The agent's average allocation as a function of age holding her wealth-income ratio fixed each period (subfigures 2.a and 2.b) differs from the function obtained when the agent's initial wealthincome ratio is fixed (subfigures 2.b and 3.b) because her wealth income ratio varies over her life when she follows the optimal strategy. Subfigures 2.c and 3.c plots how the average wealth to permanent income ratio evolves over the agent's twenty year horizon, assuming its initial value is fixed at 1 and 100 respectively. The results are obtained from the simulations performed to generate subigures 2.b and 3.b. Interestingly, for an initial wealth-income ratio of 1 (subfigure 2.c), the agent's wealth to permanent income ratio exhibits a hump shape over her life, hitting its peak around an age of 10. The function is largely unaffected by whether the 3 channels are on or off. Intuition suggests that as the initial wealth to permanent income ratio is increased, the positive sloped portion of the hump would become less steep and the results for an initial ratio of 100 in subfigure 3.c confirm this.

Table 4 reports analogous results to those in Table 2 except that the agent's labor income process includes a $10 \%$ temporary shock to per annum labor income growth; this translates into a $24.5 \%$ temporary shock to monthly growth. The allocations and incremental effects reported in Table 4 look virtually identical to those in Table 2. Thus, it appears that temporary shocks to labor income growth do not materially affect allocations, at least shocks of the magnitude documented for U.S. individuals.

The impact of an unemployment state on portfolio allocations is considered in Tables 5 and 6 . The reported results in Table 5 are analogous to those in Table 2 again, except there is a $0.05 \%$ chance each month of the agent being in an unemployment state that pays only $10 \%$ of permanent labor income. Somewhat surprisingly, the results are qualitatively similar to those without an unemployment state in Table 2. Cocco, Gomes and Maenhout (2002) examine the effect of an unemployment state in a model with annual decision-making and they present simulation results that are suggestive, but not conclusive, that an $0.05 \%$ probability of being unemployed in any given 
year has a large effect on stock allocations, particularly early in life. But their model allows for a hump-shaped labor-income profile over the agent's life and perhaps more importantly, implies some degree of persistence in the unemployment state at a monthly frequency. Table 6 reports the allocation results obtained when we use a Markov regime switching model, with two states, employment and unemployment, which allows us to exactly replicate the transition dynamics used by Cocco, Gomes and Maenhout and assumed by Carroll, by allowing the transaction matrix to be age-dependent. Table 6 shows that making the unemployment stay persistent lowers average stock allocations irrespective of which subset of channels is switched on, consistent with the results in Cocco, Gomes and Maenhout. However, the incremental effect of the channels on stock allocations largely remains the same as reported for a transitory unemployment state in Table 5 or for the case of no unemployment state at all in Table 2.

It is worth checking whether the large incremental effects reported above are specific to the aggregate labor income series Retail Trade. Table 7 examines this by reporting analogous results to those in Table 2 but for a labor income process calibrated to Total Private aggregate labor income data. The magnitude of the covariance with lagged dividend yield is lower for growth in Total Private sector earnings than for growth in Retail Trade earnings. Consequently, it is worthwhile checking whether the state-dependent mean channel continues to have a large effect when this series is used to calibrate the covariance. Panel A shows that the combined effect of the three channels on average stock allocations can be as low as $43 \%$ for a young agent whose wealth is no more than 30 times her monthly labor income. In contrast, when labor income is calibrated to Retail Trade, the reduction is never less than $52 \%$. But focussing on the young agent with a wealth to permanent income ratio of 30, switching off the state-dependent mean channel still increases her stock allocation by an amount of $20 \%$ (as opposed to an amount of $29 \%$ for retail trade) while switching off the state-dependent volatility increases her allocation by an amount of $35 \%$, which is quite close to the $39 \%$ reported for retail trade. Thus, the important of the two business-cycle predicability channels appears to be robust to choice of aggregate labor income series used in the calibration.

Table 8 reports reports state-by-state asset allocation results for a CRRA agent with a coefficient of risk aversion of 6 for the first month of her 20 year horizon, for a range of wealth to permanent income ratios from 0 to $\infty$. Hence, Table 8 has the state-by-state results from which the Table 2 results are obtained. Panel A reports stock allocations state-by-state and illustrates how when the wealth to permanent income ratio is low, the agent's stock holding is at the boundary in almost all 
dividend yield states. This table also provides information about non-participation while figure 4 plots the probability of non-participation in the first month as a function of the agent's first-month wealth-income ratio. With all three channels switched off, non-participation is a zero-probability event in the first month, irrespective of the agent's wealth-income ratio. With both business-cycle channels switched on, the probability of non-participation becomes as high as $70 \%$ for low wealthincome ratios but is less than $5 \%$ for all wealth-income ratios greater than 120 . With only SDV channel switched on, the probability of non-participation is still over $40 \%$ when the wealth income ratio is zero, while the SDM channel alone has very little effect on the level of non-participation relative to the case with all channels switched off.

We are also interested in non-participation as a function of age. Subfigures 2.d and 3.d provide results on this point plotting the probability of non-participation as a function of age for an agent whose initial wealth income ratio is 1 and 100, respectively. The two subfigures indicate that all three channels switched off leads to participation in the stock market virtually all the time, irrespective of age or initial wealth-income ratio. An examination of subfigure 2.d indicates that switching on the two business-cycle channels results in substantial non-participation by agents in their first month and that the non-participation steadily declines as the agent gets older. According to the figure, an agent with an initial wealth-income ratio of 1 decides not to participate in the stock market $70 \%$ of the time in the first month; and after ten years, this probability has declined to a fraction that is still above 20\%. In contrast figure 3.d shows that when the agent's initial wealth-income ratio is 100 , non-participation never occurs more than $10 \%$ of the time, even with all three channels switched on. The implication is that the business-cycle variation in the first 2 moments of permanent labor income growth can cause young, poor agents not to participate in the stock market a large fraction of the time. This result can be contrasted with the virtual $100 \%$ participation rate obtained for agent's irrespective of age or wealth-income ratio when all three channels switched off.

\subsection{Specification versus Rule-of-thumb Monthly Volatility}

It turns out the rule-of-thumb way of computing monthly volatility from annual volatility understates true volatility. For the Retail Trade calibration and a $15 \%$ per annum volatility, the monthly volatility is $5.26 \%$ when using the labor-income specification but only $4.33 \%$ when scaling the $15 \%$ by the square-root of 12 . Table 9 reports the same asset allocation and incremental effect results as in Table 2 for a CRRA agent with a coefficient of risk aversion of 6 for the first month of her 20 year 
horizon, except that the income process is calibrated to the rule-of-thumb volatility rather than specification-based volatility. Panel A show that the reductions in average stock allocations from switching on the three channels are smaller than those reported in Table 2 using the specificationbased volatility number. While the effect of switching off the CWR channel remains small, the incremental effect of the SDM channel on stock holdings is larger than in the case with the higher monthly volatility of permanent income growth. The overall reduction in average stock holdings because of the three channels is smaller because the incremental effect of the SDV channel on stock holdings is attenuated by the smaller volatility.

\subsection{Lifecycle Effects: Age-dependent Profile, Retirement and Death Probabil- ities}

Table 10 reports asset allocation and incremental effect results for the lifecycle case. As in Table 2, the agent has CRRA preferences with a coefficient of risk aversion of 6 for the first month of her 20 year horizon, and results are reported for a range of wealth to permanent income ratios from 0 to $\infty$. The agent starts work at age 22 and retires at 65 , receiving a lump sum payout equivalent to receiving $93.8 \%$ of her retirement permanent income until death as reported in Cocco, Gomes and Maenhout (2002) for college graduates. The agent dies with probability 1 at age 100, with death probabilities taken from the U.S. Life Tables, 2001, provided by the NCHS. The mean logarithmic monthly growth rate of permanent income is allowed to be age-dependent and is calibrated to the polynomial-smoothed income profile for college graduates in Cocco, Gomes and Maenhout (2002). The volatility of the logarithmic monthly growth rate of permanent income $\sigma_{g}$, is obtained from its annual counterpart (fixed at 15\% from Gakidis (1997)), accounting for the assumed dynamics of the permanent income growth. There are no transitory shocks to income. Retail Trade Income (series CEU4200000004 by Bureau of Labor Statistics) is also used to calibrate labor income. The agent has access to the market portfolio and to a riskless bond. The format of the table is similar

to Table 2. Panel A reports average stock holdings when all three and none of the channels are present. Panel B and C reports the incremental effects on stock holdings of switching on one of the channels. Panel B reports average reductions in fractions of stock holdings using all states, Panel $\mathrm{C}$ does the same using only non binding states.

Table 10 shows that introducing business cycle variation in the first two moments of permanent labor income growth causes the young poor lifecycle agent to reduce stock holdings even more aggressively than the young agent in the twenty-year flat profile case. For a young agent whose wealth is less than 30 times her monthly income, the average reduction is always more than $67 \%$ 
in the lifecycle case as opposed to only $52 \%$ in the twenty-year flat profile case.

Figures 5 through 7 pertain to the lifecycle case with the age-dependent income profile and lump-sum payout on retirement. Figure 5 plots stock holdings for young agents for a range of wealth to permanent income ratios from 0 to 500. The four subfigures contain plots analogous to those in the four subfigures in figure 1. Subfigure 5.a reports average stock holdings for the combinations of channels indicated in the legend. Subfigures b, c and d report the reductions in stock holdings induced by SDM, CWR and SDV channels, respectively. Subfigure 6.a plots an agent's average stock allocations as a function of age, fixing her wealth to permanent income ratio at 0 for her entire lifetime while subfigures 6.b, 6.c and 6.d plot the average fraction in stock, the average wealth-income ratio and the probability of non-participation as a function of age for an agent whose initial wealth income ratio is 0 . Finally, figure 7 plots the probability of non-participation in the first month as a function of the agent's first-month wealth-income ratio.

All the qualitative conclusions from the twenty-year flat profile case carry over to the more realistic lifecycle setting. The presence of the two business cycle channels causes the relation between stock allocation and wealth-income ratio to become positive for young agents (subfigure 5.a) and the relation between stock allocation and age to become positive for poor, young agents (subfigure 6.b). The former result is again driven by the state-dependent volatility channel while both channels are important for the latter finding. Again, the two business-cycle channels induce substantial non-participation in a setting where there would be almost none with all three channels switched off. Figure 7 shows that when the two business-cycle channels are present, a 22-year old agent with no financial wealth decides not to participate in the stock market over $80 \%$ of the time in her first year, a substantial fraction of the time in the rest of her 20s and early 30s, and always some fraction of the time through until retirement. Interestingly, the agent's long retirement period causes her wealth income ratio to be a convex, increasing function of age (subfigure 6.c) despite the lump-sum payout received at retirement. This functional form stand in sharp contrast to the hump shape reported for the twenty-year flat-profile no-retirement agent when her initial wealth-income ratio is 1 .

Table 11 reports analogous results as Table 10 for the lifecycle agent facing a flat income growth profile with the same monthly mean as in the twenty-year case rather than the hump-shaped one. It appears the hump shape is having some effect on the young agent, since the average reduction for a young agent whose wealth is less than 30 times her monthly income never exceeds $61 \%$ in Table 11 (as compared to reductions greater than $67 \%$ when the profile is hump-shaped). Figure 8 plots 
average stock allocations as a function of age for the lifecycle agent with no financial wealth initially and who faces the same flat income growth profile. Comparing the average allocation curves to those in subfigure 2.b for the lifecycle agent who faces the hump-shaped profile, we see the curves are similar, suggesting the somewhat surprising result that the agent's average stock allocation as a function of age is not much affected by whether her income growth profile is flat or hump-shaped.

Table 12 reports analogous results as Table 10 for the lifecycle agent, except no lump sum payout is received at retirement. The reported results show that eliminating the lump sum payout upon retirement has almost no impact on the stock holding by the young agent. However, figure 9 plots average stock allocations as a function of age for the lifecycle agent with no financial wealth initially and who does not receive a lump sum payment upon retirement. The allocation curves in figure 9, when compared to those in subfigure 2.b for the lifecycle agent who receives a lump sum on retirement, show that removing the lump sum payout materially decreases the agent's stock allocation in the years just prior to retirement. This result is not surprising since the lump sum payment means that the agent's total financial wealth is increasing relative to her portfolio value as retirement approaches. So in the presence of the lump sum payout, maintaining a given fraction of total financial wealth in stock requires putting a larger fraction of portfolio value in stock as retirement approaches.

\subsection{Twenty-year Flat-profile Proprietary Income Case}

As we discussed above, the three channels we consider are also likely to affect the portfolio allocations of agent's who receive proprietary income rather than wage income. Table 13 reports asset allocation and incremental effect results for a CRRA agent with a coefficient of risk aversion of 6 for the first month of her 20 year horizon, as in Table 2, except that the income process is calibrated to proprietary income rather than labor income. Panel A shows that the simultaneous presence of the three channels drastically reduces average stock allocations. For young agents with wealth less than 30 times monthly income, the reduction in holding is always at least $60 \%$. Switching off the return correlation channel has a negligible incremental effect, never more than $3 \%$, despite the larger covariance with return than the two labor income series. Our results suggest that businesscycle variation in the first two moments of proprietary income growth might be able to explain, at least partially, why the standard model produces stock holdings that are too high once proprietary income is introduced. 


\section{Conclusion}

This paper asks whether allowing the conditional joint distribution of labor income to depend on the business cycle can allow the model to generate equity holdings that better match those of U.S. households, while keeping the unconditional distribution the same as in the data. Calibrating the business-cycle variation in the first two moments of labor income growth to U.S. data leads to large reductions in stock holdings by young agents with low wealth-income ratios. The reductions are so large that young, poor agents now hold less stock than both young, rich agents and old agents, and also hold no stock a large fraction of the time. Our results suggest that the predictability of labor-income growth at a business-cycle frequency plays an important role in a young agent's decision-making about her portfolio's stock holding.

In future work, we plan to endogenize the agent's labor supply decision. Doing so may ameliorate the effects of this business cycle variation in labor income growth on the stock allocations of young, poor agents since agents can reduce hours worked when labor opportunities are poor. On the flip side, they can increase hours worked when labor opportunities are good, which would exacerbate the effects. We conjecture that the effects on the stock allocations of poor, young agents are still likely to be large, much in the same way that hedging demands induced by stock return predictability are large despite the fact that the agent's can choose how much to invest in stock. 


\section{Appendix}

This appendix sketches the numerical procedures associated with solving dynamic savings and portfolio choice problem with predictable returns in the presence of labor income.

There are two key elements to the implementation. The first is to endogenize the discrete state representation of the value function to bound error propagation at each iteration. The second is to resort to extrapolation only when the problem on hand is economically sufficiently close (in a sense to be made clear below) to a problem for which the functional form for the value function is known.

The concern giving rise to above is that the wealth to permanent labor income (wealth-income, henceforth) ratio state is unbounded on the non-negative side of the real line. To represent the value function on this dimension, this range is partitioned into three disjoint, non-degenerate intervals on which the value function of unknown form is approximated as a three-part structure. At each iteration, the lower intermediate boundary point is chosen to be the smallest value of wealth-income ratio such that an agent without the labor income for all periods to terminal date requires no more than $10 \%$ extra wealth to be equally happy as an otherwise identical agent with the labor income at that wealth-income ratio. The upper intermediate boundary point is chosen to satisfy the same definition at $1 \%$. Over the lower-end interval, the value function is approximated as a piecewise linear form or piecewise shape-preserving monotone cubic hermite interpolant of Fritsch and Carlson (1980) for the wealth-income ratio state and as a piecewise linear form for the inherited allocation state. Over the higher-end interval, the value function is taken to be that of the otherwise identical problem without the labor income. Over the middle interval, the value function is approximated as a function of the form, $V(W)=a \times(W-b)^{c}+d$, where a, b, c, d are constants in $\mathbb{R}$, to match the function and the first derivative values at the upper and the lower intermediate boundary points. Further, at any given iteration and at any given grid node of the discretized state space, the objective function has to be jointly solved for consumption and portfolio policies subject to the short sales constraints on the T-bill and the stock. A recursive golden section algorithm is used to optimize the consumption policy, defined as the fraction of last period's permanent labor income consumed, accurate to the fourth decimal digit and the portfolio policy, defined as the fraction of wealth invested in the risky asset, accurate to the third decimal digit.

We suggest a dynamic gridding algorithm to bound errors on policy functions at each iteration. This algorithm takes the value function representation for the previous iteration as given, computes the intermediate boundary points for the iteration at hand and continues to add points in the 
lower-end interval in a particular way until policies at no point on a representative grid for the next iteration differ by more than prespecified magnitudes across increasingly denser grids for the iteration on hand.

The steps of this algorithm in detail are:

1) take value function representation for the previous iteration, $V_{t+1}(\cdot)$, as given

2) initialize a set of grid nodes, $X_{t}=\left\{\Gamma_{t, 1}, \Gamma_{t, 2}, \Gamma_{t, 3}, \ldots, \Gamma_{t, n}\right\}$, in increasing order, where $\Gamma_{t, 1}=0$, $\Gamma_{t, n}=L P_{t, 10 \%}, \mathrm{n}$ is a constant, and $L P_{t, 10 \%}$ is the lower intermediate boundary point for iteration $t$ with the defining parameter set to $10 \%$

3) define $Y_{t}=\left\{\left(\Gamma_{t, 1}+\Gamma_{t, 2}\right) / 2,\left(\Gamma_{t, 2}+\Gamma_{t, 3}\right) / 2, \ldots,\left(\Gamma_{t, n-1}+\Gamma_{t, n}\right) / 2\right\}$, in increasing order

4) evaluate $V_{t}\left(X_{t}\right)$ using the value function representation, $V_{t+1}($. )

5) evaluate $V_{t}\left(Y_{t}\right)$ using the value function representation, $V_{t+1}($.

6) evaluate the lower intermediate point, $L P_{t-1,10 \%}$ for iteration $t-1$ using $V_{t}$ as represented by $X_{t} \cup Y_{t}$

7) define $A_{t-1}=\left\{(i-1) \times\left(L P_{t-1, \% 10}\right) / q\right\}_{i=1}^{q+1}$, where $q \geq 2$ is a constant.

8) evaluate $V_{t-1}\left(A_{t-1}\right)$ using $V_{t}$ as represented by $X_{t}$

9) evaluate $V_{t-1}\left(A_{t-1}\right)$ using $V_{t}$ as represented by $X_{t} \cup Y_{t}$

10) define $Z_{t-1} \subseteq A_{t-1}=\left\{x \in A_{t-1} \mid\right.$ and policy functions at $x$ using representations in steps 8) and 9) differ more than prespecified magnitudes\}

11) if $Z_{t-1}=\varnothing$, accept $X_{t} \cup Y_{t}$ as sufficient representation for $V_{t}$, exit subroutine.

12) compute the range of wealth-income, $\Gamma_{t}$, range the system can possibly assume by starting at any point in $\mathrm{Z}$ under any realization of the return and the labor income shocks and under any allowed policy. This range is generically of the form $\left[\begin{array}{ll}0 & h_{t}\end{array}\right]$, for some $h_{t}>0$.

13) update $X_{t}$ as $X_{t} \cup Y_{t}$, in increasing order,

14) update $Y_{t}$ as $\left\{\left(X_{t, 1}+X_{t, 2}\right) / 2,\left(X_{t, 2}+X_{t, 3}\right) / 2, \ldots,\left(X_{t, k-1}+X_{t, k}\right) / 2\right.$; where $\mathrm{k}$ is the smallest positive integer satisfying $X_{t, k}>=\min \left(h_{t}, L P_{t}\right)$.

15) return to step 4) and repeat.

Step 10) ensures that the maximal absolute scaled deviation in consumption policy (defined as the fraction of last period's permanent component of labor income consumed $), \mid\left(\hat{\kappa}_{\text {coarse }}-\right.$ $\left.\hat{\kappa}_{\text {dense }}\right) / \hat{\kappa}_{\text {dense }} \mid$ is bounded from above by $10^{-3}$ and the maximal absolute deviation in portfolio policy (defined as the fraction of wealth invested in the risky asset), $\left|\alpha_{\text {coarse }}-\alpha_{\text {dense }}\right|$, is bounded from above by $10^{-2}$. $q$ and $n$ are set to 50 . The initialization in step 2) is designed to take advantage of the previous iteration's $\left(V_{t+2}\right)$ representation. 
This algorithm, given the choice of the interpolant produces a set of grid nodes which then, can represent the value function at hand sufficiently well before one goes on to the next iteration.

This procedure implies that the joint state for the base case specification with predictable returns and when All effects are present (SDM, SDV and CWR) is on average (over the 20-year horizon), represented with approximately $19 \times 450=8550$ grid nodes.

To ensure that results are robust to the parameters of the solution algorithm, we change the defining parameter for the lower boundary point from $10 \%$ to $9 \%, 8 \%, 7 \%$, and $6 \%$ for the base case specification when all effects are present (SDM, SDV and CWR). The maximal $\left|\left(\hat{\kappa}_{10 \%}-\hat{\kappa}_{x \%}\right) / \hat{\kappa}_{x \%}\right|$, for an equally spaced 100 -node grid on $\left[\begin{array}{ll}0 & L P_{t, 10 \%}\end{array}\right]$ is less than $10^{-3}$ for all $\mathrm{t}=1, \ldots, 240$ and $\mathrm{x}$ $=6,7,8,9$. Similarly, the maximal $\left|\alpha_{10 \%}-\alpha_{x \%}\right|$ is less than $10^{-2}$. Fixing the defining parameter for the lower boundary point at $10 \%$, we change the precision on the consumption policy, $\hat{\kappa}$, from $10^{-4}$ to $10^{-5}$ and $10^{-6}$. We again note that the maximal absolute scaled consumption policies is less than than $10^{-3}$ across 20 -year horizon. 


\section{References}

Balduzzi, P., Lynch A., 1999. Transaction costs and predictability: some utility cost calculations. Journal of Financial Economics 52, 47-78.

Barberis N., 2000. Investing for the long run when returns are predictable. Journal of Finance 55, 225-64.

Botazzi, L., Pesenti, P., Wincoop, E., 1996. Wages, profits and the international portfolio puzzle. European Economic Review 40, 219-254.

Carroll, C., 1992. Buffer-stock theory of saving: Some macroeconomic evidence. Brookings Papers on Economic Activity 61-156.

Carroll, C., 1996. Buffer-stock saving: Some theory, Working paper, Johns Hopkins University.

Carroll, C., 1997. Buffer-stock saving and the life cycle/permanent income hypothesis. Quarterly Journal of Economics 112, 1-55.

Carroll, C., Samwick, A., 1997. The nature of precautionary wealth. Journal of Monetary Economics 40, 41-71.

Cocco, J., Gomes, F., Maenhaut, P., 2002. Consumption and portfolio choice over the life cycle. Working paper, London Business School.

Constantinides, G., 1990. Habit formation: A resolution of the equity premium puzzle. Journal of Political Economy 98, 519-543.

Campbell, J., 1987. Stock returns and the term structure. Journal of Financial Economics 18, 373-399.

Campbell, J., 1991. A variance decomposition for stock returns. A Variance decomposition for stock returns. The Economic Journal 101, 157-179.

Campbell, J., Shiller, R., 1988a. The dividend-price ratio and expectations of future dividends and discount factors. Review of Financial Studies 1, 195-227. 
Campbell, J., Shiller, R., 1988b. Stock prices, earnings, and expected dividends. Journal of Finance 43, 661-676.

Campbell, J., Viceira, L., 1999. Consumption and portfolio decisions when expected returns are time varying. Quarterly Journal of Economics 114, 433-495.

Chamberlain, G., Hirano, K., 1997. Predictive distributions based on longitudinal earnings data. Working paper, Harvard University.

Cocco, J, Gomes, F., Maenhout, P., 2002. Consumption and portfolio choice over the life-cycle. forthcoming Review of Financial Studies.

Davis, S., Willen, P., 2000a. Occupation-level income shocks and asset returns: their covariance and implications for portfolio choice. Unpublished working paper. University of Chicago.

Davis ,S., Willen P., 2000b. Using financial assets to hedge labor income risks: estimating the benefits. Unpublished working paper. University of Chicago.

Deaton, A., 1991. Saving and Liquidity Constraints. Econometrica 59, 1221-48.

Fama, E., French, K., 1988. Dividend yileds and expected stock returns. Journal of Financial Economics 22, 3-27.

Fama, E., French, K., 1989. Business conditions and expected returns on stocks and bonds. Journal of Financial Economics 25, 23-49.

Fama, E., Schwert, W., 1977. Human capital and capital market equilibrium. Journal of Financial Economics 4, 95-125.

Fritsch, F. N., Carlson, R. E., 1980. Monotone piecewise cubic interpolation. SIAM Journal of Numerical Analysis 17, 238-246.

Gakidis, H., 1997. Earnings uncertainty and life-cycle portfolio choice. Working paper, MIT.

Gourinchas, P., Parker,J., 2002. Consumption over the Life Cycle. Econometrica 70, 47-89.

Heaton, J., Lucas, D., 1997. Market frictions, savings behavior and portfolio choice. Macroeconomic Dynamics 1, 76-101. 
Keim, D., Stambaugh, R., 1986. Predicting returns in the stock and bond markets. Journal of Financial Economics 17, 357-390.

Lettau, M., Ludvigson, S., 2001. Resurrecting the (C)CAPM: A cross-sectional test when risk premia are time varying. Journal of Political Economy 109, 1238-1287.

Lynch A. W., 2000. Portfolio choice and equity characteristics: characterizing the hedging demands induced by return predictability. Journal of Financial Economics 62, 67-130.

Lynch, A. W., Tan, S., 2004. Explaining the magnitude of liquidity premia: the roles of return predictability, wealth shocks and state-dependent transactions costs. Unpublished working paper. New York University.

Michaelides, A., 2003. Portfolio choice, liquidity constraints and stock market mean reversion.

Polkovnichenko, V., 2003. ife cycle consumption and portfolio choice with additive habit formation preferences and uninsurable labor income risk.

Storesletten, K., Telmer, C., Yaron, A. 2004. Cyclical dynamics in idiosyncratic labor-market risk. Journal of Political Economy 112, 695-717.

Tauchen, G., Hussey, R., 1991. Quadrature-based methods for obtaining approximate solutions to nonlinear asset pricing models. Econometrica 59, 317-96.

Viceira. L., 1997. Optimal portfolio choice for long-horizon investors with non-tradable labor income. Working paper, Harvard University.

Viceira, L., 2001. Optimal portfolio choice for long-horizon investors with non-tradable labor income. Journal of Finance 56, 433-470.

Zeldes, S., 1989. Optimal consumption with stochastic income: deviations form certainty equivalence. Quarterly Journal of Economics 104, 275-298. 
Table 1. CALIBRATION. The table reports calibration and data values for the parameters of the VAR specification introduced in section 2.1 of the text:

$r_{t+1}=a_{r}+b_{r} d_{t}+e_{t+1}$,
$d_{t+1}=a_{d}+b_{d} d_{t}+w_{t+1}$,
$g_{t+1} \equiv y_{t+1}^{P}-y_{t}^{P}=\bar{g}+b_{g} d_{t}+u_{t+1}$.

The dependent variables are logarithmic return on the Market Portfolio, $r$, logarithmic growth rate of permanent income, $g$ and 12-month dividend yield and the independent variable is the lagged dividend yield. $\mu$ refers to unconditional mean. $\sigma$ with one (two) subscript letter(s) refer to unconditional standard deviation (covariance). $\sigma_{u \mid \text { exp }},\left(\sigma_{u \mid r e c}\right)$ refers to the conditional volatility of the permanent income growth shock in expansion (recession) states. $\rho$ refers to unconditional covariance. -1 used as a subscript implies the lagged value for a variable. $\epsilon$ is the transitory shock to income. The Market portfolio is the value-weighted return on all NYSE, AMEX, and NASDAQ stocks obtained from Kenneth French's website. Dividend yield is the 12-month dividend yield on the NYSE index. Aggregate labor income data is from the Bureau of Labor Statistics website. Retail Trade is series CEU4200000004. Total Private is series CEU0500000004. Proprietor's income data is from Department of Commerce, Burea of Economic Analysis website. The series is the Non Farm Proprietor's income in NIPA table 2.6. Individual labor income moments are taken from Gakidis (1997) based on PSID data for professionals and managers not self-employed under age 45 and for Non Farm Proprietor's income from Heaton and Lucas (2000). All data is measured at a monthly frequency. We use Retail Trade income data starting from January 1972, Total Private income data from January 1964, Proprietor's income data from January 1959. Return on the market and dividend yield start from January 1927. All data series end in January 2004. Income and return data are disinflated using a CPI measure, series CPIAUCNS, available from U.S. Department of Labor: Bureau of Labor Statistics. Per capita income values are generated by dividing all income series with a population measure, series POP, available from U.S. Department of Commerce: Census Bureau. Panel A reports VAR coefficients, means and covariances for $r$ and $d$ using OLS regression to obtain the data values. Panel B reports means and volatilities for labor income together with correlation and covariances with $r$ and $d$. SDM, CWR and SDV stand for state dependent mean, covariance with return and state dependent volatility channels respectively, for permanent income growth as described in section 2.1 of the text. A + (-) sign means that the channel at the start of the row is present (not present) for the case in consideration. Given the data values for aggregate or individual income in the last two columns, the calibration procedure generates the values in the first eight columns, one for each case considered. To determine the transitory and permanent income volatility values at monthly frequencies, we utilize a loglinear approximation, relating these parameter values to their annual counterparts, while explicitly accounting for the predictable dynamics of the permanent income growth. Details of this approximation is available from the authors.

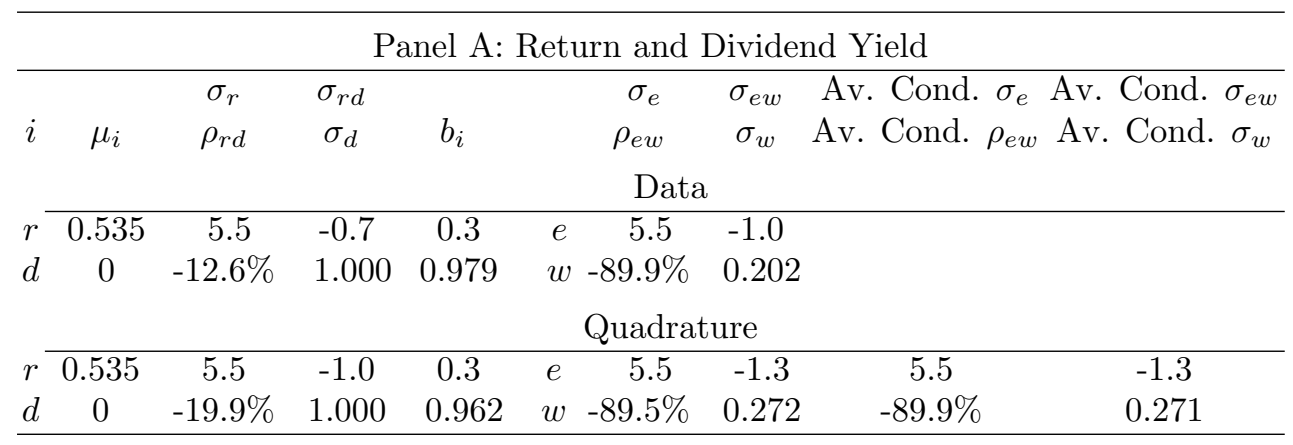


Table 1 cont

\begin{tabular}{|c|c|c|c|c|c|c|c|c|c|c|}
\hline \multicolumn{11}{|c|}{ Panel B: Labor Income } \\
\hline SDM & + & + & + & + & - & - & - & - & & \\
\hline CWR & + & + & - & - & + & + & - & - & & \\
\hline SDV & + & - & + & - & + & - & + & - & & \\
\hline \multicolumn{9}{|c|}{ Calibrated (same as Quadrature) } & Ag. & Indiv. \\
\hline & \multicolumn{10}{|c|}{ Retail Trade } \\
\hline$\mu_{g}$ & 0.153 & 0.153 & 0.153 & 0.153 & 0.153 & 0.153 & 0.153 & 0.153 & & 0.153 \\
\hline Annual $\sigma_{g}$ & 15 & 15 & 15 & 15 & 15 & 15 & 15 & 15 & & 15 \\
\hline$\sigma_{g}$ & 5.260 & 5.260 & 5.260 & 5.260 & 5.260 & 5.260 & 5.260 & 5.260 & & \\
\hline$b_{g}$ & -0.161 & -0.161 & -1.613 & -0.161 & 0 & 0 & 0 & 0 & -0.161 & \\
\hline$\rho_{g_{-1}}$ & $-3.07 \%$ & $-3.07 \%$ & $-3.07 \%$ & $-3.07 \%$ & 0 & 0 & 0 & 0 & & \\
\hline$\sigma_{g r}$ & 0.090 & 0.090 & -0.495 & -0.495 & 1.397 & 1.397 & 0 & 0 & 0.901 & \\
\hline$\rho_{g r}$ & $0.31 \%$ & $0.31 \%$ & $-0.17 \%$ & $-0.17 \%$ & $0.48 \%$ & $0.48 \%$ & 0 & 0 & & \\
\hline$\rho_{e u}$ & $0.48 \%$ & $0.48 \%$ & 0 & 0 & $0.48 \%$ & $0.48 \%$ & 0 & 0 & & \\
\hline$\sigma_{e u}=$ Av. Cond $\sigma_{e u}$ & 0.1396 & 0.1396 & 0 & 0 & 0.1397 & 0.1397 & 0 & 0 & & \\
\hline Av. Cond. $\rho_{e u}$ & $0.50 \%$ & $0.48 \%$ & 0 & 0 & $0.50 \%$ & $0.48 \%$ & 0 & 0 & & \\
\hline$\sigma_{u \mid \exp }$ & 4.063 & 5.258 & 4.063 & 5.258 & 4.065 & 5.260 & 4.065 & 5.260 & & \\
\hline$\sigma_{u \mid r e c}$ & 7.110 & 5.258 & 7.110 & 5.258 & 7.113 & 5.260 & 7.113 & 5.260 & & \\
\hline$\sigma_{w u}=$ Av. Cond $\sigma_{w u}$ & 0 & 0 & 0 & 0 & 0 & 0 & 0 & 0 & & \\
\hline Annual $\sigma_{\epsilon}$ & 10 & 10 & 10 & 10 & 10 & 10 & 10 & 10 & & 10 \\
\hline \multirow[t]{2}{*}{$\sigma_{\epsilon}$} & 24.5 & 24.5 & 24.5 & 24.5 & 24.5 & 24.5 & 24.5 & 24.5 & & \\
\hline & \multicolumn{10}{|c|}{ Total Private } \\
\hline$\mu_{g}$ & 0.153 & 0.153 & 0.153 & 0.153 & 0.153 & 0.153 & 0.153 & 0.153 & & 0.153 \\
\hline Annual $\sigma_{g}$ & 15 & 15 & 15 & 15 & 15 & 15 & 15 & 15 & & 15 \\
\hline$\sigma_{g}$ & 5.281 & 5.281 & 5.281 & 5.281 & 5.281 & 5.281 & 5.281 & 5.281 & & \\
\hline$b_{g}$ & -0.102 & -0.102 & -0.102 & -0.102 & 0 & 0 & 0 & 0 & -1.020 & \\
\hline$\rho_{g d_{-1}}$ & $-1.93 \%$ & $-1.93 \%$ & $-1.93 \%$ & $-1.93 \%$ & 0 & 0 & 0 & 0 & & \\
\hline$\sigma_{g r}$ & -0.159 & -0.159 & -0.031 & -0.031 & -0.128 & -0.128 & 0 & 0 & -0.159 & \\
\hline$\rho_{g r}$ & $-0.54 \%$ & $-0.54 \%$ & $-0.11 \%$ & $-0.11 \%$ & $-0.44 \%$ & $-0.44 \%$ & 0 & 0 & & \\
\hline$\rho_{e u}$ & $-0.44 \%$ & $-0.44 \%$ & 0 & 0 & $-0.44 \%$ & $-0.44 \%$ & 0 & 0 & & \\
\hline$\sigma_{e u}=$ Av. Cond. $\sigma_{e u}$ & -0.1274 & -0.1274 & 0 & 0 & -0.1275 & -0.1275 & 0 & 0 & & \\
\hline Av. Cond. $\rho_{e u}$ & $-0.46 \%$ & $-0.44 \%$ & 0 & 0 & $-0.46 \%$ & $-0.44 \%$ & 0 & 0 & & \\
\hline$\sigma_{u \mid \exp }$ & 4.079 & 5.280 & 4.079 & 5.280 & 4.080 & 5.281 & 4.080 & 5.281 & & \\
\hline$\sigma_{u \mid r e c}$ & 7.139 & 5.280 & 7.139 & 5.280 & 7.140 & 5.281 & 7.140 & 5.281 & & \\
\hline$\sigma_{w u}=$ Av. Cond $\sigma_{w u}$ & 0 & 0 & 0 & 0 & 0 & 0 & 0 & 0 & & \\
\hline \multicolumn{11}{|c|}{ Proprietary Income } \\
\hline$\mu_{g}$ & 0.153 & 0.153 & 0.153 & 0.153 & 0.153 & 0.153 & 0.153 & 0.153 & & 0.153 \\
\hline Annual $\sigma_{g}$ & 25 & 25 & 25 & 25 & 25 & 25 & 25 & 25 & & 25 \\
\hline$\sigma_{g}$ & 8.810 & 8.810 & 8.810 & 8.810 & 8.810 & 8.810 & 8.810 & 8.810 & & \\
\hline$b_{g} \times$ & -0.134 & -0.134 & -0.134 & -0.134 & 0 & 0 & 0 & 0 & -0.134 & \\
\hline$\rho_{g d_{-1}}$ & $-1.52 \%$ & $-1.52 \%$ & $-1.52 \%$ & $-1.52 \%$ & 0 & 0 & 0 & 0 & & \\
\hline$\sigma_{g r}$ & 0.545 & 0.545 & -0.041 & -0.041 & 0.587 & 0.587 & 0 & 0 & 0.545 & \\
\hline$\rho_{g r}$ & $1.12 \%$ & $1.12 \%$ & $-0.08 \%$ & $-0.08 \%$ & $1.21 \%$ & $1.21 \%$ & 0 & 0 & & \\
\hline$\rho_{\text {eu }}$ & $1.21 \%$ & $1.21 \%$ & 0 & 0 & $1.21 \%$ & $1.21 \%$ & 0 & 0 & & \\
\hline$\sigma_{e u}=$ Av. Cond. $\sigma_{e u}$ & 0.5864 & 0.5864 & 0 & 0 & 0.5865 & 0.5865 & 0 & 0 & & \\
\hline Av. Cond $\rho_{e u}$ & $1.26 \%$ & $1.21 \%$ & 0 & 0 & $1.26 \%$ & $1.21 \%$ & 0 & 0 & & \\
\hline$\sigma_{u \mid \exp }$ & 6.806 & 8.809 & 6.806 & 8.809 & 6.807 & 8.810 & 6.807 & 8.810 & & \\
\hline$\sigma_{u \mid r e c}$ & 11.911 & 8.809 & 11.911 & 8.809 & 11.912 & 8.810 & 11.912 & 8.810 & & \\
\hline$\sigma_{w u}=$ Av. Cond. $\sigma_{w u}$ & 0 & 0 & 0 & 0 & 0 & 0 & 0 & 0 & & \\
\hline
\end{tabular}


Table 2. FIRST MONTH ALLOCATION RESULTS. FLAT INCOME GROWTH PROFILE. SPECIFICATION-BASED PERMANENT INCOME VOLATILITY. NO TRANSITORY SHOCKS. RETAIL TRADE DATA. The table reports asset allocation results for a CRRA agent with a coefficient of risk aversion of 6 for the first month of her 20 year horizon, for a range of wealth to permanent income ratios from 0 to $\infty$. The mean monthly growth rate of permanent income is set to $3 \%$ p.a. based on Gakidis (1997). The volatility of the logarithmic monthly growth rate of permanent income $\sigma_{g}$, is obtained from its annual counterpart (fixed at $15 \%$ from Gakidis (1997)), accounting for the assumed dynamics of permanent income growth. There are no transitory shocks to income. Retail Trade Income (series CEU4200000004 by Bureau of Labor Statistics) is also used to calibrate labor income as described in Table 1. Agent has access to the market portfolio (value-weighted return on all NYSE, AMEX, and NASDAQ stocks) and to a riskless bond. Calibrations of these assets are as described in section 3 of the text. SDM, CWR and SDV denote, respectively, the state-dependent mean, return covariance and state-dependent volatility channels through which permanent labor income growth can affect stock holdings (see section 2.1 for descriptions). Panel A reports average stock holdings when all three and none of the channels are present. Panel B and C reports the incremental effects on stock holdings of switching on one of the channels. Each of these channels can be switched on when both, one, or none of the other channels are present and the four rows of each channel's subpanel report the incremental stock-holding reductions for these 4 cases. The calibration of the 8 problems needed to do the comparisons is detailed in section 3 of the text. Panel B reports average reductions in fractions of stock holdings using all states, Panel $\mathrm{C}$ does the same using only non binding states, states for which fractions of stock holdings for both cases are strictly between 0 and 1.

\begin{tabular}{|c|c|c|c|c|c|c|c|c|}
\hline \multicolumn{9}{|c|}{ Panel A: Allocations Averaged Across All States } \\
\hline & \multicolumn{8}{|c|}{ Wealth/Income Ratio } \\
\hline & 0 & 1 & 10 & 30 & 70 & 100 & 1000 & $\infty$ \\
\hline All & 0.203 & 0.220 & 0.252 & 0.370 & 0.479 & 0.503 & 0.514 & 0.464 \\
\hline None & 0.975 & 0.975 & 0.955 & 0.905 & 0.835 & 0.796 & 0.569 & 0.464 \\
\hline \multicolumn{9}{|c|}{ Panel B: Incremental Effects Averaged Across All States } \\
\hline & \multicolumn{8}{|c|}{ Wealth/Income Ratio } \\
\hline & 0 & 1 & 10 & 30 & 70 & 100 & 1000 & $\infty$ \\
\hline & \multicolumn{8}{|c|}{ State Dependent Mean } \\
\hline Both & -0.060 & -0.043 & -0.346 & -0.298 & -0.183 & -0. & -0.040 & 0.000 \\
\hline CWR & -0.1 & -0.124 & -0.133 & -0 . & & & & 0.000 \\
\hline SDV & -0.060 & -0.041 & -0.3 & -0. & & & -0 & 0.000 \\
\hline None & -0.124 & -0.116 & -0.129 & -0.139 & -0.137 & -0.130 & -0.044 & 0.000 \\
\hline & \multicolumn{8}{|c|}{ Covariance with Return } \\
\hline Both & 0.00 & -0.011 & -0.005 & -0.008 & -0.006 & -0.005 & -0.001 & 0.000 \\
\hline SDM & 0.000 & -0.008 & -0.007 & -0.006 & -0.0 & -0.0 & -0. & 0.000 \\
\hline SDV & 0.000 & -0.010 & -0.019 & -0.009 & -0. & $-0 .($ & -0.002 & 0.000 \\
\hline None & 0.000 & 0.000 & -0.004 & -0.003 & -0.004 & -0.004 & -0.001 & 0.000 \\
\hline \multicolumn{9}{|c|}{ State Dependent Volatility } \\
\hline Both & -0.64 & -0.631 & -0.566 & -0.389 & -0.213 & -0.159 & -0.009 & 0.000 \\
\hline & -0.647 & -0.628 & -0.568 & -0. & -0. & -0 . & -0.009 & 0.000 \\
\hline CWR & -0.712 & -0.712 & -0.353 & -0.2 & -0. & -0.142 & -0.013 & 0.000 \\
\hline None & -0.712 & -0.702 & -0.338 & -0.228 & -0.167 & -0.141 & -0.013 & 0.000 \\
\hline
\end{tabular}

Panel C: Incremental Effects Averaged Across Non Binding States

\begin{tabular}{ccccccccc}
\hline & \multicolumn{8}{c}{ Wealth/Income Ratio } \\
& 0 & 1 & 10 & 30 & 70 & 100 & 1000 & $\infty$ \\
Both & - & - & -0.728 & -0.439 & -0.237 & -0.185 & -0.040 & 0.000 \\
CWR & - & - & - & -0.428 & -0.248 & -0.199 & -0.044 & 0.000 \\
SDV & - & - & -0.728 & -0.438 & -0.238 & -0.185 & -0.041 & 0.000 \\
None & - & - & -0.856 & -0.404 & -0.248 & -0.199 & -0.044 & 0.000 \\
\multicolumn{8}{c}{ State Dependent Mean } \\
Both & - & -0.192 & -0.042 & -0.014 & -0.008 & -0.006 & -0.001 & 0.000 \\
SDM & - & - & -0.034 & -0.014 & -0.008 & -0.006 & -0.001 & 0.000 \\
SDV & - & - & -0.028 & -0.013 & -0.008 & -0.006 & -0.002 & 0.000 \\
None & - & - & -0.035 & -0.013 & -0.008 & -0.006 & -0.001 & 0.000 \\
& & \multicolumn{8}{c}{ State Dependent Volatility } \\
Both & - & - & - & -0.660 & -0.283 & -0.203 & -0.009 & 0.000 \\
SDM & - & - & - & -0.659 & -0.284 & -0.202 & -0.009 & 0.000 \\
CWR & - & - & -0.735 & -0.359 & -0.224 & -0.182 & -0.013 & 0.000 \\
None & - & - & -0.740 & -0.360 & -0.225 & -0.183 & -0.013 & 0.000 \\
\hline
\end{tabular}


Table 3. LAST MONTH ALLOCATION RESULTS. FLAT INCOME GROWTH PROFILE. SPECIFICATION-BASED PERMANENT INCOME VOLATILITY. NO TRANSITORY SHOCKS. RETAIL TRADE DATA. The table reports asset allocation results for a CRRA agent with a coefficient of risk aversion of 6 for the last month of her 20 year horizon, for a range of wealth to permanent income ratios from 0 to $\infty$. The mean monthly growth rate of permanent income is set to $3 \%$ p.a. based on Gakidis (1997). The volatility of the logarithmic monthly growth rate of permanent income $\sigma_{g}$, is obtained from its annual counterpart (fixed at $15 \%$ from Gakidis (1997)), accounting for the assumed dynamics of permanent income growth. There are no transitory shocks to income. Retail Trade Income (series CEU4200000004 by Bureau of Labor Statistics) is also used to calibrate labor income as described in Table 1. Agent has access to the market portfolio (value-weighted return on all NYSE, AMEX, and NASDAQ stocks) and to a riskless bond. Calibrations of these assets are as described in section 3 of the text. SDM, CWR and SDV denote, respectively, the state-dependent mean, return covariance and state-dependent volatility channels through which permanent labor income growth can affect stock holdings (see section 2.1 for descriptions). Panel A reports average stock holdings when all three and none of the channels are present. Panel B and C reports the incremental effects on stock holdings of switching on one of the channels. Each of these channels can be switched on when both, one, or none of the other channels are present and the four rows of each channel's subpanel report the incremental stock-holding reductions for these 4 cases. The calibration of the 8 problems needed to do the comparisons is detailed in section 3 of the text. Panel B reports average reductions in fractions of stock holdings using all states, Panel $\mathrm{C}$ does the same using only non binding states, states for which fractions of stock holdings for both cases are strictly between 0 and 1.

\begin{tabular}{|c|c|c|c|c|c|c|c|c|}
\hline \multicolumn{9}{|c|}{ Panel A: Allocations Averaged Across All States } \\
\hline & \multicolumn{8}{|c|}{ Wealth/Income Ratio } \\
\hline & 0 & 1 & 10 & 30 & 70 & 100 & 1000 & $\infty$ \\
\hline All & 1.000 & 0.806 & 0.417 & 0.371 & & 0.355 & 0.349 & 0.464 \\
\hline None & 0.987 & 0.807 & 0.418 & 0.371 & 0.358 & 0.355 & 0.349 & 0.464 \\
\hline \multicolumn{9}{|c|}{ Panel B: Incremental Effects Averaged Across All States } \\
\hline & \multicolumn{8}{|c|}{ Wealth/Income Ratio } \\
\hline & 0 & 1 & 10 & 30 & 70 & 100 & 1000 & $\infty$ \\
\hline & \multicolumn{8}{|c|}{ State Dependent Mean } \\
\hline Both & 0.000 & 0.000 & -0.000 & -0.000 & 0.000 & 0.000 & 0.000 & 0.000 \\
\hline CWR & 0.0 & 0.001 & -0.0 & $-0 .($ & -0. & $-0 .($ & & 0.000 \\
\hline $\mathrm{SDV}$ & 0.000 & 0.000 & $-0 .($ & 0.000 & -0 . & 0.0 & 0.1 & 0.000 \\
\hline None & 0.000 & 0.001 & -0.000 & 0.000 & -0.000 & -0.000 & 0.000 & 0.000 \\
\hline & \multicolumn{8}{|c|}{ Covariance with Return } \\
\hline Both & 0.000 & -0.003 & -0.001 & -0.000 & -0.000 & -0.000 & -0.000 & 0.000 \\
\hline SDM & -0.012 & -0.004 & -0.001 & -0.000 & -0.000 & -0.000 & -0. & 0.000 \\
\hline $\mathrm{SDV}$ & -0.012 & -0.003 & -0.001 & -0.000 & -0.000 & -0.000 & -0.000 & 0.000 \\
\hline None & -0.012 & -0.004 & -0.001 & -0.000 & -0.000 & -0.000 & -0.000 & 0.000 \\
\hline \multicolumn{9}{|c|}{ State Dependent Volatility } \\
\hline Both & 0 & 0.002 & 0.000 & -0.000 & 0.000 & 0.000 & 0.000 & 0.000 \\
\hline & & 0.001 & -0.000 & 0.000 & 0.000 & 0.000 & 0.000 & 0.000 \\
\hline CWR & 0.000 & 0.002 & -0.000 & -0.000 & -0.000 & -0.000 & 0.000 & 0.000 \\
\hline None & 0.000 & 0.002 & -0.000 & 0.000 & 0.000 & 0.000 & 0.000 & 0.000 \\
\hline
\end{tabular}

Panel C: Incremental Effects Averaged Across Non Binding States

\begin{tabular}{ccccccccc}
\hline & \multicolumn{8}{c}{ Wealth/Income Ratio } \\
& 0 & 1 & 10 & 30 & 70 & 100 & 1000 & $\infty$ \\
Both & - & 0.000 & -0.000 & -0.000 & 0.000 & 0.000 & 0.000 & 0.000 \\
CWR & - & 0.002 & -0.000 & -0.000 & -0.000 & -0.000 & 0.000 & 0.000 \\
SDV & - & 0.000 & -0.000 & 0.000 & -0.000 & 0.000 & 0.000 & 0.000 \\
None & 0.001 & 0.002 & -0.000 & 0.000 & -0.000 & -0.000 & 0.000 & 0.000 \\
\multicolumn{8}{c}{ Covariance } & with Return \\
Both & - & -0.007 & -0.001 & -0.000 & -0.000 & -0.000 & -0.000 & 0.000 \\
SDM & - & -0.009 & -0.001 & -0.000 & -0.000 & -0.000 & -0.000 & 0.000 \\
SDV & - & -0.007 & -0.001 & -0.000 & -0.000 & -0.000 & -0.000 & 0.000 \\
None & - & -0.009 & -0.001 & -0.000 & -0.000 & -0.000 & -0.000 & 0.000 \\
& & \multicolumn{7}{c}{ State Dependent Volatility } \\
Both & - & 0.004 & 0.000 & -0.000 & 0.000 & 0.000 & 0.000 & 0.000 \\
SDM & - & 0.002 & -0.000 & 0.000 & 0.000 & 0.000 & 0.000 & 0.000 \\
CWR & - & 0.005 & -0.000 & -0.000 & -0.000 & -0.000 & 0.000 & 0.000 \\
None & 0.003 & 0.003 & -0.000 & 0.000 & 0.000 & 0.000 & 0.000 & 0.000 \\
\hline
\end{tabular}


Table 4. FIRST MONTH ALLOCATION RESULTS. FLAT INCOME GROWTH PROFILE. SPECIFICATION-BASED PERMANENT INCOME VOLATILITY. TRANSITORY SHOCKS. RETAIL TRADE DATA. The table reports asset allocation results for a CRRA agent with a coefficient of risk aversion of 6 for the first month of her 20 year horizon, for a range of wealth to permanent income ratios from 0 to $\infty$. The mean monthly growth rate of permanent income is set to $3 \%$ p.a. based on Gakidis (1997). The volatility of the logarithmic monthly growth rate of permanent income $\sigma_{g}$, is obtained from its annual counterpart (fixed at 15\% from Gakidis (1997)), accounting for the assumed dynamics of permanent income growth. A similar procedure is used to obtain the volatility of the logarithmic transitory income $\epsilon$, from its annual counterpart (fixed at $10 \%$ from Gakidis, 1997). Retail Trade Income (series CEU4200000004 by Bureau of Labor Statistics) is also used to calibrate labor income as described in Table 1. Agent has access to the market portfolio (value-weighted return on all NYSE, AMEX, and NASDAQ stocks) and to a riskless bond. Calibrations of these assets are as described in section 3 of the text. SDM, CWR and SDV denote, respectively, the state-dependent mean, return covariance and state-dependent volatility channels through which permanent labor income growth can affect stock holdings (see section 2.1 for descriptions). Panel A reports average stock holdings when all three and none of the channels are present. Panel B and C reports the incremental effects on stock holdings of switching on one of the channels. Each of these channels can be switched on when both, one, or none of the other channels are present and the four rows of each channel's subpanel report the incremental stock-holding reductions for these 4 cases. The calibration of the 8 problems needed to do the comparisons is detailed in section 3 of the text. Panel B reports average reductions in fractions of stock holdings using all states, Panel C does the same using only non binding states, states for which fractions of stock holdings for both cases are strictly between 0 and 1.

\begin{tabular}{|c|c|c|c|c|c|c|c|c|}
\hline \multicolumn{9}{|c|}{ Panel A: Allocations Averaged Across All States } \\
\hline & \multicolumn{8}{|c|}{ Wealth/Income Ratio } \\
\hline & 0 & 1 & 10 & 30 & 70 & 100 & 1000 & $\infty$ \\
\hline All & 0.203 & 0.218 & 0.252 & 0.369 & 0.480 & 0.503 & 0.514 & 0.464 \\
\hline \multirow[t]{5}{*}{ None } & 0.975 & 0.975 & 0.954 & 0.905 & 0.834 & 0.796 & 0.568 & 0.464 \\
\hline & \multicolumn{8}{|c|}{ Panel B: Incremental Effects Averaged Across All States } \\
\hline & \multicolumn{8}{|c|}{ Wealth/Income Ratio } \\
\hline & 0 & 1 & 10 & 30 & 70 & 100 & 1000 & $\infty$ \\
\hline & \multicolumn{8}{|c|}{ State Dependent Mean } \\
\hline Both & -0.060 & -0.047 & -0.345 & -0.298 & -0.182 & -0.148 & -0.040 & 0.000 \\
\hline CWR & -0.124 & -0.124 & -0.133 & -0.142 & -0.139 & -0.131 & -0.044 & 0.000 \\
\hline SDV & -0.054 & -0.040 & -0.359 & -0.299 & -0.182 & -0.147 & -0.041 & 0.000 \\
\hline None & -0.124 & -0.116 & -0.129 & -0.140 & -0.137 & -0.130 & -0.044 & 0.000 \\
\hline & \multicolumn{8}{|c|}{ Covariance with Return } \\
\hline Both & -0.005 & -0.013 & -0.005 & -0.008 & -0.006 & -0.005 & -0.001 & 0.000 \\
\hline SDM & 0.000 & -0.008 & -0.007 & -0.006 & -0.005 & -0.005 & -0.001 & 0.000 \\
\hline SDV & 0.000 & -0.007 & -0.019 & -0.009 & -0.006 & -0.005 & -0.002 & 0.000 \\
\hline None & 0.000 & 0.000 & -0.003 & -0.003 & -0.004 & -0.004 & -0.001 & 0.000 \\
\hline \multicolumn{9}{|c|}{ State Dependent Volatility } \\
\hline Both & -0.647 & -0.633 & -0.567 & -0.390 & -0.213 & -0.158 & -0.009 & 0.000 \\
\hline SDM & -0.642 & -0.627 & -0.568 & -0.388 & -0.212 & -0.158 & -0.009 & 0.000 \\
\hline CWR & -0.712 & -0.710 & -0.354 & -0.235 & -0.169 & -0.142 & -0.013 & 0.000 \\
\hline None & -0.712 & -0.703 & -0.338 & -0.229 & -0.167 & -0.140 & -0.012 & 0.000 \\
\hline
\end{tabular}

Panel C: Incremental Effects Averaged Across Non Binding States

\begin{tabular}{lcccccccc}
\hline & & \multicolumn{7}{c}{ Wealth/Income Ratio } \\
& 0 & 1 & 10 & 30 & 70 & 100 & 1000 & $\infty$ \\
Both & - & - & -0.733 & -0.440 & -0.237 & -0.185 & -0.040 & 0.000 \\
CWR & - & - & - & -0.427 & -0.247 & -0.198 & -0.044 & 0.000 \\
SDV & - & - & -0.729 & -0.439 & -0.237 & -0.185 & -0.041 & 0.000 \\
None & - & - & -0.859 & -0.406 & -0.247 & -0.198 & -0.044 & 0.000 \\
& & & & \multicolumn{7}{c}{ Covariance } & with Return & & \\
Both & - & -0.223 & -0.043 & -0.014 & -0.008 & -0.006 & -0.001 & 0.000 \\
SDM & - & - & -0.032 & -0.014 & -0.008 & -0.006 & -0.001 & 0.000 \\
SDV & - & -0.209 & -0.028 & -0.013 & -0.008 & -0.006 & -0.002 & 0.000 \\
None & - & - & -0.032 & -0.013 & -0.008 & -0.006 & -0.001 & 0.000 \\
& & & & State Dependent Volatility & & \\
Both & - & - & - & -0.663 & -0.282 & -0.202 & -0.009 & 0.000 \\
SDM & - & - & - & -0.663 & -0.283 & -0.201 & -0.009 & 0.000 \\
CWR & - & - & -0.730 & -0.363 & -0.223 & -0.182 & -0.013 & 0.000 \\
None & - & - & -0.737 & -0.363 & -0.224 & -0.182 & -0.012 & 0.000 \\
\hline
\end{tabular}


Table 5. FIRST MONTH ALLOCATION RESULTS. FLAT INCOME GROWTH PROFILE. SPECIFICATION-BASED PERMANENT INCOME VOLATILITY. TRANSITORY SHOCKS. I.I.D. UNEMPLOYMENT STATE. RETAIL TRADE DATA. The table reports asset allocation results for a CRRA agent with a coefficient of risk aversion of 6 for the first month of her 20 year horizon, for a range of wealth to permanent income ratios from 0 to $\infty$. The mean monthly growth rate of permanent income is set to $3 \%$ p.a. based on Gakidis (1997). The volatility of the logarithmic monthly growth rate of permanent income $\sigma_{g}$, is obtained from its annual counterpart (fixed at $15 \%$ from Gakidis (1997)), accounting for the assumed dynamics of permanent income growth. A similar procedure is used to obtain the volatility of the logarithmic transitory income $\epsilon$, from its annual counterpart (fixed at 10\% from Gakidis, 1997). We allow for transitory unemployment by introducing an i.i.d. unemployment shock: each month the agent receives $10 \%$ of her monthly permanent income with $\% 0.5$ probability, which is consistent with findings in Carroll (1992). Retail Trade Income (series CEU4200000004 by Bureau of Labor Statistics) is also used to calibrate labor income as described in Table 1. Agent has access to the market portfolio (value-weighted return on all NYSE, AMEX, and NASDAQ stocks) and to a riskless bond. Calibrations of these assets are as described in section 3 of the text. SDM, CWR and SDV denote, respectively, the state-dependent mean, return covariance and state-dependent volatility channels through which permanent labor income growth can affect stock holdings (see section 2.1 for descriptions). Panel A reports average stock holdings when all three and none of the channels are present. Panel B and C reports the incremental effects on stock holdings of switching on one of the channels. Each of these channels can be switched on when both, one, or none of the other channels are present and the four rows of each channel's subpanel report the incremental stock-holding reductions for these 4 cases. The calibration of the 8 problems needed to do the comparisons is detailed in section 3 of the text. Panel B reports average reductions in fractions of stock holdings using all states, Panel C does the same using only non binding states, states for which fractions of stock holdings for both cases are strictly between 0 and 1.

\begin{tabular}{|c|c|c|c|c|c|c|c|c|}
\hline \multicolumn{9}{|c|}{ Panel A: Allocations Averaged Across All States } \\
\hline & \multicolumn{8}{|c|}{ Wealth/Income Ratio } \\
\hline & 0 & 1 & 10 & 30 & 70 & 100 & 1000 & $\infty$ \\
\hline All & 0.222 & 0.215 & 0.248 & 0.361 & 0.468 & 0.493 & 0.504 & 0.464 \\
\hline None & 0.937 & 0.975 & 0.950 & 0.900 & 0.826 & 0.787 & 0.559 & 0.464 \\
\hline \multicolumn{9}{|c|}{ Panel B: Incremental Effects Averaged Across All States } \\
\hline & \multicolumn{8}{|c|}{ Wealth/Income Ratio } \\
\hline & 0 & 1 & 10 & 30 & 70 & 100 & 1000 & $\infty$ \\
\hline & \multicolumn{8}{|c|}{ State Dependent Mean } \\
\hline Both & -0.200 & -0.048 & -0.326 & -0.293 & -0.181 & -0.147 & -0.040 & 0.000 \\
\hline CWR & -0.114 & -0.124 & -0.1 & -0. & -0 . & & -0. & 0.000 \\
\hline SDV & -0.198 & -0.042 & -0.340 & -0.2 & -0 . & -0 . & -0. & 0.000 \\
\hline None & -0.109 & -0.119 & -0.133 & -0.143 & -0.140 & -0.131 & -0.044 & 0.000 \\
\hline & \multicolumn{8}{|c|}{ Covariance with Return } \\
\hline Both & -0.009 & -0.013 & -0.005 & -0.008 & -0.006 & -0.005 & -0.001 & 0.000 \\
\hline SDM & -0.007 & -0.005 & -0.008 & -0.0 & -0. & -0. & -0. & 0.000 \\
\hline SDV & -0.008 & -0.007 & -0.020 & -0.009 & -0.0 & -0. & -0.002 & 0.000 \\
\hline None & -0.002 & 0.000 & -0.003 & -0.003 & -0.004 & -0.004 & -0.001 & 0.000 \\
\hline \multicolumn{9}{|c|}{ State Dependent Volatility } \\
\hline Both & -0.599 & -0.636 & -0.562 & -0.391 & -0.214 & -0.158 & -0.009 & 0.000 \\
\hline SDM & -0.596 & -0.628 & -0.564 & -0.389 & -0.213 & -0.158 & -0.009 & 0.000 \\
\hline CWR & -0.513 & -0.712 & -0.374 & -0.243 & -0.173 & -0.143 & -0.013 & 0.000 \\
\hline None & -0.507 & -0.705 & -0.357 & -0.237 & -0.171 & -0.142 & -0.012 & 0.000 \\
\hline
\end{tabular}

Panel C: Incremental Effects Averaged Across Non Binding States

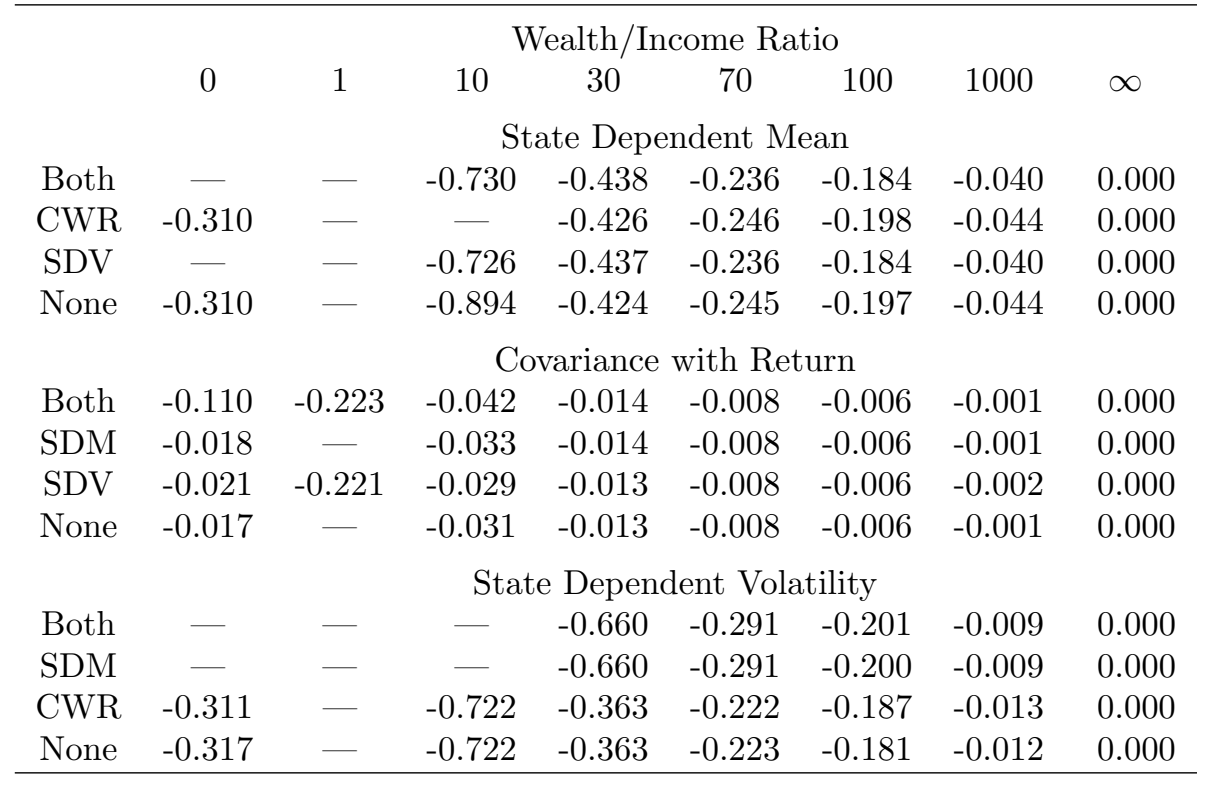




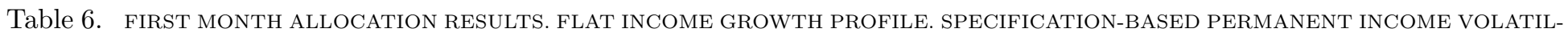

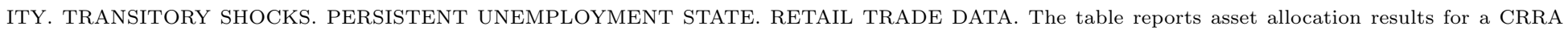

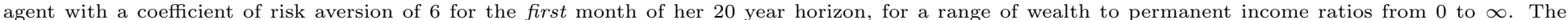

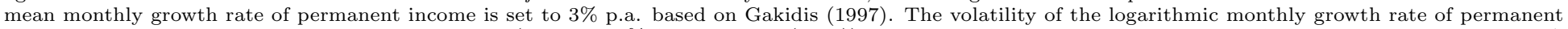

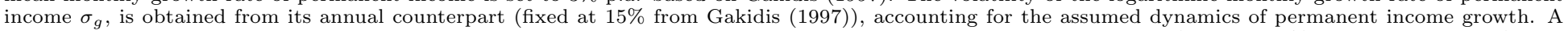

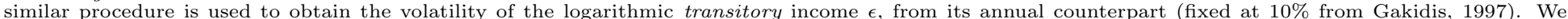

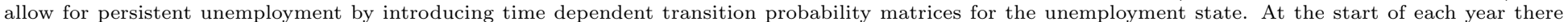

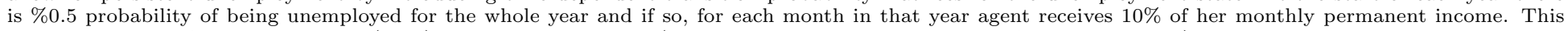

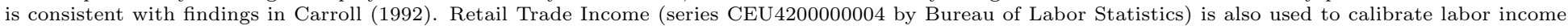

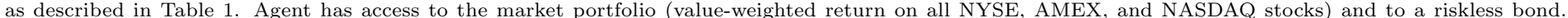

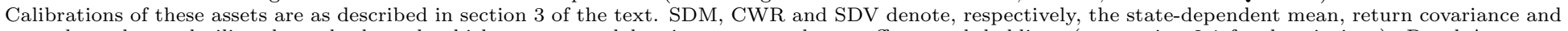

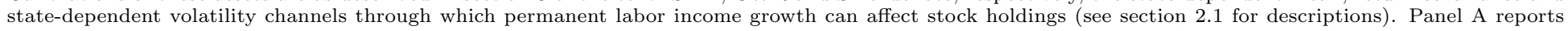

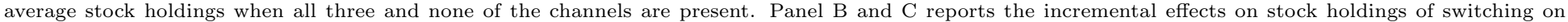

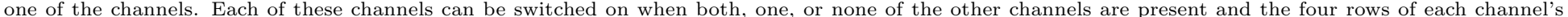

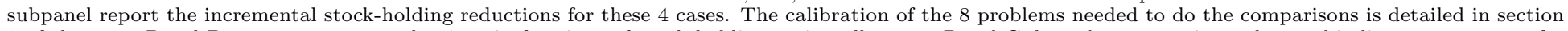

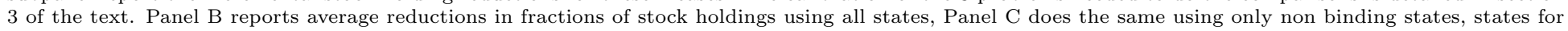
which fractions of stock holdings for both cases are strictly between 0 and 1 .

\begin{tabular}{|c|c|c|c|c|c|c|c|c|}
\hline \multicolumn{9}{|c|}{ Panel A: Allocations Averaged Across All States } \\
\hline & \multicolumn{8}{|c|}{ Wealth/Income Ratio } \\
\hline & 0 & 1 & 10 & 30 & 70 & 100 & 1000 & $\infty$ \\
\hline All & 0.172 & 0.233 & 0.253 & 0.371 & 0.477 & 0.501 & 0.510 & 0.464 \\
\hline \multirow[t]{5}{*}{ None } & 0.698 & 0.859 & 0.883 & 0.875 & 0.815 & 0.789 & 0.564 & 0.464 \\
\hline & \multicolumn{8}{|c|}{ Panel B: Incremental Effects Averaged Across All States } \\
\hline & \multicolumn{8}{|c|}{ Wealth/Income Ratio } \\
\hline & 0 & 1 & 10 & 30 & 70 & 100 & 1000 & $\infty$ \\
\hline & \multicolumn{8}{|c|}{ State Dependent Mean } \\
\hline Both & -0.332 & -0.191 & -0.286 & -0.268 & -0.167 & -0.145 & -0.040 & 0.000 \\
\hline CWR & -0.073 & -0.093 & -0.120 & -0.135 & -0.135 & -0.129 & -0.043 & 0.000 \\
\hline SDV & -0.347 & -0.231 & -0.299 & -0.270 & -0.168 & -0.144 & -0.040 & 0.000 \\
\hline None & -0.069 & -0.086 & -0.116 & -0.133 & -0.134 & -0.128 & -0.043 & 0.000 \\
\hline & \multicolumn{8}{|c|}{ Covariance with Return } \\
\hline Both & -0.027 & -0.013 & -0.005 & -0.008 & -0.005 & -0.005 & -0.001 & 0.000 \\
\hline SDM & -0.004 & -0.007 & -0.007 & -0.005 & -0.005 & -0.005 & -0.001 & 0.000 \\
\hline $\mathrm{SDV}$ & -0.041 & -0.053 & -0.018 & -0.009 & -0.006 & -0.005 & -0.001 & 0.000 \\
\hline None & 0.000 & -0.000 & -0.002 & -0.003 & -0.003 & -0.004 & -0.001 & 0.000 \\
\hline \multicolumn{9}{|c|}{ State Dependent Volatility } \\
\hline Both & -0.452 & -0.533 & -0.508 & -0.366 & -0.200 & -0.155 & -0.009 & 0.000 \\
\hline SDM & -0.429 & -0.528 & -0.510 & -0.363 & -0.199 & -0.155 & -0.009 & 0.000 \\
\hline CWR & -0.193 & -0.436 & -0.342 & -0.233 & -0.167 & -0.140 & -0.012 & 0.000 \\
\hline None & -0.152 & -0.383 & -0.326 & -0.227 & -0.164 & -0.139 & -0.012 & 0.000 \\
\hline
\end{tabular}

Panel C: Incremental Effects Averaged Across Non Binding States

\begin{tabular}{lcccccccc}
\hline & & \multicolumn{7}{c}{ Wealth/Income Ratio } \\
& 0 & 1 & 10 & 30 & 70 & 100 & 1000 & $\infty$ \\
Both & -0.251 & -0.040 & -0.727 & -0.436 & -0.235 & -0.183 & -0.041 & 0.000 \\
CWR & -0.041 & -0.078 & -0.361 & -0.439 & -0.251 & -0.197 & -0.044 & 0.000 \\
SDV & -0.185 & -0.040 & -0.722 & -0.439 & -0.235 & -0.183 & -0.041 & 0.000 \\
None & -0.036 & -0.097 & -0.333 & -0.434 & -0.251 & -0.197 & -0.044 & 0.000 \\
& & & \multicolumn{7}{c}{ Covariance with Return } & & \\
Both & -0.111 & -0.200 & -0.043 & -0.014 & -0.008 & -0.006 & -0.001 & 0.000 \\
SDM & -0.005 & -0.012 & -0.029 & -0.013 & -0.008 & -0.006 & -0.001 & 0.000 \\
SDV & -0.056 & -0.131 & -0.029 & -0.013 & -0.008 & -0.006 & -0.002 & 0.000 \\
None & 0.000 & -0.000 & -0.008 & -0.013 & -0.008 & -0.006 & -0.001 & 0.000 \\
& & & \multicolumn{7}{c}{ State Dependent Volatility } & & \\
Both & -0.256 & -0.052 & - & -0.658 & -0.300 & -0.200 & -0.009 & 0.000 \\
SDM & -0.189 & -0.053 & - & -0.640 & -0.301 & -0.199 & -0.009 & 0.000 \\
CWR & -0.109 & -0.557 & -0.569 & -0.389 & -0.222 & -0.186 & -0.013 & 0.000 \\
None & -0.073 & -0.506 & -0.541 & -0.363 & -0.222 & -0.187 & -0.013 & 0.000 \\
\hline
\end{tabular}


Table 7. FIRST MONTH ALLOCATION RESULTS. FLAT INCOME GROWTH PROFILE. SPECIFICATION-BASED PERMANENT INCOME VOLATILITY. NO TRANSITORY SHOCKS. TOTAL PRIVATE DATA. The table reports asset allocation results for a CRRA agent with a coefficient of risk aversion of 6 for the first month of her 20 year horizon, for a range of wealth to permanent income ratios from 0 to $\infty$. The mean monthly growth rate of permanent income is set to $3 \%$ p.a. based on Gakidis (1997). The volatility of the logarithmic monthly growth rate of permanent income $\sigma_{g}$, is obtained from its annual counterpart (fixed at $15 \%$ from Gakidis (1997)), accounting for the assumed dynamics of permanent income growth. There are no transitory shocks to income. Total Private Income (series CEU0500000004 by Bureau of Labor Statistics) is also used to calibrate labor income as described in Table 1. Agent has access to the market portfolio (value-weighted return on all NYSE, AMEX, and NASDAQ stocks) and to a riskless bond. Calibrations of these assets are as described in section 3 of the text. SDM, CWR and SDV denote, respectively, the state-dependent mean, return covariance and state-dependent volatility channels through which permanent labor income growth can affect stock holdings (see section 2.1 for descriptions). Panel A reports average stock holdings when all three and none of the channels are present. Panel B and C reports the incremental effects on stock holdings of switching on one of the channels. Each of these channels can be switched on when both, one, or none of the other channels are present and the four rows of each channel's subpanel report the incremental stock-holding reductions for these 4 cases. The calibration of the 8 problems needed to do the comparisons is detailed in section 3 of the text. Panel B reports average reductions in fractions of stock holdings using all states, Panel $\mathrm{C}$ does the same using only non binding states, states for which fractions of stock holdings for both cases are strictly between 0 and 1.

\begin{tabular}{|c|c|c|c|c|c|c|c|c|}
\hline \multicolumn{9}{|c|}{ Panel A: Allocations Averaged Across All States } \\
\hline & \multicolumn{8}{|c|}{ Wealth/Income Ratio } \\
\hline & 0 & 1 & 10 & 30 & 70 & 100 & 1000 & $\infty$ \\
\hline All & 0.263 & 0.263 & 0.290 & 0.482 & & 0.565 & 0.531 & 0.464 \\
\hline None & 0.975 & 0.975 & 0.954 & 0.905 & 0.834 & 0.796 & 0.568 & 0.464 \\
\hline \multicolumn{9}{|c|}{ Panel B: Incremental Effects Averaged Across All States } \\
\hline & \multicolumn{8}{|c|}{ Wealth/Income Ratio } \\
\hline & 0 & 1 & 10 & 30 & 70 & 100 & 1000 & $\infty$ \\
\hline & \multicolumn{8}{|c|}{ State Dependent Mean } \\
\hline Both & 0.000 & -0.020 & -0.339 & -0.201 & -0.116 & -0.094 & -0.026 & 0.000 \\
\hline CWR & -0.0 & -0.036 & -0.0 & -0. & & -0 . & -0 & 0.000 \\
\hline SDV & 0.000 & -0.007 & -0.325 & -0. & & -0 . & -0 . & 0.000 \\
\hline None & -0.035 & -0.035 & -0.060 & -0.075 & -0.080 & -0.078 & $-0 .($ & 0.000 \\
\hline & \multicolumn{8}{|c|}{ Covariance with Return } \\
\hline Both & 0.00 & 0.000 & 0.004 & 0.009 & 0.005 & 0.005 & 0.001 & 0.000 \\
\hline SDM & 0.000 & 0.000 & 0.005 & 0.005 & 0.0 & 0.004 & 0.001 & 0.000 \\
\hline SDV & 0.000 & 0.013 & 0.018 & 0.008 & 0.006 & 0.005 & 0.001 & 0.000 \\
\hline None & 0.000 & 0.001 & 0.003 & 0.003 & 0.003 & 0.003 & 0.001 & 0.000 \\
\hline \multicolumn{9}{|c|}{ State Dependent Volatility } \\
\hline Both & -0.677 & -0.677 & -0.609 & -0.352 & -0.202 & -0.157 & -0.010 & 0.000 \\
\hline & -0.677 & -0.677 & -0.607 & -0.356 & -0.2 & -0.157 & -0.010 & 0.000 \\
\hline CWR & -0.712 & -0.693 & -0.328 & -0.225 & -0. & -0.140 & -0.012 & 0.000 \\
\hline None & -0.712 & -0.705 & -0.343 & -0.230 & -0.168 & -0.141 & -0.013 & 0.000 \\
\hline
\end{tabular}

Panel C: Incremental Effects Averaged Across Non Binding States

\begin{tabular}{|c|c|c|c|c|c|c|c|c|}
\hline & \multicolumn{8}{|c|}{ Wealth/Income Ratio } \\
\hline & 0 & 1 & 10 & 30 & 70 & 100 & 1000 & $\infty$ \\
\hline & \multicolumn{8}{|c|}{ State Dependent Mean } \\
\hline Both & - & - & -0.463 & -0.287 & -0.150 & -0.117 & -0.026 & 0.000 \\
\hline CWR & - & - & -0.474 & -0.250 & -0.149 & -0.120 & -0.028 & 0.000 \\
\hline SDV & - & - & -0.477 & -0.287 & -0.149 & -0.117 & -0.026 & 0.000 \\
\hline None & - & - & -0.471 & -0.251 & -0.154 & -0.121 & -0.028 & 0.000 \\
\hline \multicolumn{9}{|c|}{ Covariance with Return } \\
\hline Both & - & - & 0.048 & 0.012 & 0.007 & 0.005 & 0.001 & 0.000 \\
\hline SDM & - & - & 0.029 & 0.012 & 0.008 & 0.006 & 0.001 & 0.000 \\
\hline SDV & - & 0.199 & 0.026 & 0.012 & 0.007 & 0.006 & 0.001 & 0.000 \\
\hline None & - & - & 0.033 & 0.011 & 0.007 & 0.006 & 0.001 & 0.000 \\
\hline \multicolumn{9}{|c|}{ State Dependent Volatility } \\
\hline Both & - & - & - & -0.525 & -0.266 & -0.197 & -0.010 & 0.000 \\
\hline SDM & - & - & — & -0.525 & -0.265 & -0.196 & -0.010 & 0.000 \\
\hline CWR & - & - & -0.654 & -0.362 & -0.217 & -0.170 & -0.012 & 0.000 \\
\hline None & - & - & -0.736 & -0.362 & -0.225 & -0.183 & -0.013 & 0.000 \\
\hline
\end{tabular}


Table 8. FIRST MONTH STATE-BY-STATE ALLOCATION RESULTS. FLAT INCOME GROWTH PROFILE. SPECIFICATION-BASED PERMANENT INCOME VOLATILITY. NO TRANSITORY SHOCKS. RETAIL TRADE DATA. The table reports state by state asset allocation results for a CRRA agent with a coefficient of risk aversion of 6 for the first month of her 20 year horizon, for a range of wealth to permanent income ratios from 0 to $\infty$. The mean monthly growth rate of permanent income is set to $3 \%$ p.a. based on Gakidis (1997). The volatility of the logarithmic monthly growth rate of permanent income $\sigma_{g}$, is obtained from its annual counterpart (fixed at $15 \%$ from Gakidis (1997)), accounting for the assumed dynamics of permanent income growth. There are no transitory shocks to income. Retail Trade Income (series CEU4200000004 by Bureau of Labor Statistics) is also used to calibrate labor income as described in Table 1. Agent has access to the market portfolio (value-weighted return on all NYSE, AMEX, and NASDAQ stocks) and to a riskless bond. Calibrations of these assets are as described in section 3 of the text. SDM, CWR and SDV denote, respectively, the state-dependent mean, return covariance and state-dependent volatility channels through which permanent labor income growth can affect stock holdings (see section 2.1 for descriptions). Panel A reports state by state stock holdings when all three channels are present (labelled "All Effects"), and when none are present (labelled "No Effects"). Panel B,(C,D) reports incremental reductions in fraction of stock holdings state by state when SDM (CWR,SDV) is switched on. The left hand columns report reductions when no other effect is present, while the right-hand columns when both other effects are present. The last 4 rows of panels B,C and D report averages taken over all or only non-binding states of the recession states (the highest 7 dividend yield states) and the expansion states (the lowest 12). Values for which both cases needed for comparison are strictly between 0 and 1 are italicized. 
Table 8 cont.

\begin{tabular}{|c|c|c|c|c|c|c|c|c|c|c|c|c|}
\hline \multicolumn{13}{|c|}{ Panel A: Allocations } \\
\hline & \multicolumn{12}{|c|}{ Wealth/Income Ratio } \\
\hline & 1 & 10 & 30 & 70 & 100 & 1000 & 1 & 10 & 30 & 70 & 100 & 1000 \\
\hline $\mathrm{d} / \mathrm{p}$ state & \multicolumn{6}{|c|}{ All Effects } & \multicolumn{6}{|c|}{ No Effects } \\
\hline 1 & 0.000 & 0.000 & 0.000 & 0.000 & 0.000 & 0.024 & 0.000 & 0.059 & 0.057 & 0.057 & 0.056 & 0.048 \\
\hline 2 & 0.000 & 0.000 & 0.000 & 0.000 & 0.000 & 0.106 & 1.000 & 0.518 & 0.294 & 0.223 & 0.205 & 0.143 \\
\hline 3 & 0.000 & 0.000 & 0.000 & 0.004 & 0.054 & 0.177 & 1.000 & 0.878 & 0.502 & 0.362 & 0.327 & 0.222 \\
\hline 4 & 0.000 & 0.000 & 0.000 & 0.064 & 0.119 & 0.239 & 1.000 & 1.000 & 0.676 & 0.487 & 0.433 & 0.289 \\
\hline 5 & 0.000 & 0.000 & 0.000 & 0.131 & 0.185 & 0.295 & 1.000 & 1.000 & 0.828 & 0.599 & 0.528 & 0.349 \\
\hline 6 & 0.000 & 0.000 & 0.000 & 0.200 & 0.249 & 0.348 & 1.000 & 1.000 & 0.969 & 0.700 & 0.618 & 0.404 \\
\hline 7 & 0.000 & 0.000 & 0.054 & 0.267 & 0.310 & 0.396 & 1.000 & 1.000 & 1.000 & 0.794 & 0.702 & 0.455 \\
\hline 8 & 0.000 & 0.000 & 0.116 & 0.328 & 0.368 & 0.443 & 1.000 & 1.000 & 1.000 & 0.882 & 0.781 & 0.503 \\
\hline 9 & 0.000 & 0.000 & 0.184 & 0.384 & 0.424 & 0.488 & 1.000 & 1.000 & 1.000 & 0.965 & 0.857 & 0.549 \\
\hline 10 & 0.000 & 0.000 & 0.238 & 0.435 & 0.475 & 0.531 & 1.000 & 1.000 & 1.000 & 1.000 & 0.929 & 0.593 \\
\hline 11 & 0.000 & 0.000 & 0.277 & 0.485 & 0.525 & 0.573 & 1.000 & 1.000 & 1.000 & 1.000 & 0.998 & 0.636 \\
\hline 12 & 0.000 & 0.000 & 0.361 & 0.550 & 0.585 & 0.614 & 1.000 & 1.000 & 1.000 & 1.000 & 1.000 & 0.676 \\
\hline 13 & 0.000 & 0.101 & 0.533 & 0.657 & 0.669 & 0.654 & 1.000 & 1.000 & 1.000 & 1.000 & 1.000 & 0.716 \\
\hline 14 & 0.284 & 0.709 & 0.791 & 0.793 & 0.775 & 0.694 & 1.000 & 1.000 & 1.000 & 1.000 & 1.000 & 0.753 \\
\hline 15 & 1.000 & 1.000 & 1.000 & 0.930 & 0.885 & 0.733 & 1.000 & 1.000 & 1.000 & 1.000 & 1.000 & 0.788 \\
\hline 16 & 1.000 & 1.000 & 1.000 & 1.000 & 0.987 & 0.769 & 1.000 & 1.000 & 1.000 & 1.000 & 1.000 & 0.820 \\
\hline 17 & 1.000 & 1.000 & 1.000 & 1.000 & 1.000 & 0.803 & 1.000 & 1.000 & 1.000 & 1.000 & 1.000 & 0.848 \\
\hline 18 & 1.000 & 1.000 & 1.000 & 1.000 & 1.000 & 0.843 & 1.000 & 1.000 & 1.000 & 1.000 & 1.000 & 0.884 \\
\hline 19 & 1.000 & 1.000 & 1.000 & 1.000 & 1.000 & 0.924 & 1.000 & 1.000 & 1.000 & 1.000 & 1.000 & 0.959 \\
\hline
\end{tabular}

Panel B: Incremental Effects: State Dependent Mean (SDM)

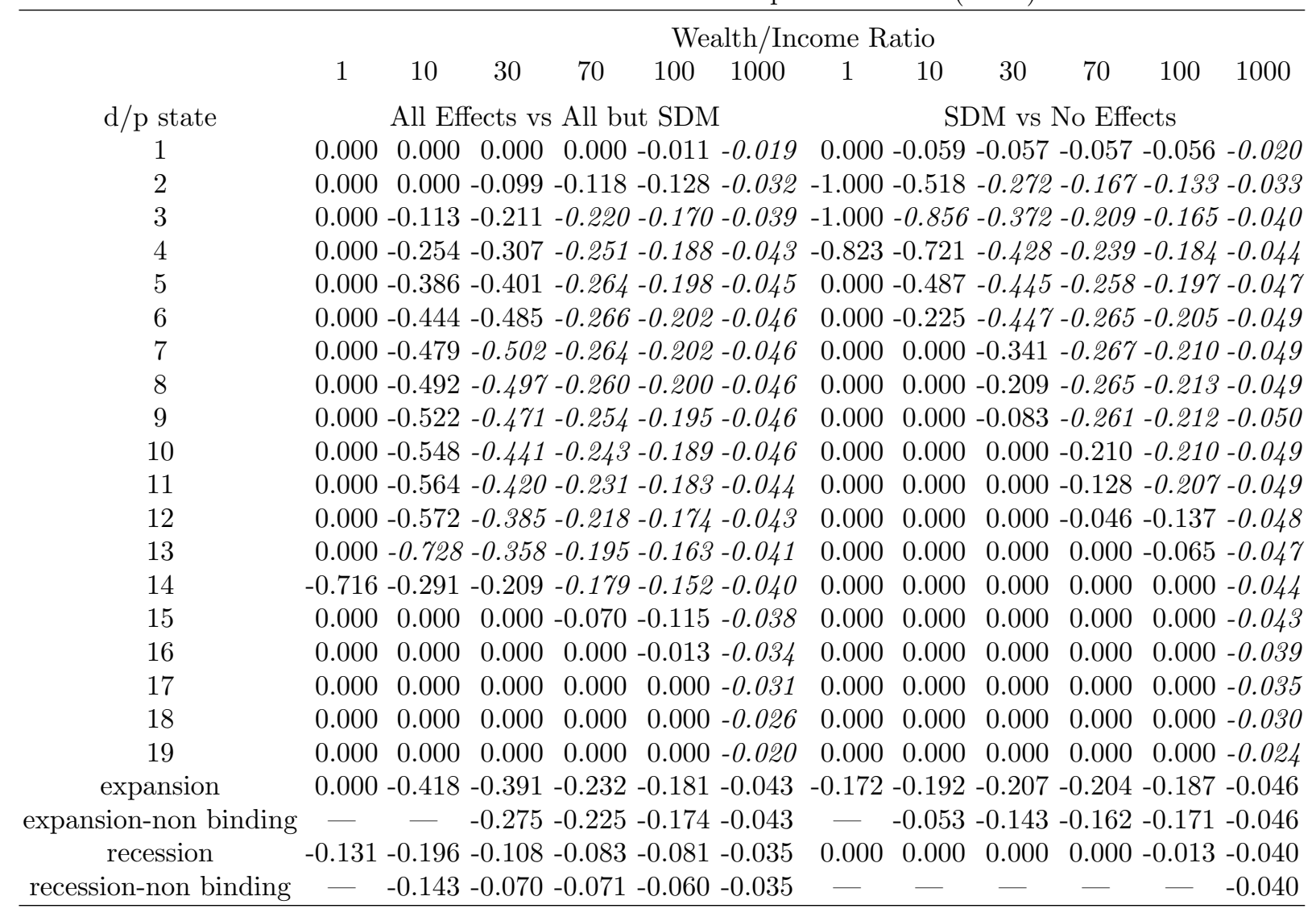


Table 8 cont.

Panel C: Incremental Effects: Return Covariance (CWR)

Wealth/Income Ratio

$\begin{array}{llllllllllll}1 & 10 & 30 & 70 & 100 & 1000 & 1 & 10 & 30 & 70 & 100 & 1000\end{array}$

$\mathrm{d} / \mathrm{p}$ state

1

2

3

4

5

6

7

8

9

10

11

12

13

14

15

16

17

18

19

expansion
All Effects vs All Effects but CWR

$\begin{array}{lllllll}0.000 & 0.000 & 0.000 & 0.000 & 0.000 & -0.001\end{array}$

$\begin{array}{lllllll}0.000 & 0.000 & 0.000 & 0.000 & 0.000 & -0.001\end{array}$

$\begin{array}{lllll}0.000 & 0.000 & 0.000 & -0.007-0.005-0.001\end{array}$

$0.000 \quad 0.000 \quad 0.000-0.008-0.006-0.001$

$\begin{array}{llll}0.000 & 0.000 & 0.000-0.008-0.006-0.001\end{array}$

$0.000 \quad 0.000 \quad 0.000-0.008-0.006-0.001$

$0.000 \quad 0.000-0.016-0.008-0.006-0.001$

$0.000 \quad 0.000-0.014-0.007-0.006-0.001$

$0.000 \quad 0.000-0.013-0.008-0.006-0.001$

$0.000 \quad 0.000-0.012-0.007-0.006-0.001$

$0.000 \quad 0.000-0.013-0.007-0.006-0.001$

$0.000 \quad 0.000-0.013-0.007-0.006-0.001$

$0.000-0.039-0.018-0.010-0.008-0.002$

$-0.192-0.044-0.016-0.009-0.008-0.002$

$\begin{array}{llll}0.000 & 0.000 & 0.000 & -0.009-0.008-0.002\end{array}$

$\begin{array}{llllll}0.000 & 0.000 & 0.000 & 0.000 & -0.007 & -0.002\end{array}$

$\begin{array}{lllllll}0.000 & 0.000 & 0.000 & 0.000 & 0.000 & -0.002\end{array}$

$\begin{array}{lllllll}0.000 & 0.000 & 0.000 & 0.000 & 0.000 & -0.002\end{array}$

$\begin{array}{lllllll}0.000 & 0.000 & 0.000 & 0.000 & 0.000 & -0.002\end{array}$

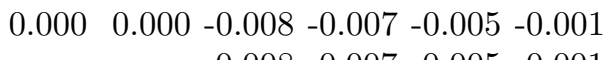

- — $-0.008-0.007-0.005-0.001$

$-0.035-0.016-0.006-0.005-0.005-0.002$
CWR vs No Effects

$0.000-0.041-0.013-0.007-0.006-0.001$

$0.000-0.038-0.014-0.008-0.006-0.002$

$0.000-0.030-0.014-0.008-0.006-0.001$

$0.000 \quad 0.000-0.013-0.009-0.006-0.001$

$0.000 \quad 0.000-0.013-0.008-0.006-0.001$

$0.000 \quad 0.000-0.013-0.008-0.007-0.001$

$\begin{array}{llll}0.000 & 0.000 & 0.000 & -0.008-0.006-0.001\end{array}$

$0.000 \quad 0.000 \quad 0.000-0.008-0.006-0.001$

$0.000 \quad 0.000 \quad 0.000-0.008-0.006-0.002$

$\begin{array}{llllll}0.000 & 0.000 & 0.000 & 0.000 & -0.006 & -0.001\end{array}$

$\begin{array}{llllll}0.000 & 0.000 & 0.000 & 0.000 & -0.006 & -0.001\end{array}$

$\begin{array}{lllllll}0.000 & 0.000 & 0.000 & 0.000 & 0.000 & -0.001\end{array}$

$\begin{array}{lllllll}0.000 & 0.000 & 0.000 & 0.000 & 0.000 & -0.001\end{array}$

$\begin{array}{lllllll}0.000 & 0.000 & 0.000 & 0.000 & 0.000 & -0.001\end{array}$

$\begin{array}{lllllll}0.000 & 0.000 & 0.000 & 0.000 & 0.000 & -0.001\end{array}$

$\begin{array}{lllllll}0.000 & 0.000 & 0.000 & 0.000 & 0.000 & -0.001\end{array}$

$\begin{array}{lllllll}0.000 & 0.000 & 0.000 & 0.000 & 0.000 & -0.001\end{array}$

$\begin{array}{lllllll}0.000 & 0.000 & 0.000 & 0.000 & 0.000 & -0.002\end{array}$

$\begin{array}{lllllll}0.000 & 0.000 & 0.000 & 0.000 & 0.000 & -0.002\end{array}$

$0.000-0.005-0.005-0.005-0.006-0.001$

$\begin{array}{llllll}- & -0.005 & -0.005 & -0.005 & -0.006 & -0.001\end{array}$

$\begin{array}{lllllll}0.000 & 0.000 & 0.000 & 0.000 & 0.000 & -0.001\end{array}$ $-0.001$

recession- non binding $-0.035-0.016-0.006-0.005-0.005-0.002$

Panel D: Incremental Effects: State Dependent Volatility (SDV)

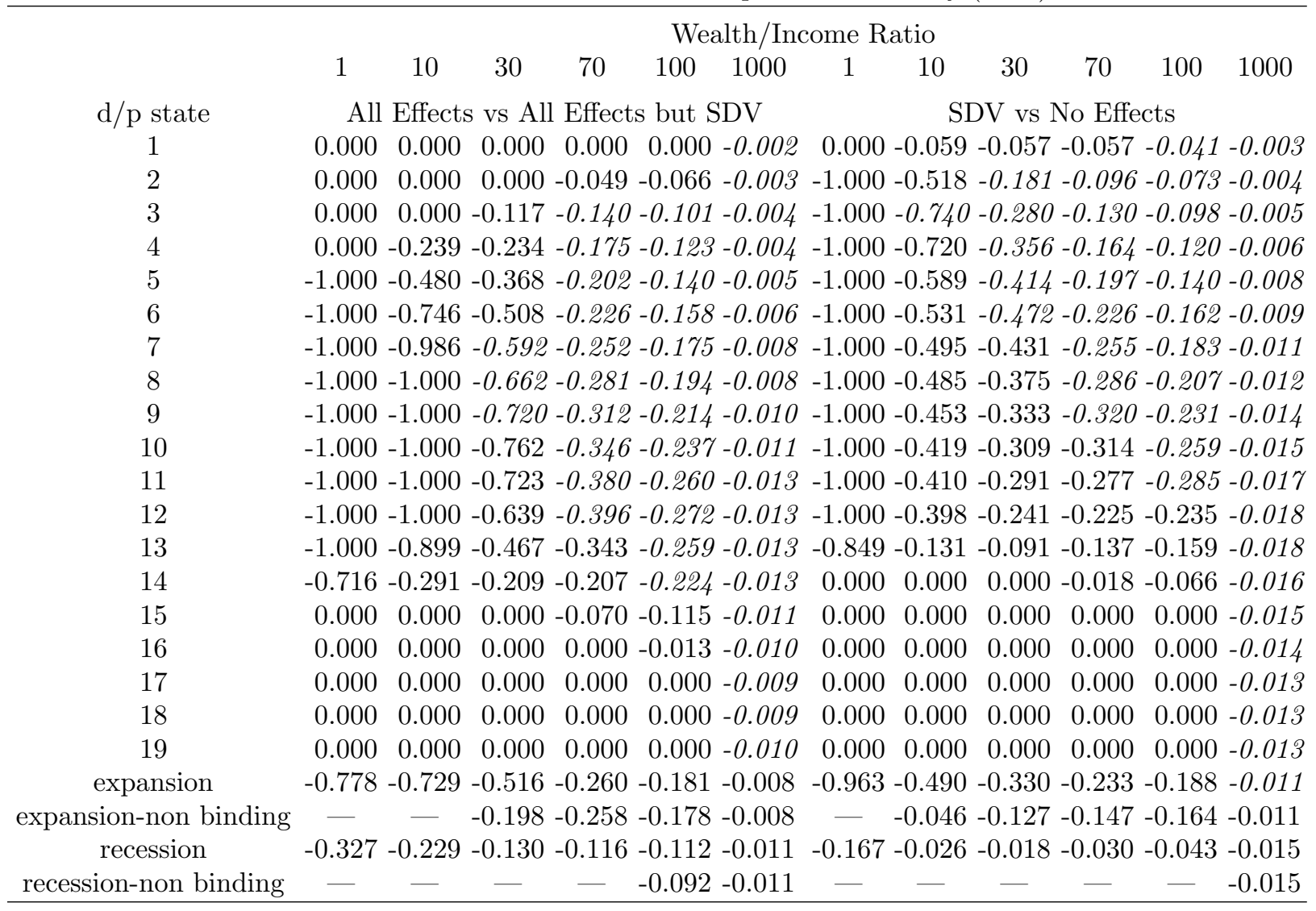


Table 9. FIRST MONTH ALLOCATION RESULTS. FLAT INCOME GROWTH PROFILE. RULE-OF-THUMB PERMANENT INCOME VOLATILITY. NO TRANSITORY SHOCKS. RETAIL TRADE DATA. The table reports asset allocation results for a CRRA agent with a coefficient of risk aversion of 6 for the first month of her 20 year horizon, for a range of wealth to permanent income ratios from 0 to $\infty$. The mean monthly growth rate of permanent income is set to $3 \%$ p.a. based on Gakidis (1997). Volatility of logarithmic monthly growth in permanent income $\sigma_{g}$ is set to $1 / \sqrt{12}$ of its annual counterpart of $15 \%$ from Gakidis (1997). There are no transitory shocks to income. Retail Trade Income (series CEU4200000004 by Bureau of Labor Statistics) is also used to calibrate labor income as described in Table 1. Agent has access to the market portfolio (value-weighted return on all NYSE, AMEX, and NASDAQ stocks) and to a riskless bond. Calibrations of these assets are as described in section 3 of the text. SDM, CWR and SDV denote, respectively, the state-dependent mean, return covariance and state-dependent volatility channels through which permanent labor income growth can affect stock holdings (see section 2.1 for descriptions). Panel A reports average stock holdings when all three and none of the channels are present. Panel B and C reports the incremental effects on stock holdings of switching on one of the channels. Each of these channels can be switched on when both, one, or none of the other channels are present and the four rows of each channel's subpanel report the incremental stock-holding reductions for these 4 cases. The calibration of the 8 problems needed to do the comparisons is detailed in section 3 of the text. Panel B reports average reductions in fractions of stock holdings using all states, Panel $\mathrm{C}$ does the same using only non binding states, states for which fractions of stock holdings for both cases are strictly between 0 and 1 .

\begin{tabular}{|c|c|c|c|c|c|c|c|c|}
\hline \multicolumn{9}{|c|}{ Panel A: Allocations Averaged Across All States } \\
\hline & \multicolumn{8}{|c|}{ Wealth/Income Ratio } \\
\hline & 0 & 1 & 10 & 30 & 70 & 100 & 1000 & $\infty$ \\
\hline All & 0.263 & 0.263 & 0.306 & 0.442 & 0.528 & 0.539 & 0.517 & 0.464 \\
\hline \multirow[t]{5}{*}{ None } & 0.975 & 0.975 & 0.953 & 0.908 & 0.835 & 0.794 & 0.540 & 0.464 \\
\hline & \multicolumn{8}{|c|}{ Panel B: Incremental Effects Averaged Across All States } \\
\hline & \multicolumn{8}{|c|}{ Wealth/Income Ratio } \\
\hline & 0 & 1 & 10 & 30 & 70 & 100 & 1000 & $\infty$ \\
\hline & \multicolumn{8}{|c|}{ State Dependent Mean } \\
\hline Both & -0.655 & -0.639 & -0.552 & -0.341 & -0.210 & -0.185 & -0.044 & 0.000 \\
\hline CWR & -0.124 & -0.145 & -0.151 & -0. & -0. & -0 . & -0 & 0.000 \\
\hline SDV & -0.655 & -0.655 & -0.560 & -0 & -0. & -0 . & -0.016 & 0.000 \\
\hline None & -0.124 & -0.130 & -0.144 & -0.148 & -0.125 & -0.106 & -0.014 & 0.000 \\
\hline & \multicolumn{8}{|c|}{ Covariance with Return } \\
\hline Both & 0.000 & 0.000 & -0.006 & -0.010 & -0.007 & -0.006 & -0.001 & 0.000 \\
\hline SDM & -0.000 & -0.016 & -0.008 & -0.0 & -0.0 & -0.006 & -0.001 & 0.000 \\
\hline SDV & -0.016 & -0.016 & -0.013 & -0.008 & 0.0 & 0.027 & 0.026 & 0.000 \\
\hline None & 0.000 & 0.000 & -0.001 & 0.000 & 0.010 & 0.024 & 0.026 & 0.000 \\
\hline \multicolumn{9}{|c|}{ State Dependent Volatility } \\
\hline Both & -0.606 & -0.567 & -0.496 & -0.312 & -0.177 & -0.143 & -0.008 & 0.000 \\
\hline SDM & -0.606 & -0.582 & -0.498 & -0.309 & -0.176 & -0.142 & -0.007 & 0.000 \\
\hline CWR & -0.076 & -0.073 & -0.095 & -0.126 & -0.108 & -0.094 & -0.006 & 0.000 \\
\hline None & -0.027 & -0.057 & -0.082 & -0.117 & -0.111 & -0.097 & -0.006 & 0.000 \\
\hline
\end{tabular}

Panel C: Incremental Effects Averaged Across Non Binding States

\begin{tabular}{|c|c|c|c|c|c|c|c|c|}
\hline & \multicolumn{8}{|c|}{ Wealth/Income Ratio } \\
\hline & 0 & 1 & 10 & 30 & 70 & 100 & 1000 & $\infty$ \\
\hline & \multicolumn{8}{|c|}{ State Dependent Mean } \\
\hline Both & - & - & - & -0.566 & -0.293 & -0.246 & -0.044 & 0.000 \\
\hline CWR & - & - & - & -0.491 & -0.273 & -0.226 & -0.042 & 0.000 \\
\hline SDV & - & - & - & -0.559 & -0.262 & -0.199 & -0.016 & 0.000 \\
\hline None & - & - & - & -0.471 & -0.241 & -0.169 & -0.014 & 0.000 \\
\hline \multicolumn{9}{|c|}{ Covariance with Return } \\
\hline Both & - & 一 & -0.042 & -0.016 & -0.009 & -0.008 & -0.001 & 0.000 \\
\hline SDM & - & -0.228 & -0.037 & -0.016 & -0.009 & -0.008 & -0.001 & 0.000 \\
\hline SDV & - & -0.390 & -0.049 & -0.014 & 0.020 & 0.037 & 0.026 & 0.000 \\
\hline None & - & - & 0.001 & -0.003 & 0.022 & 0.044 & 0.026 & 0.000 \\
\hline \multicolumn{9}{|c|}{ State Dependent Volatility } \\
\hline Both & - & 一 & 一 & -0.557 & -0.257 & -0.190 & -0.008 & 0.000 \\
\hline SDM & - & 一 & 一 & -0.557 & -0.237 & -0.191 & -0.007 & 0.000 \\
\hline CWR & - & - & -0.558 & -0.275 & -0.173 & -0.130 & -0.006 & 0.000 \\
\hline None & - & - & -0.486 & -0.273 & -0.161 & -0.134 & -0.006 & 0.000 \\
\hline
\end{tabular}


Table 10. FIRST MONTH ALLOCATION RESUlTS. LIFE CYCLE SPECIFICATION. AGE-DEPENDENT INCOME GROWTH PROFILE. LUMP SUM RETIREMENT MONEY. SPECIFICATION-BASED PERMANENT INCOME VOLATILITY. NO TRANSITORY SHOCKS. RETAIL TRADE DATA. The table reports asset allocation results for a CRRA agent with a coefficient of risk aversion of 6 for the first month of her 78 year horizon, for a range of wealth to permanent income ratios from 0 to $\infty$. The agent starts work at age 22 and retires at 65 , receiving a lump sum payout equivalent to receiving $93.8 \%$ of her retirement permanent income until death as reported in Cocco, Gomes and Maenhout (2002) for college graduates. The agent dies with probability 1 at age 100, with death probabilities taken from the U.S. Life Tables, 2001, provided by the NCHS. The mean logarithmic monthly growth rate of permanent income is allowed to be age-dependent and is calibrated to the polynomial-smoothed income profile for college graduates in Cocco, Gomes and Maenhout (2002). The volatility of the logarithmic monthly growth rate of permanent income $\sigma_{g}$, is obtained from its annual counterpart (fixed at 15\% from Gakidis (1997)), accounting for the assumed dynamics of the permanent income growth. There are no transitory shocks to income. Retail Trade Income (series CEU4200000004 by Bureau of Labor Statistics) is also used to calibrate labor income as described in Table 1. Agent has access to the market portfolio (value-weighted return on all NYSE, AMEX, and NASDAQ stocks) and to a riskless bond. Calibrations of these assets are as described in section 3 of the text. SDM, CWR and SDV denote, respectively, the state-dependent mean, return covariance and state-dependent volatility channels through which permanent labor income growth can affect stock holdings (see section 2.1 for descriptions).Panel A reports average stock holdings when all three and none of the channels are present. Panel B and C reports the incremental effects on stock holdings of switching on one of the channels. Each of these channels can be switched on when both, one, or none of the other channels are present and the four rows of each channel's subpanel report the incremental stock-holding reductions for these 4 cases. he calibration of the 8 problems needed to do the comparisons is detailed in section 3 of the text. Panel B reports average reductions in fractions of stock holdings using all states, Panel C does the same using only non binding states, states for which fractions of stock holdings for both cases are strictly between 0 and 1.

\begin{tabular}{|c|c|c|c|c|c|c|c|c|}
\hline \multicolumn{9}{|c|}{ Panel A: Allocations Averaged Across All States } \\
\hline & \multicolumn{8}{|c|}{ Wealth/Income Ratio } \\
\hline & 0 & 1 & 10 & 30 & 70 & 100 & 1000 & $\infty$ \\
\hline All & 0.203 & 0.203 & 0.219 & 0.248 & 0.334 & 0.388 & 0.517 & 0.464 \\
\hline None & 0.975 & 0.975 & 0.961 & 0.929 & 0.883 & 0.862 & 0.684 & 0.464 \\
\hline \multicolumn{9}{|c|}{ Panel B: Incremental Effects Averaged Across All States } \\
\hline & \multicolumn{8}{|c|}{ Wealth/Income Ratio } \\
\hline & 0 & 1 & 10 & 30 & 70 & 100 & 1000 & $\infty$ \\
\hline & \multicolumn{8}{|c|}{ State Dependent Mean } \\
\hline Both & -0.060 & -0.060 & -0.060 & -0.247 & (1) & -0.2 & -0 & 0.000 \\
\hline & & -0 & & & & & & 0.000 \\
\hline & & -0.0 & & & & & & 0.000 \\
\hline None & -0.166 & -0.161 & 165 & -0.167 & -0.156 & -0.150 & -0.090 & 0.000 \\
\hline & \multicolumn{8}{|c|}{ Covariance with Return } \\
\hline Both & 0.000 & 0.000 & -0.003 & -0.0 & -0.006 & -0.006 & -0.003 & 0.000 \\
\hline SDM & -0.012 & -0.01 & -0.0 & -0 . & & & -0 & 0.000 \\
\hline $\mathrm{SD}$ & 0.000 & 0.00 & -0.0 & -0. & -0 & & -0 & 0.000 \\
\hline None & 0.000 & 0.000 & -0.002 & -0.003 & -0.003 & -0.003 & -0.002 & 0.000 \\
\hline \multicolumn{9}{|c|}{ State Dependent Volatility } \\
\hline Both & -0.593 & -0.593 & -0.571 & -0.508 & -0.387 & -0.319 & -0.074 & 0.000 \\
\hline SDM & -0.605 & -0.611 & -0.575 & -0.510 & -0.3 & & -0.074 & 0.000 \\
\hline CWR & -0.712 & -0.712 & -0.681 & -0.4 & -0.2 & -0.222 & -0.071 & 0.000 \\
\hline None & -0.712 & -0.712 & -0.679 & -0.422 & -0.269 & -0.219 & -0.070 & 0.000 \\
\hline
\end{tabular}

Panel C: Incremental Effects Averaged Across Non Binding States

\begin{tabular}{|c|c|c|c|c|c|c|c|c|}
\hline & \multicolumn{8}{|c|}{ Wealth/Income Ratio } \\
\hline & 0 & 1 & 10 & 30 & 70 & 100 & 1000 & $\infty$ \\
\hline & \multicolumn{8}{|c|}{ State Dependent Mean } \\
\hline Both & - & - & - & -0.465 & -0.381 & -0.336 & -0.102 & 0.000 \\
\hline CWR & - & - & - & -0.628 & -0.389 & -0.317 & -0.100 & 0.000 \\
\hline SDV & - & - & - & -0.468 & -0.391 & -0.335 & -0.101 & 0.000 \\
\hline \multirow[t]{2}{*}{ None } & - & - & - & -0.631 & -0.385 & -0.314 & -0.100 & 0.000 \\
\hline & \multicolumn{8}{|c|}{ Covariance with Return } \\
\hline Both & - & - & -0.046 & -0.022 & -0.012 & -0.010 & -0.003 & 0.000 \\
\hline SDM & - & - & -0.057 & -0.019 & -0.012 & -0.009 & -0.003 & 0.000 \\
\hline SDV & - & - & -0.053 & -0.018 & -0.010 & -0.009 & -0.003 & 0.000 \\
\hline \multirow[t]{2}{*}{ None } & - & - & -0.039 & -0.021 & -0.010 & -0.007 & -0.002 & 0.000 \\
\hline & \multicolumn{8}{|c|}{ State Dependent Volatility } \\
\hline Both & - & - & - & - & -0.663 & -0.482 & -0.080 & 0.000 \\
\hline SDM & - & - & - & - & -0.663 & -0.482 & -0.080 & 0.000 \\
\hline CWR & - & - & - & -0.644 & -0.387 & -0.308 & -0.078 & 0.000 \\
\hline None & - & - & - & -0.649 & -0.387 & -0.307 & -0.077 & 0.000 \\
\hline
\end{tabular}


Table 11. FIRST MONTH ALLOCATION RESULTS. LIFE CYCLE SPECIFICATION. FLAT INCOME GROWTH PROFILE. LUMP SUM RETIREMENT MONEY. SPECIFICATION-BASED PERMANENT INCOME VOLATILITY. NO TRANSITORY SHOCKS. RETAIL TRADE DATA. The table reports asset allocation results for a CRRA agent with a coefficient of risk aversion of 6 for the first month of her 78 year horizon, for a range of wealth to permanent income ratios from 0 to $\infty$. The agent starts work at age 22 and retires at 65 , receiving a lump sum payout equivalent to receiving $93.8 \%$ of her retirement permanent income until death as reported in Cocco, Gomes and Maenhout (2002) for college graduates. The agent dies with probability 1 at age 100, with death probabilities taken from the U.S. Life Tables, 2001, provided by the NCHS. The mean monthly growth rate of permanent income is set to $3 \%$ p.a. based on Gakidis (1997). The volatility of the logarithmic monthly growth rate of permanent income $\sigma_{g}$, is obtained from its annual counterpart (fixed at $15 \%$ from Gakidis (1997)), accounting for the assumed dynamics of the permanent income growth. There are no transitory shocks to income. Retail Trade Income (series CEU4200000004 by Bureau of Labor Statistics) is also used to calibrate labor income as described in Table 1. Agent has access to the market portfolio (value-weighted return on all NYSE, AMEX, and NASDAQ stocks) and to a riskless bond. Calibrations of these assets are as described in section 3 of the text. SDM, CWR and SDV denote, respectively, the state-dependent mean, return covariance and state-dependent volatility channels through which permanent labor income growth can affect stock holdings (see section 2.1 for descriptions).Panel A reports average stock holdings when all three and none of the channels are present. Panel B and C reports the incremental effects on stock holdings of switching on one of the channels. Each of these channels can be switched on when both, one, or none of the other channels are present and the four rows of each channel's subpanel report the incremental stock-holding reductions for these 4 cases. he calibration of the 8 problems needed to do the comparisons is detailed in section 3 of the text. Panel B reports average reductions in fractions of stock holdings using all states, Panel $\mathrm{C}$ does the same using only non binding states, states for which fractions of stock holdings for both cases are strictly between 0 and 1.

\begin{tabular}{|c|c|c|c|c|c|c|c|c|}
\hline \multicolumn{9}{|c|}{ Panel A: Allocations Averaged Across All States } \\
\hline & \multicolumn{8}{|c|}{ Wealth/Income Ratio } \\
\hline & 0 & 1 & 10 & 30 & 70 & 100 & 1000 & $\infty$ \\
\hline All & 0.203 & 0.203 & 0.239 & 0.306 & 0.432 & 0.471 & 0.544 & 0.476 \\
\hline None & 0.975 & 0.975 & 0.964 & 0.923 & 0.875 & 0.844 & 0.674 & 0.476 \\
\hline \multicolumn{9}{|c|}{ Panel B: Incremental Effects Averaged Across All States } \\
\hline & \multicolumn{8}{|c|}{ Wealth/Income Ratio } \\
\hline & 0 & 1 & 10 & 30 & 70 & 100 & 1000 & $\infty$ \\
\hline & \multicolumn{8}{|c|}{ State Dependent Mean } \\
\hline Both & -0.060 & -0.060 & -0.285 & -0.340 & -0.232 & -0.214 & -0.079 & 0.000 \\
\hline CWR & -0.124 & -0.124 & -0.1 & -0 . & -0 . & & -0. & 0.000 \\
\hline SDV & -0.060 & -0.060 & -0.306 & -0. & -0. & -0 & $-0 .($ & 0.000 \\
\hline None & -0.124 & -0.124 & -0.142 & -0.147 & -0.152 & -0.134 & -0.085 & 0.000 \\
\hline & \multicolumn{8}{|c|}{ Covariance with Return } \\
\hline Both & 0.000 & 0.000 & -0.003 & -0.007 & -0.006 & -0.006 & -0.003 & 0.000 \\
\hline SDM & 0.000 & 0.000 & -0.006 & -0.0 & -0. & -0. & -0. & 0.000 \\
\hline SDV & 0.000 & 0.000 & -0.023 & -0.0 & -0.0 & -0.0 & -0.002 & 0.000 \\
\hline None & 0.000 & 0.000 & -0.004 & -0.003 & -0.003 & -0.003 & -0.002 & 0.000 \\
\hline \multicolumn{9}{|c|}{ State Dependent Volatility } \\
\hline Both & -0.647 & -0.647 & -0.577 & -0.463 & -0.284 & -0.233 & -0.042 & 0.000 \\
\hline SDM & -0.647 & -0.647 & -0.580 & -0.462 & -0.284 & -0.233 & -0.041 & 0.000 \\
\hline CWR & -0.712 & -0.712 & -0.436 & -0.273 & -0.208 & -0.156 & -0.049 & 0.000 \\
\hline None & -0.712 & -0.712 & -0.416 & -0.265 & -0.202 & -0.153 & -0.049 & 0.000 \\
\hline
\end{tabular}

Panel C: Incremental Effects Averaged Across Non Binding States

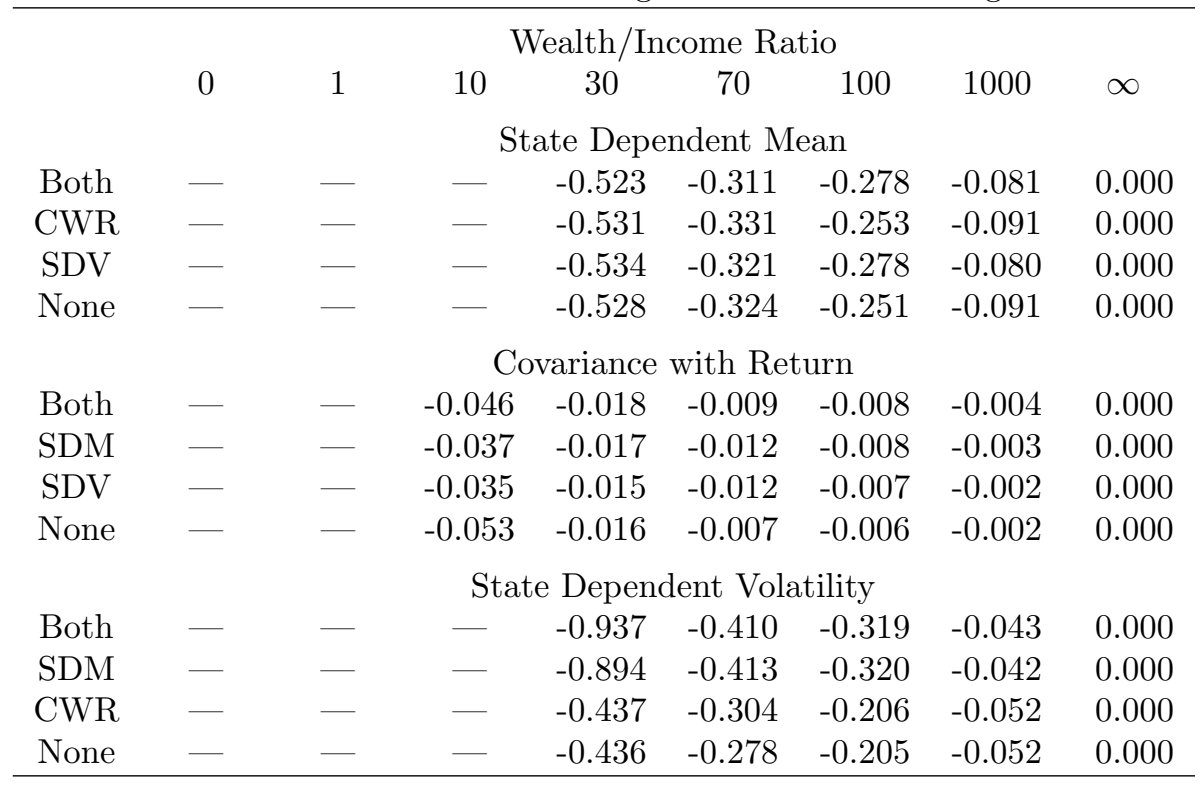


Table 12. FIRST MONTH ALLOCATION RESUlTS. LIFE CYCLE SPECIFICATION. AGE-DEPENDENT INCOME GROWTH PROFILE. NO RETIREMENT MONEY. SPECIFICATION-BASED PERMANENT INCOME VOLATILITY. NO TRANSITORY SHOCKS. RETAIL TRADE DATA. The table reports

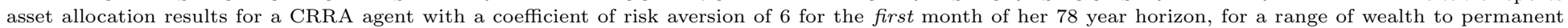

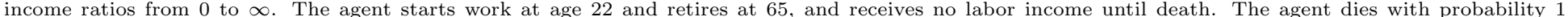

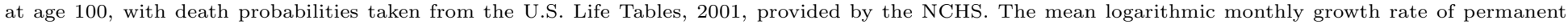

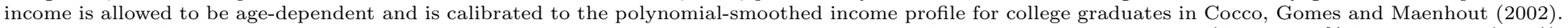

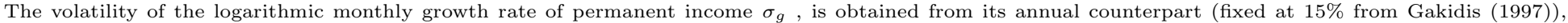

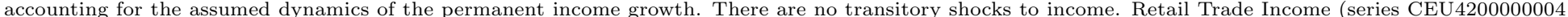

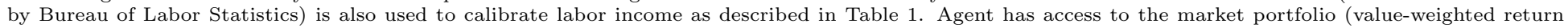

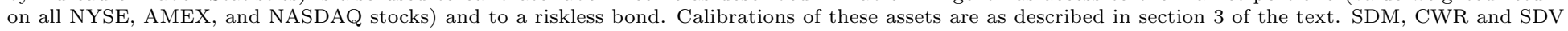

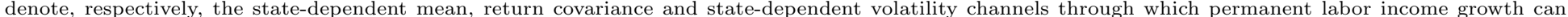

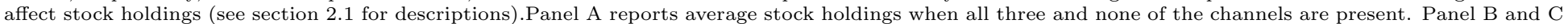

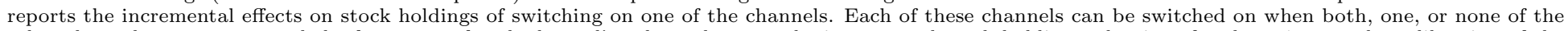

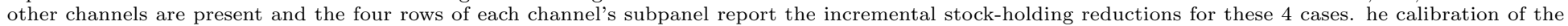

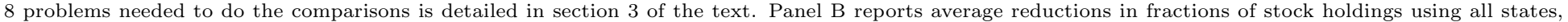
Panel $\mathrm{C}$ does the same using only non binding states, states for which fractions of stock holdings for both cases are strictly between 0 and 1.

\begin{tabular}{|c|c|c|c|c|c|c|c|c|}
\hline \multicolumn{9}{|c|}{ Panel A: Allocations Averaged Across All States } \\
\hline & \multicolumn{8}{|c|}{ Wealth/Income Ratio } \\
\hline & 0 & 1 & 10 & 30 & 70 & 100 & 1000 & $\infty$ \\
\hline All & 0.203 & 0.203 & 0.219 & 0.246 & 0.331 & 0.384 & 0.537 & 0.464 \\
\hline \multirow[t]{5}{*}{ None } & 0.975 & 0.975 & 0.962 & 0.935 & 0.893 & 0.872 & 0.702 & 0.464 \\
\hline & \multicolumn{8}{|c|}{ Panel B: Incremental Effects Averaged Across All States } \\
\hline & \multicolumn{8}{|c|}{ Wealth/Income Ratio } \\
\hline & 0 & 1 & 10 & 30 & 70 & 100 & 1000 & $\infty$ \\
\hline & \multicolumn{8}{|c|}{ State Dependent Mean } \\
\hline Both & -0.060 & -0.060 & -0.058 & -0.249 & -0.275 & -0.232 & -0.093 & 0.000 \\
\hline CWR & -0.178 & -0.178 & -0.166 & -0.176 & -0.165 & -0.171 & -0.101 & 0.000 \\
\hline SDV & -0.060 & -0.060 & -0.062 & -0.259 & -0.278 & -0.233 & -0.093 & 0.000 \\
\hline None & -0.161 & -0.159 & -0.162 & -0.172 & -0.161 & -0.169 & -0.100 & 0.000 \\
\hline & \multicolumn{8}{|c|}{ Covariance with Return } \\
\hline Both & 0.000 & 0.000 & -0.003 & -0.004 & -0.007 & -0.007 & -0.003 & 0.000 \\
\hline SDM & -0.018 & -0.019 & -0.006 & -0.007 & -0.007 & -0.006 & -0.003 & 0.000 \\
\hline SDV & 0.000 & 0.000 & -0.006 & -0.014 & -0.011 & -0.008 & -0.003 & 0.000 \\
\hline None & 0.000 & 0.000 & -0.002 & -0.003 & -0.003 & -0.004 & -0.002 & 0.000 \\
\hline \multicolumn{9}{|c|}{ State Dependent Volatility } \\
\hline Both & -0.593 & -0.594 & -0.576 & -0.510 & -0.394 & -0.314 & -0.062 & 0.000 \\
\hline SDM & -0.611 & -0.612 & -0.579 & -0.513 & -0.393 & -0.313 & -0.062 & 0.000 \\
\hline CWR & -0.712 & -0.712 & -0.683 & -0.436 & -0.283 & -0.252 & -0.069 & 0.000 \\
\hline None & -0.712 & -0.712 & -0.679 & -0.426 & -0.276 & -0.248 & -0.069 & 0.000 \\
\hline
\end{tabular}

Panel C: Incremental Effects Averaged Across Non Binding States

\begin{tabular}{|c|c|c|c|c|c|c|c|c|}
\hline & \multicolumn{8}{|c|}{ Wealth/Income Ratio } \\
\hline & 0 & 1 & 10 & 30 & 70 & 100 & 1000 & $\infty$ \\
\hline & \multicolumn{8}{|c|}{ State Dependent Mean } \\
\hline Both & - & 一 & 一 & -0.562 & -0.386 & -0.313 & -0.099 & 0.000 \\
\hline CWR & - & - & - & -0.696 & -0.417 & -0.350 & -0.113 & 0.000 \\
\hline SDV & - & - & - & -0.566 & -0.387 & -0.317 & -0.099 & 0.000 \\
\hline \multirow[t]{2}{*}{ None } & - & - & - & -0.696 & -0.405 & -0.350 & -0.112 & 0.000 \\
\hline & \multicolumn{8}{|c|}{ Covariance with Return } \\
\hline Both & - & - & -0.043 & -0.028 & -0.013 & -0.010 & -0.003 & 0.000 \\
\hline SDM & - & -0.344 & -0.049 & -0.023 & -0.015 & -0.010 & -0.003 & 0.000 \\
\hline SDV & - & - & -0.092 & -0.020 & -0.014 & -0.010 & -0.003 & 0.000 \\
\hline \multirow[t]{2}{*}{ None } & - & - & -0.044 & -0.022 & -0.010 & -0.010 & -0.003 & 0.000 \\
\hline & \multicolumn{8}{|c|}{ State Dependent Volatility } \\
\hline Both & - & - & - & - & -0.642 & -0.469 & -0.066 & 0.000 \\
\hline SDM & - & - & - & - & -0.645 & -0.452 & -0.066 & 0.000 \\
\hline CWR & - & - & - & -0.669 & -0.400 & -0.353 & -0.077 & 0.000 \\
\hline None & - & - & - & -0.670 & -0.362 & -0.353 & -0.077 & 0.000 \\
\hline
\end{tabular}


Table 13. FIRST MONTH ALLOCATION RESULTS. FLAT INCOME GROWTH PROFILE. SPECIFICATION-BASED PERMANENT INCOME VOLATILITY. NO TRANSITORY SHOCKS. PROPRIETARY INCOME DATA. The table reports asset allocation results for a CRRA agent with a coefficient of risk aversion of 6 for the first month of her 20 year horizon, for a range of wealth to permanent income ratios from 0 to $\infty$. The mean monthly growth rate of permanent income is set to $3 \%$ p.a. based on Gakidis (1997). The volatility of the logarithmic monthly growth rate of permanent income $\sigma_{g}$, is obtained from its annual counterpart (fixed at $25 \%$ from Heaton and Lucas (2000)), accounting for the assumed dynamics of permanent income growth. There are no transitory shocks to income. Proprietary Income (Non farm Proprietor's income in NIPA table 2.6) is also used to calibrate labor income as described in Table 1. Agent has access to the market portfolio (value-weighted return on all NYSE, AMEX, and NASDAQ stocks) and to a riskless bond. Calibrations of these assets are as described in section 3 of the text. SDM, CWR and SDV denote, respectively, the state-dependent mean, return covariance and state-dependent volatility channels through which permanent labor income growth can affect stock holdings (see section 2.1 for descriptions). Panel A reports average stock holdings when all three and none of the channels are present. Panel B and C reports the incremental effects on stock holdings of switching on one of the channels. Each of these channels can be switched on when both, one, or none of the other channels are present and the four rows of each channel's subpanel report the incremental stock-holding reductions for these 4 cases. The calibration of the 8 problems needed to do the comparisons is detailed in section 3 of the text. Panel B reports average reductions in fractions of stock holdings using all states, Panel $\mathrm{C}$ does the same using only non binding states, states for which fractions of stock holdings for both cases are strictly between 0 and 1.

\begin{tabular}{|c|c|c|c|c|c|c|c|c|}
\hline \multicolumn{9}{|c|}{ Panel A: Allocations Averaged Across All States } \\
\hline & \multicolumn{8}{|c|}{ Wealth/Income Ratio } \\
\hline & 0 & 1 & 10 & 30 & 70 & 100 & 1000 & $\infty$ \\
\hline All & 0.025 & 0.030 & 0.085 & 0.138 & 0.147 & 0.202 & 0.455 & 0.464 \\
\hline None & 0.874 & 0.864 & 0.861 & 0.768 & 0.669 & 0.631 & 0.540 & 0.464 \\
\hline \multicolumn{9}{|c|}{ Panel B: Incremental Effects Averaged Across All States } \\
\hline & \multicolumn{8}{|c|}{ Wealth/Income Ratio } \\
\hline & 0 & 1 & 10 & 30 & 70 & 100 & 1000 & $\infty$ \\
\hline & \multicolumn{8}{|c|}{ State Dependent Mean } \\
\hline Both & -0.035 & -0.028 & -0.018 & -0.069 & -0.196 & -0.180 & -0.065 & 0.000 \\
\hline CWR & -0.1 & -0.114 & -0.070 & -0 & & -0 & -0 & 0.000 \\
\hline SDV & -0.014 & -0.014 & -0.018 & $-0 .($ & & -0 & -0 . & 0.000 \\
\hline None & -0.057 & -0.055 & -0.047 & -0.199 & -0.230 & -0.209 & -0.068 & 0.000 \\
\hline & \multicolumn{8}{|c|}{ Covariance with Return } \\
\hline Both & -0.02 & -0.016 & -0.009 & -0.008 & -0.009 & -0.011 & -0.0 & 0.000 \\
\hline SDM & -0.080 & -0.072 & -0.016 & -0.0 & -0. & $-0 .($ & -0. & 0.000 \\
\hline SDV & 0.000 & -0.002 & -0.009 & -0.0 & -0 . & -0.017 & $-0 .($ & 0.000 \\
\hline None & -0.023 & -0.013 & 0.007 & -0.013 & -0.026 & -0.013 & -0.005 & 0.000 \\
\hline \multicolumn{9}{|c|}{ State Dependent Volatility } \\
\hline Both & -0.712 & -0.707 & -0.712 & -0.387 & -0.256 & -0.206 & -0.013 & 0.000 \\
\hline & -0.771 & -0.763 & -0.720 & -0.424 & -0.2 & -0.209 & -0. & 0.000 \\
\hline CWR & -0.791 & -0.793 & -0.764 & -0.5 & -0.299 & -0.235 & -0.016 & 0.000 \\
\hline None & -0.815 & -0.804 & -0.749 & -0.547 & -0.308 & -0.232 & -0.016 & 0.000 \\
\hline
\end{tabular}

Panel C: Incremental Effects Averaged Across Non Binding States

\begin{tabular}{ccccccccc}
\hline & \multicolumn{8}{c}{ Wealth/Income Ratio } \\
& 0 & 1 & 10 & 30 & 70 & 100 & 1000 & $\infty$ \\
Both & - & -0.802 & -0.205 & -0.339 & -0.288 & -0.232 & -0.066 & 0.000 \\
CWR & - & - & -0.282 & -0.414 & -0.329 & -0.261 & -0.069 & 0.000 \\
SDV & - & - & -0.205 & -0.340 & -0.287 & -0.234 & -0.066 & 0.000 \\
None & - & - & -0.067 & -0.411 & -0.329 & -0.260 & -0.069 & 0.000 \\
& & \multicolumn{8}{c}{ Covariance } & with Return \\
Both & - & -0.468 & -0.098 & -0.047 & -0.025 & -0.017 & -0.005 & 0.000 \\
SDM & - & - & -0.084 & -0.038 & -0.022 & -0.019 & -0.005 & 0.000 \\
SDV & - & - & -0.097 & -0.054 & -0.021 & -0.019 & -0.005 & 0.000 \\
None & - & - & 0.129 & -0.037 & -0.022 & -0.019 & -0.005 & 0.000 \\
& & \multicolumn{8}{c}{ State Dependent Volatility } \\
Both & - & - & - & - & -0.430 & -0.282 & -0.013 & 0.000 \\
SDM & - & - & - & - & -0.454 & -0.284 & -0.013 & 0.000 \\
CWR & - & - & - & - & -0.342 & -0.252 & -0.016 & 0.000 \\
None & - & - & - & - & -0.324 & -0.252 & -0.016 & 0.000 \\
\hline
\end{tabular}




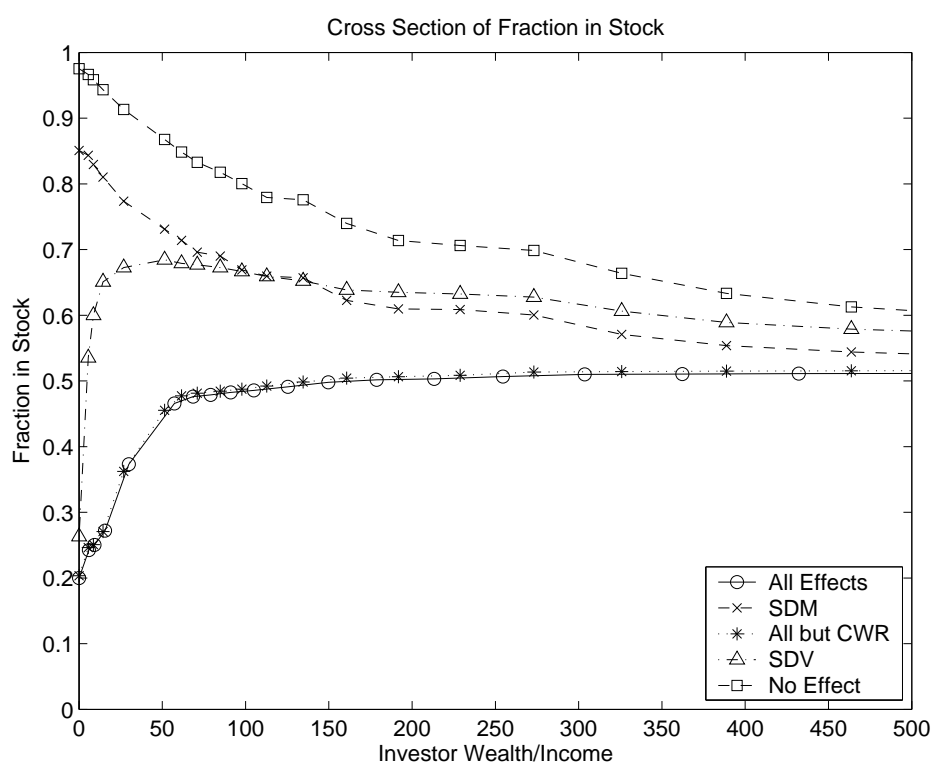

1.a Cross-sectional Fraction in Stock

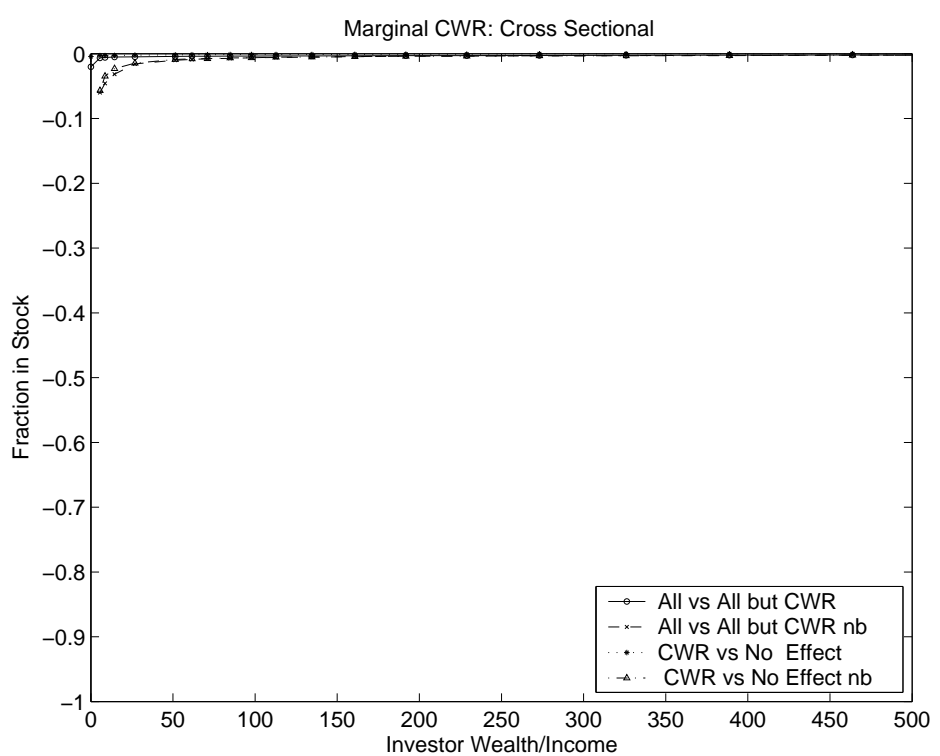

1.c Cross-sectional Impact on Fraction in Stock: CWR

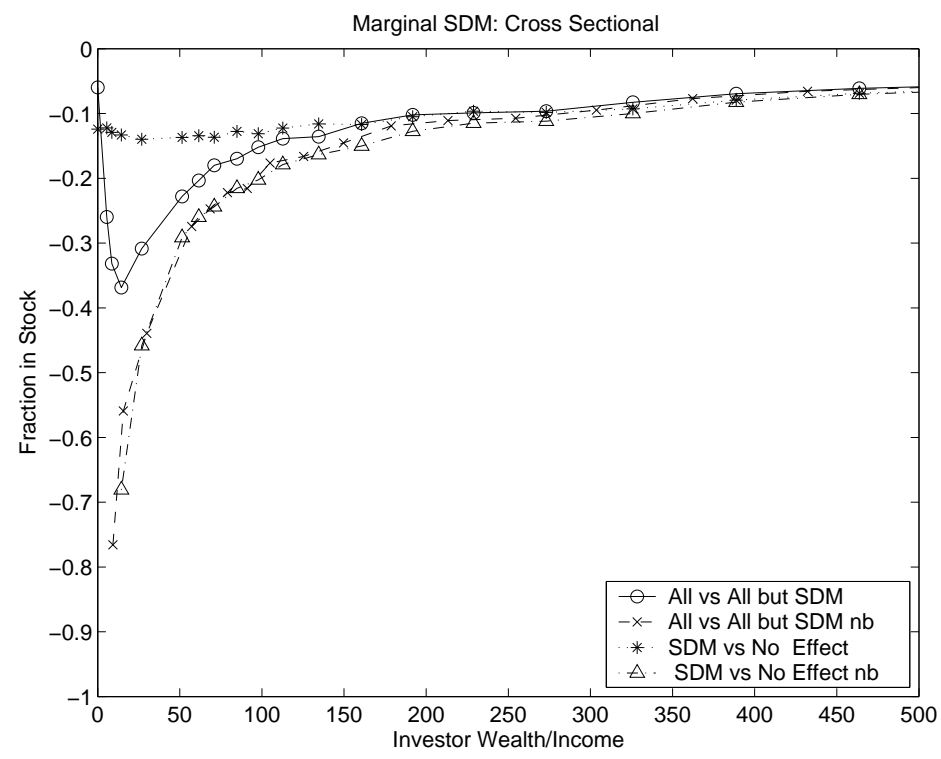

1.b Cross-sectional Impact on Fraction in Stock: SDM

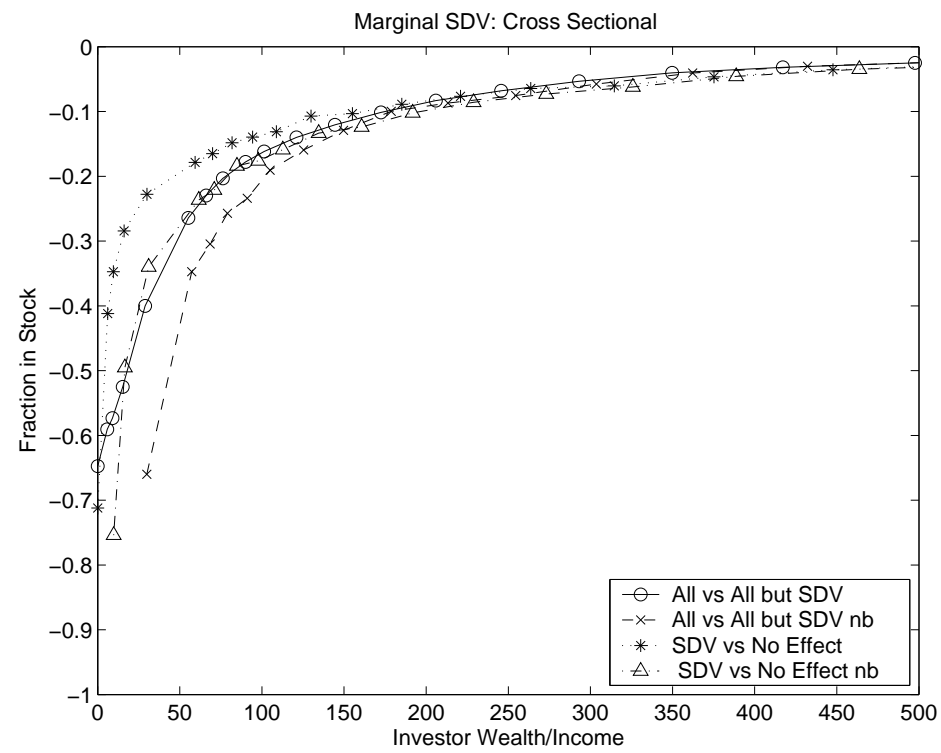

1.d Cross-sectional Impact on Fraction in Stock: SDV

FIGURE 1. FIRST MONTH CROSS-SECTIONAL ALLOCATION RESULTS. FLAT INCOME GROWTH PROFILE. SPECIFICATION-BASED PERMANENT INCOME VOLATILITY. NO TRANSITORY SHOCKS. RETAIL TRADE DATA. The figure reports cross-sectional asset allocation results for a CRRA agent with a coefficient of risk aversion of 6 for the first month of her 20 year horizon, for a range of wealth to permanent income ratios from 0 to 500 . The mean monthly growth rate of permanent income is set to $3 \%$ p.a. based on Gakidis (1997). The volatility of the logarithmic monthly growth rate of permanent income $\sigma_{g}$, is obtained from its annual counterpart (fixed at $15 \%$ from Gakidis (1997)), accounting for the assumed dynamics of permanent income growth. There are no transitory shocks to income. Retail Trade Income (series CEU4200000004 by Bureau of Labor Statistics) is also used to calibrate labor income as described in Table 1. Agent has access to the market portfolio (value-weighted return on all NYSE, AMEX, and NASDAQ stocks) and to a riskless bond. Calibrations of these assets are as described in section 3 of the text. SDM, CWR and SDV denote, respectively, the state-dependent mean, return covariance and state-dependent volatility channels through which permanent labor income growth can affect stock holdings (see section 2.1 for descriptions). Subfigure 1.a reports average stock holdings for the combinations of channels indicated in the legend. Subfigures $b, c$ and $d$ report the reductions in stock holdings induced by SDM, CWR and SDV channels, respectively. This can be done either by switching on the channel in question when no other effect is present (i.e. SDM, CWR or SDV vs. No Effect) or switching off the channel when all other effects are present (i.e. All vs. All but SDM, CWR or SDV). $n b$ indicates that only states for which fractions of stock holdings for both cases needed for the comparison are strictly between 0 and 1 . The calibration of the 8 problems needed to do the comparisons is detailed in section 3 of the text. 


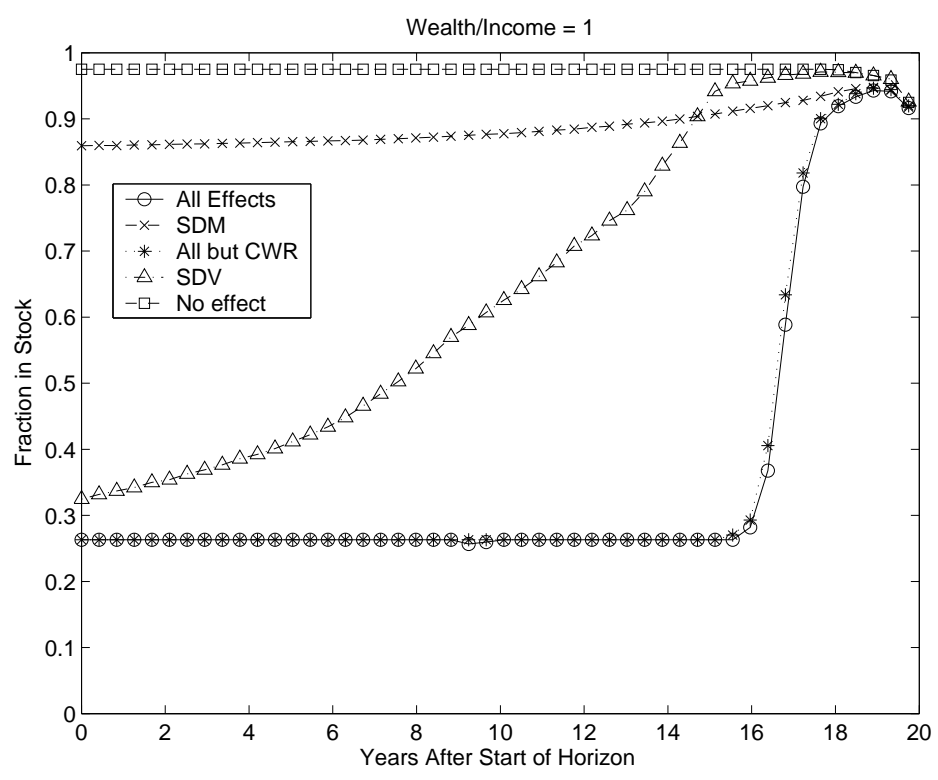

2.a Time Series Fraction in Stock

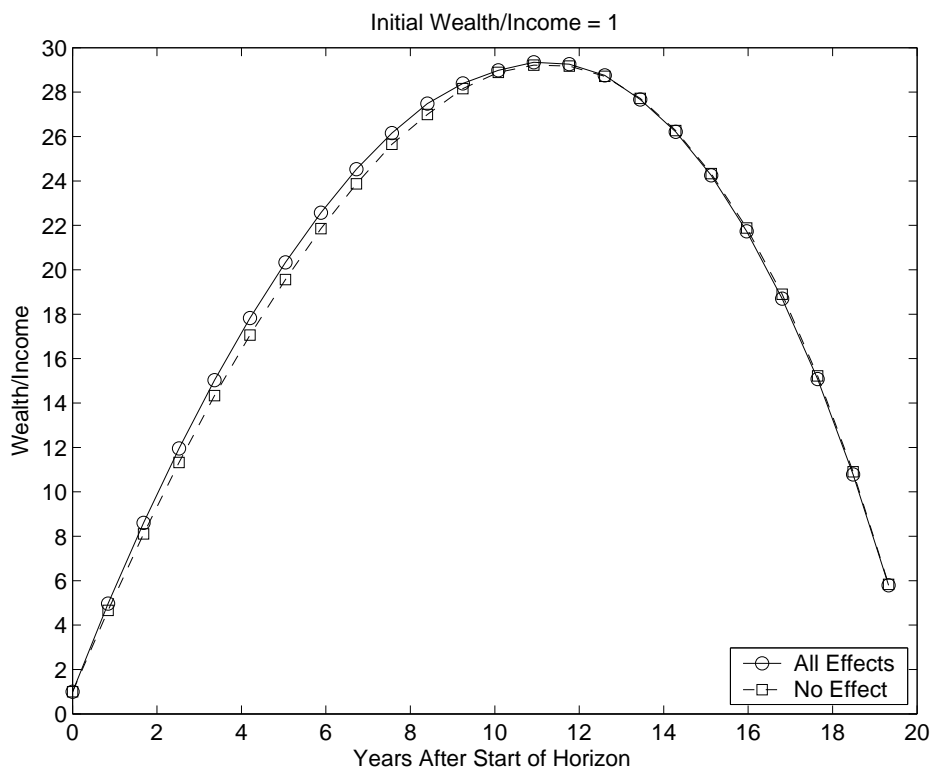

2.c Simulation Wealth/Income Stock

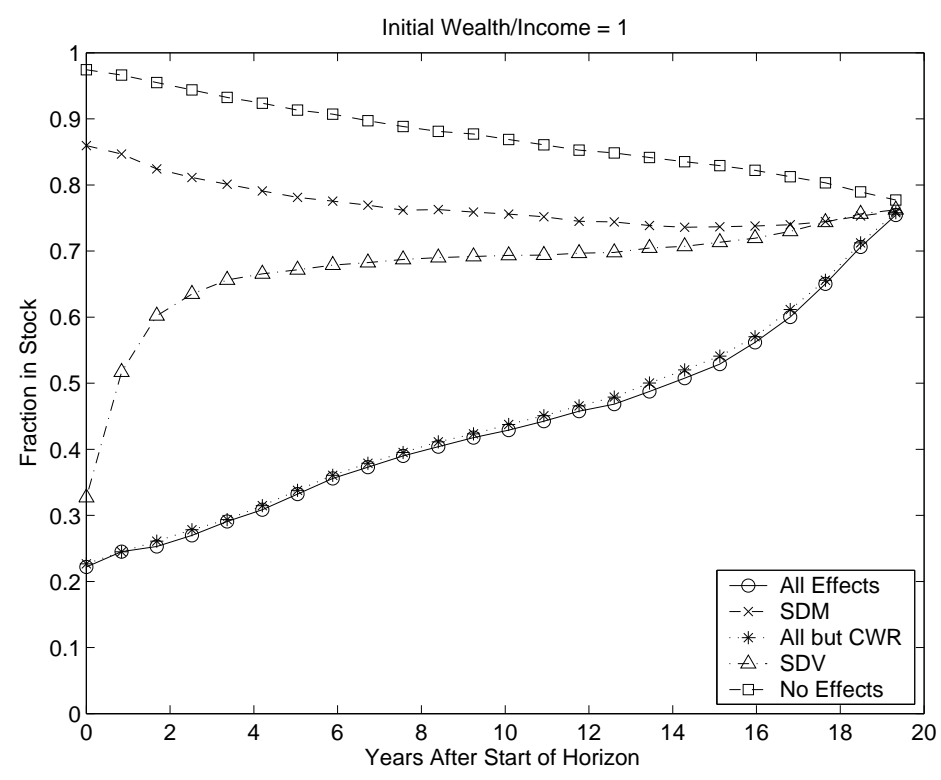

2.b Simulation Fraction in Stock

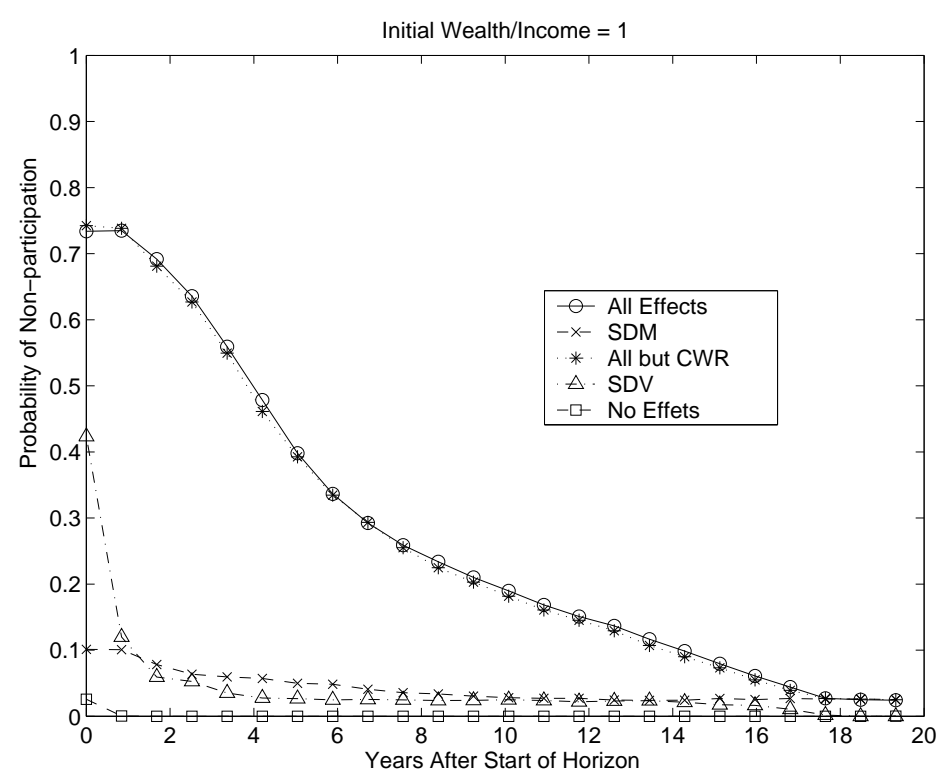

2.d Simulation Probability of Non-participation

FIGURE 2. TIME SERIES ALLOCATION RESULTS WHEN WEALTH/INCOME IS 1. FLAT INCOME GROWTH PROFILE. SPECIFICATION-BASED PERMANENT INCOME VOLATILITY. NO TRANSITORY SHOCKS. RETAIL TRADE DATA. The figure reports times series results for a CRRA agent with a coefficient of risk aversion of 6 . Subfigure 2.a always fixes the wealth to permanent income ratio at 1 for her entire lifetime. Subfigures b,c and d fix the initial wealth to permanent income ratio at 1.500000 paths are simulated for each case in consideration, and average allocations, wealth income ratios and fraction of non-participating paths are recorded at each age is recorded. Subfigures b,c,d report average allocations, wealth income ratios and fraction of non participating paths respectively. Each subfigure reports quantities for the combinations of the channels in its legend. The mean monthly growth rate of permanent income is set to $3 \%$ p.a. based on Gakidis (1997). The volatility of the logarithmic monthly growth rate of permanent income $\sigma_{g}$, is obtained from its annual counterpart (fixed at $15 \%$ from Gakidis (1997)), accounting for the assumed dynamics of permanent income growth. There are no transitory shocks to income. Retail Trade Income (series CEU4200000004 by Bureau of Labor Statistics) is also used to calibrate labor income as described in Table 1. Agent has access to the market portfolio (value-weighted return on all NYSE, AMEX, and NASDAQ stocks) and to a riskless bond. Calibrations of these assets are as described in section 3 of the text. SDM, CWR and SDV denote, respectively, the state-dependent mean, return covariance and state-dependent volatility channels through which permanent labor income growth can affect stock holdings (see section 2.1 for descriptions). The calibration of the 8 problems needed to do the comparisons is detailed in section 3 of the text. 


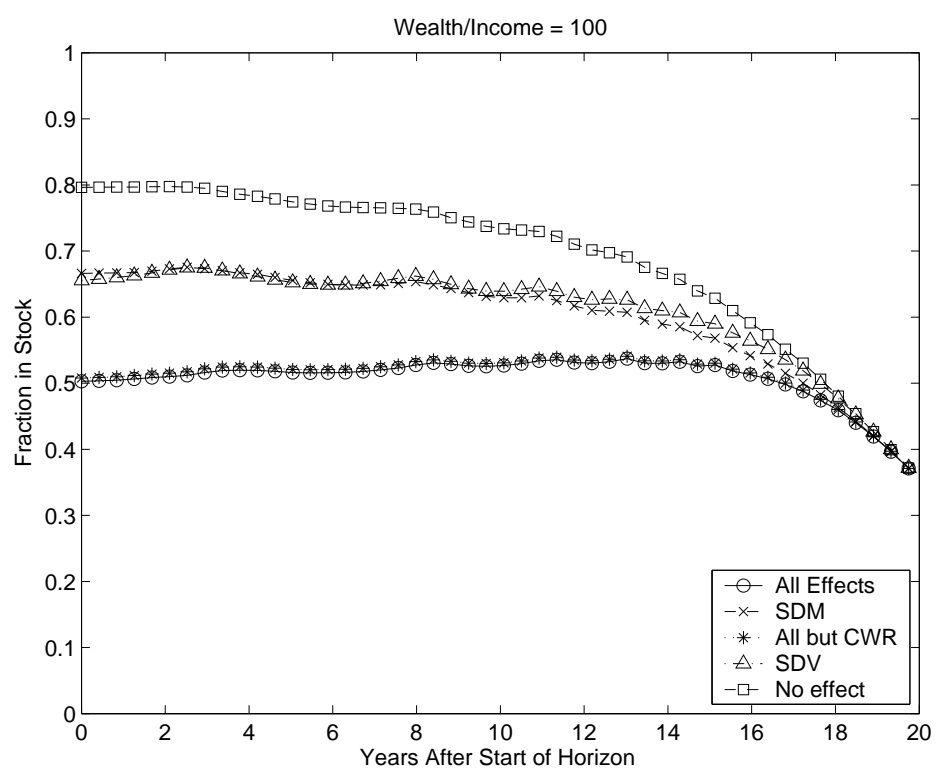

3.a Time Series Fraction in Stock

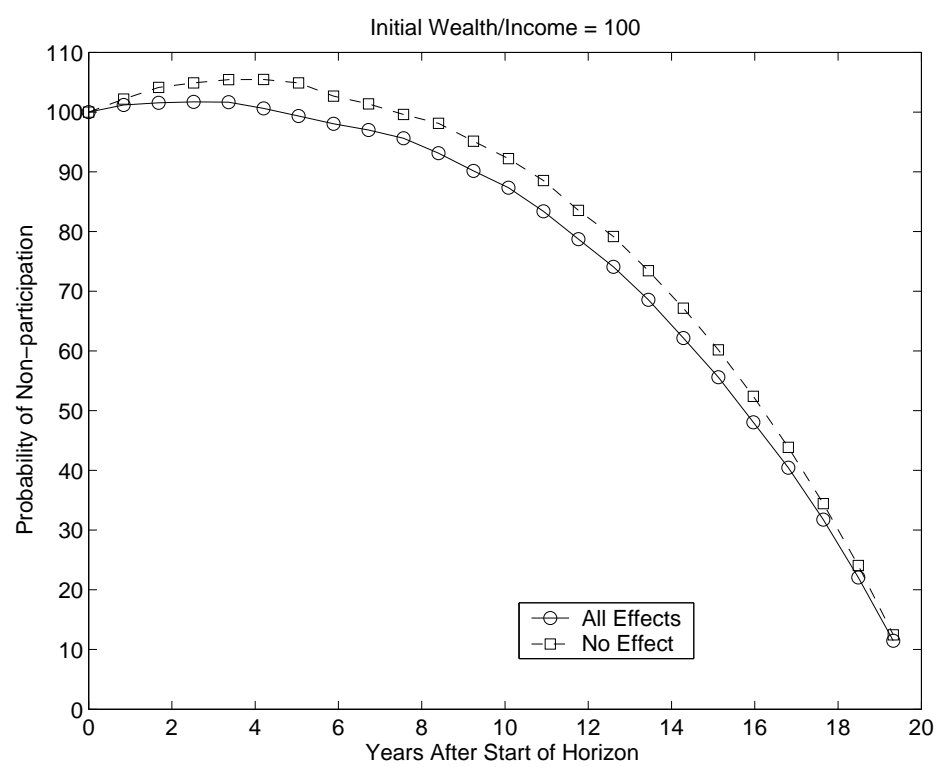

3.c Simulation Wealth/Income Stock

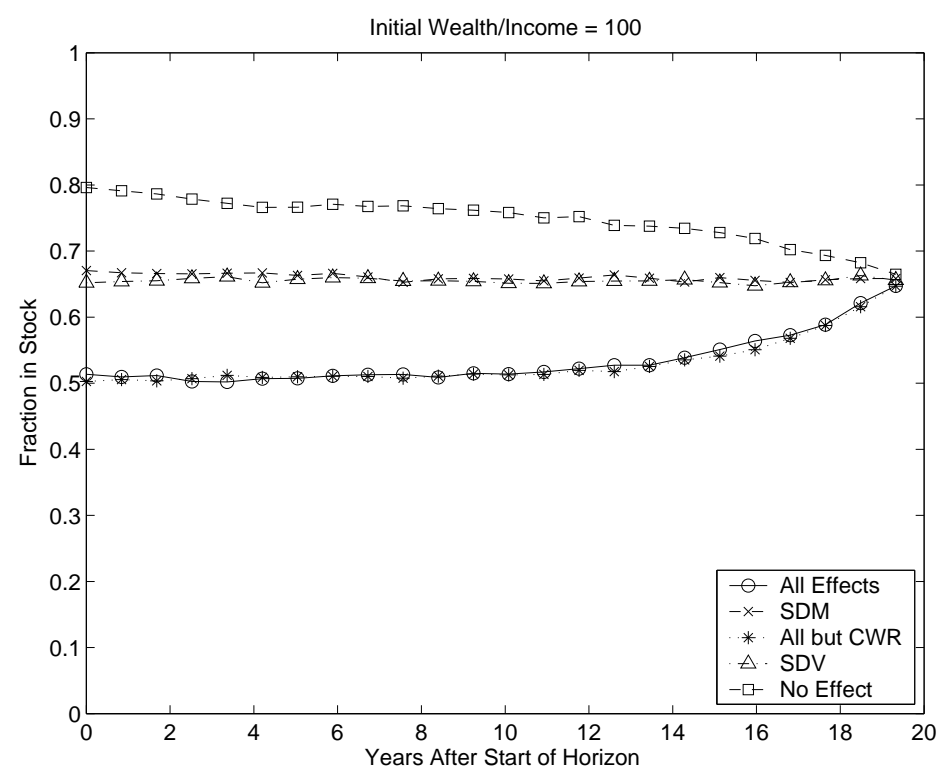

3.b Simulation Fraction in Stock

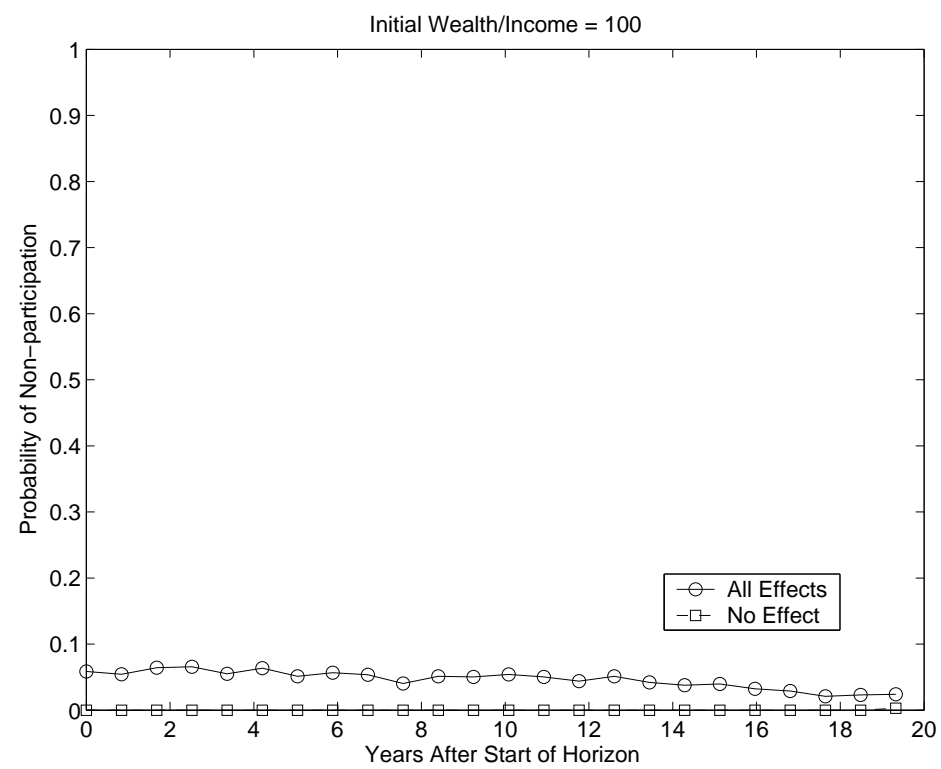

3.d Simulation Probability of Non-participation

FIGURE 3. TIME SERIES ALLOCATION RESULTS WHEN WEALTH/INCOME IS 100. FLAT INCOME GROWTH PROFILE. SPECIFICATIONBASED PERMANENT INCOME VOLATILITY. NO TRANSITORY SHOCKS. RETAIL TRADE DATA. The figure reports times series asset allocation results for a CRRA agent with a coefficient of risk aversion of 6. Subfigure 3.a always fixes the wealth to permanent income ratio at 100 for her entire lifetime. Subfigures $\mathrm{b}, \mathrm{c}$ and d fix the initial wealth to permanent income ratio at 100.500000 paths are simulated for each case in consideration, and average allocations, wealth income ratios and fraction of non-participating paths are recorded at each age is recorded. Subfigures b,c,d report average allocations, wealth income ratios and fraction of non participating paths respectively. Each subfigure reports quantities for the combinations of the channels in its legend. The mean monthly growth rate of permanent income is set to $3 \%$ p.a. based on Gakidis (1997). The volatility of the logarithmic monthly growth rate of permanent income $\sigma_{g}$, is obtained from its annual counterpart (fixed at $15 \%$ from Gakidis (1997)), accounting for the assumed dynamics of permanent income growth. There are no transitory shocks to income. Retail Trade Income (series CEU4200000004 by Bureau of Labor Statistics) is also used to calibrate labor income as described in Table 1. Agent has access to the market portfolio (value-weighted return on all NYSE, AMEX, and NASDAQ stocks) and to a riskless bond. Calibrations of these assets are as described in section 3 of the text. SDM, CWR and SDV denote, respectively, the state-dependent mean, return covariance and state-dependent volatility channels through which permanent labor income growth can affect stock holdings (see section 2.1 for descriptions). The calibration of the 8 problems needed to do the comparisons is detailed in section 3 of the text. 


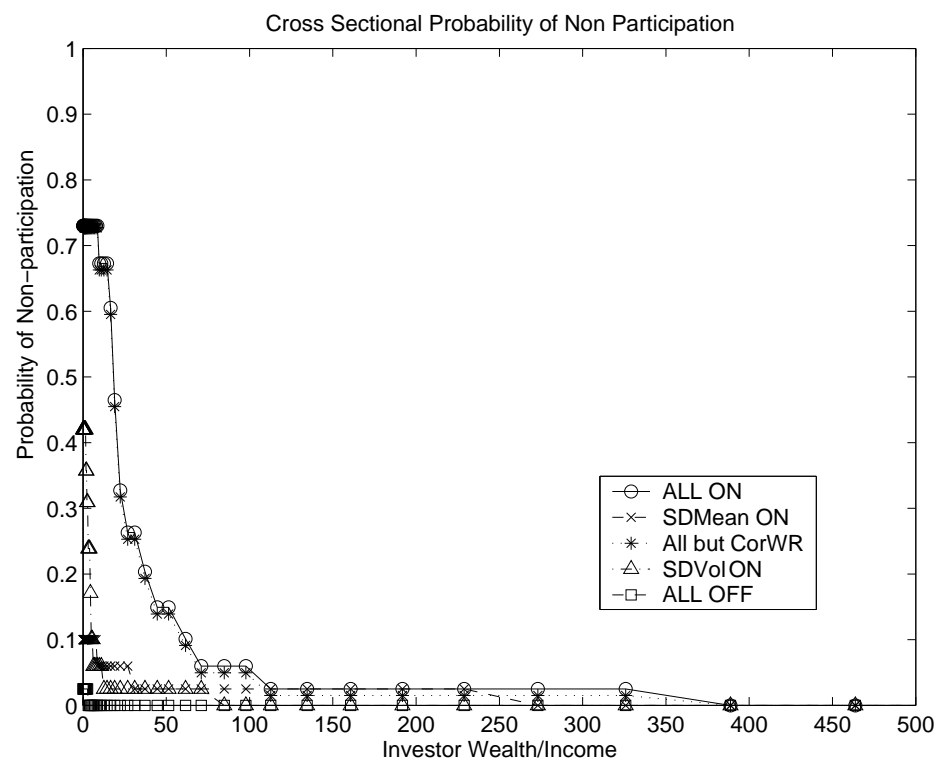

Cross-sectional Non-participation Probabilities

FIGURE 4. FIRST MONTH CROSS-SECTIONAL NON-PARTICIPATION RESULTS. FLAT INCOME GROWTH PROFILE. SPECIFICATION-BASED PERMANENT INCOME VOLATILITY. NO TRANSITORY SHOCKS. RETAIL TRADE DATA. The figure reports cross-sectional Non-participation probabilities for a CRRA agent with a coefficient of risk aversion of 6 for the first month of her 20 year horizon, for a range of wealth to permanent income ratios from 0 to 500. The mean monthly growth rate of permanent income is set to $3 \%$ p.a. based on Gakidis (1997). The volatility of the logarithmic monthly growth rate of permanent income $\sigma_{g}$, is obtained from its annual counterpart (fixed at $15 \%$ from Gakidis (1997)), accounting for the assumed dynamics of permanent income growth. There are no transitory shocks to income. Retail Trade Income (series CEU4200000004 by Bureau of Labor Statistics) is also used to calibrate labor income as described in Table 1. Agent has access to the market portfolio (value-weighted return on all NYSE, AMEX, and NASDAQ stocks) and to a riskless bond. Calibrations of these assets are as described in section 3 of the text. SDM, CWR and SDV denote, respectively, the state-dependent mean, return covariance and state-dependent volatility channels through which permanent labor income growth can affect stock holdings (see section 2.1 for descriptions). Figure reports average non-participation probabilities for the combinations of channels indicated in the legend. The calibration of the 8 problems needed to do the comparisons is detailed in section 3 of the text. 


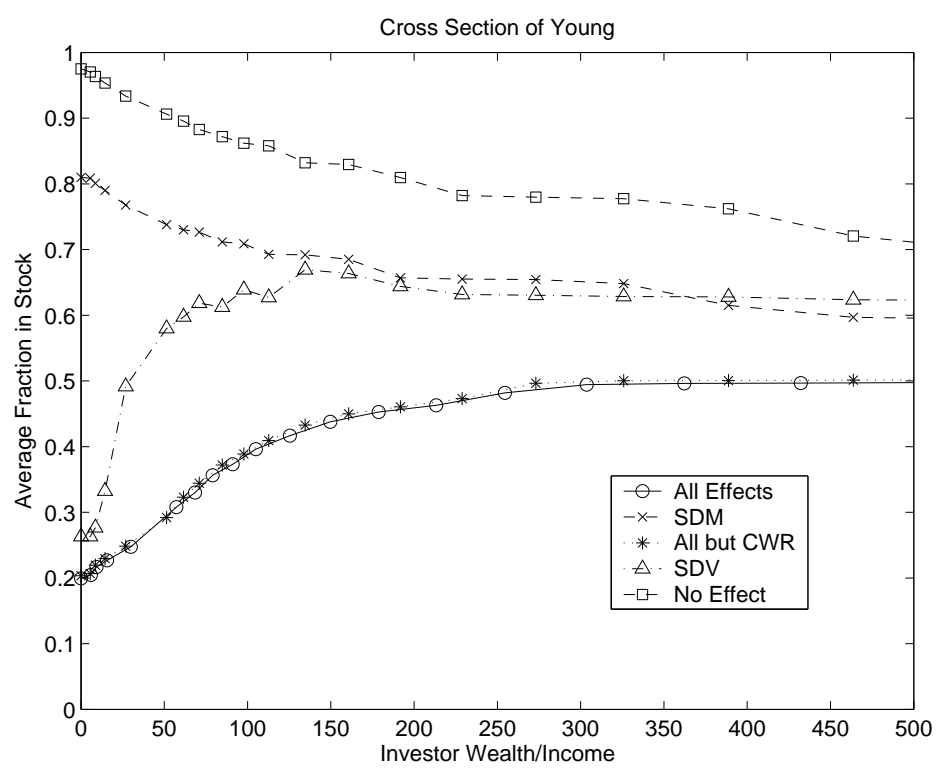

5.a Cross-sectional Fraction in Stock

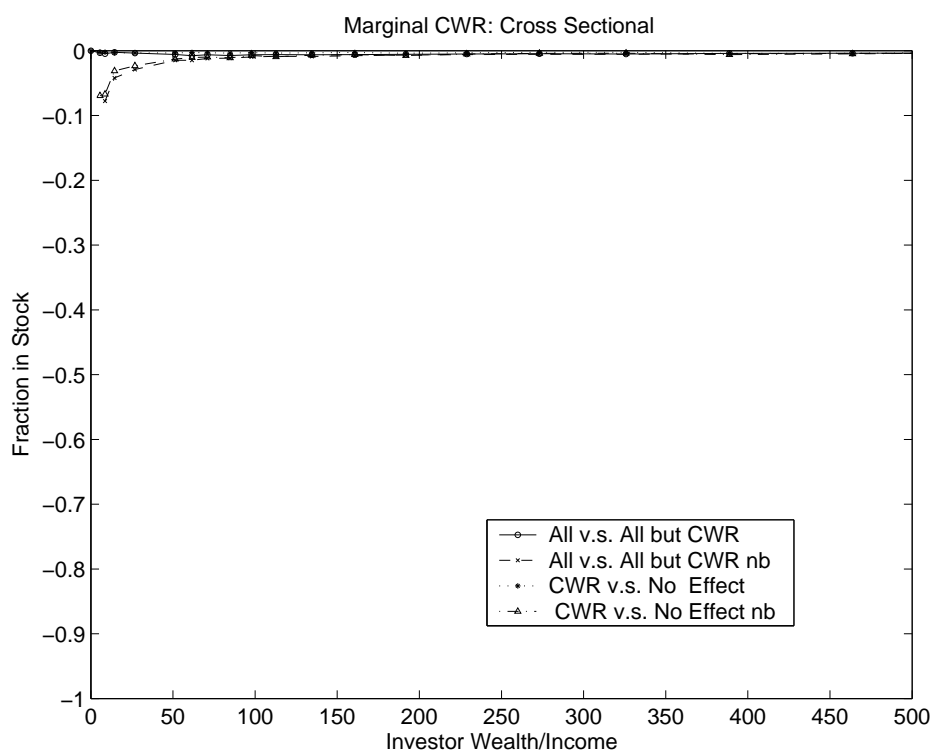

5.c Cross-sectional Impact on Fraction in Stock: CWR

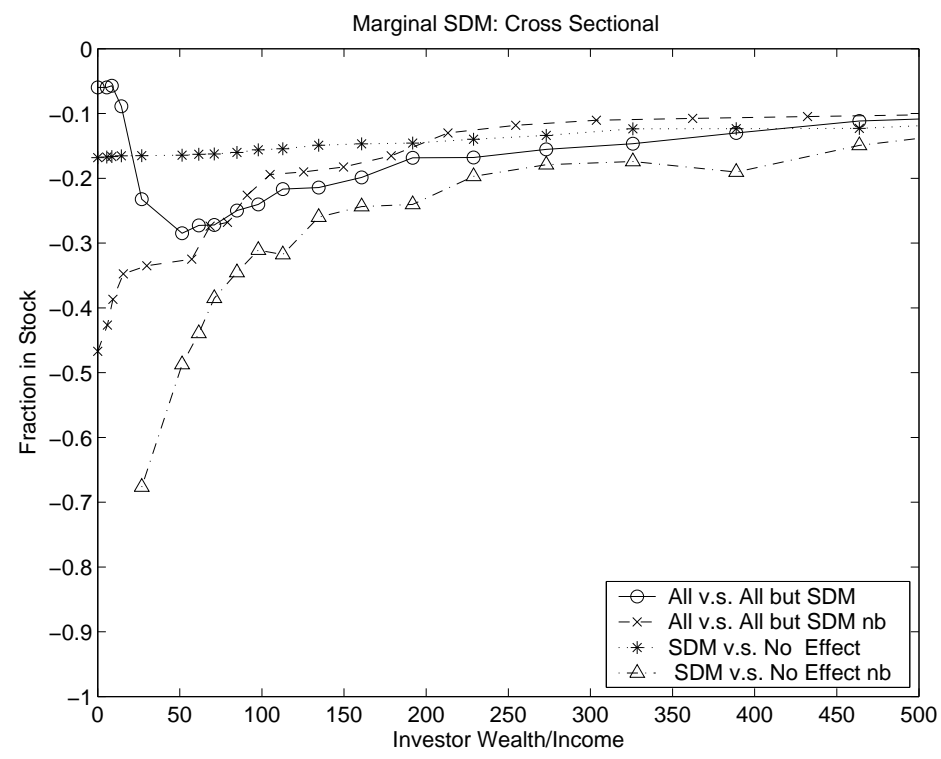

5.b Cross-sectional Impact on Fraction in Stock: SDM

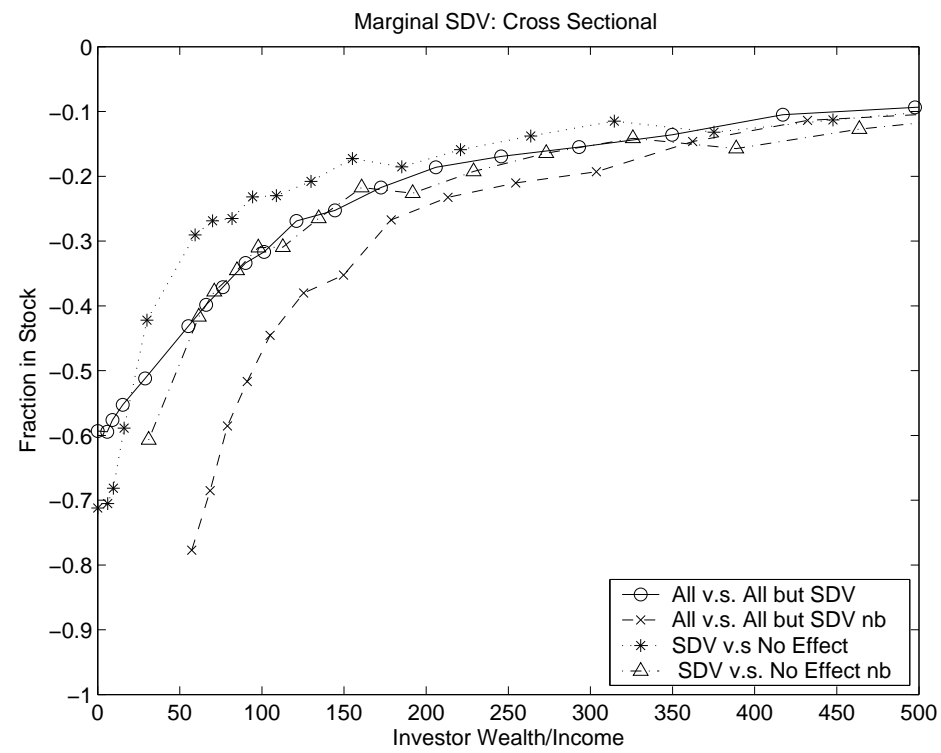

5.d Cross-sectional Impact on Fraction in Stock: SDV

FIGURE 5. FIRST MONTH CROSS-SECTIONAL ALLOCATION RESULTS. LIFE CYCLE SPECIFICATION. AGE-DEPENDENT INCOME GROWTH PROFILE. LUMP SUM RETIREMENT MONEY. SPECIFICATION-BASED PERMANENT INCOME VOLATILITY. NO TRANSITORY SHOCKS. RETAIL TRADE DATA. The figure reports cross sectional asset allocation results for a CRRA agent with a coefficient of risk aversion of 6 for the first month of her 78 year horizon, for a range of wealth to permanent income ratios of 0 to 500 . The agent starts work at age 22 and retires at 65 , receiving a lump sum payout equivalent to receiving $93.8 \%$ of her retirement permanent income until death as reported in Cocco, Gomes and Maenhout (2002) for college graduates. The agent dies with probability 1 at age 100, with death probabilities taken from the U.S. Life Tables, 2001, provided by the NCHS. The mean logarithmic monthly growth rate of permanent income is allowed to be age-dependent and is calibrated to the polynomial-smoothed income profile for college graduates in Cocco, Gomes and Maenhout (2002). The volatility of the logarithmic monthly growth rate of permanent income $\sigma_{g}$, is obtained from its annual counterpart (fixed at $15 \%$ from Gakidis (1997)), accounting for the assumed dynamics of the permanent income growth. There are no transitory shocks to income. Retail Trade Income (series CEU4200000004 by Bureau of Labor Statistics) is also used to calibrate labor income as described in Table 1. Agent has access to the market portfolio (value-weighted return on all NYSE, AMEX, and NASDAQ stocks) and to a riskless bond. Calibrations of these assets are as described in section 3 of the text. SDM, CWR and SDV denote, respectively, the state-dependent mean, return covariance and state-dependent volatility channels through which permanent labor income growth can affect stock holdings (see section 2.1 for descriptions). Subfigure 5.a reports average stock holdings for the combinations of channels indicated in the legend. Subfigures $b, c$ and $d$ report the reductions in stock holdings induced by SDM, CWR and SDV channels, respectively. This can be done either by switching on the channel in question when no other effect is present (i.e. SDM, CWR or SDV vs. No Effect) or switching off the channel when all other effects are present (i.e. All vs. All but SDM, CWR or SDV). $n b$ indicates that only states for which fractions of stock holdings for both cases needed for the comparison are strictly between 0 and 1 . The calibration of the 8 problems needed to do the comparisons is detailed in section 3 of the text. 


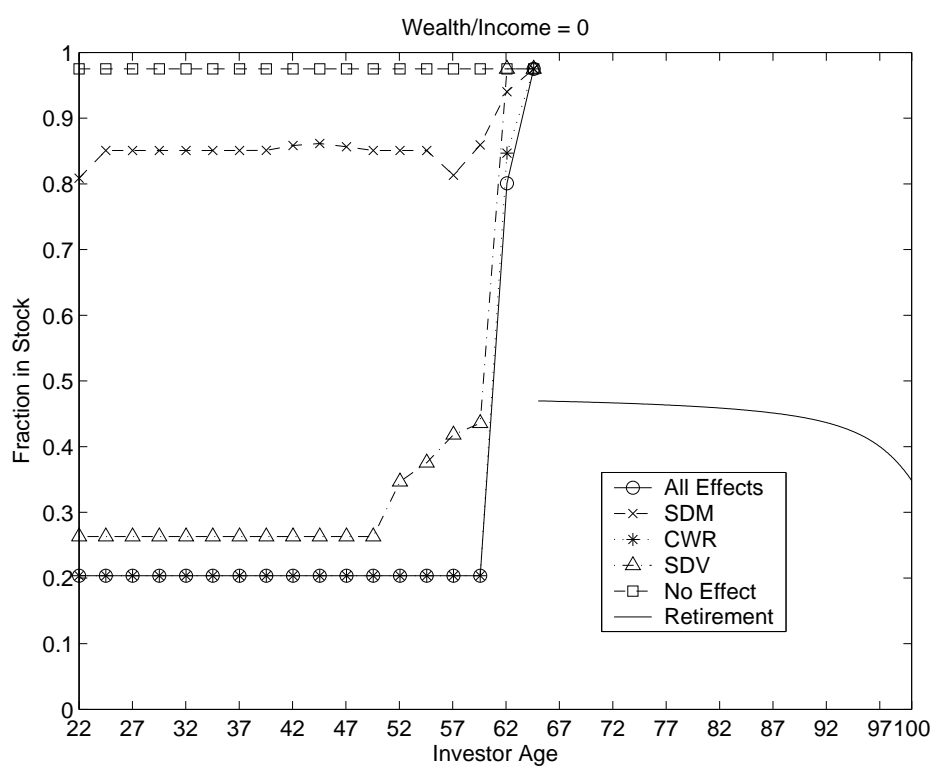

6.a Time Series Fraction in Stock

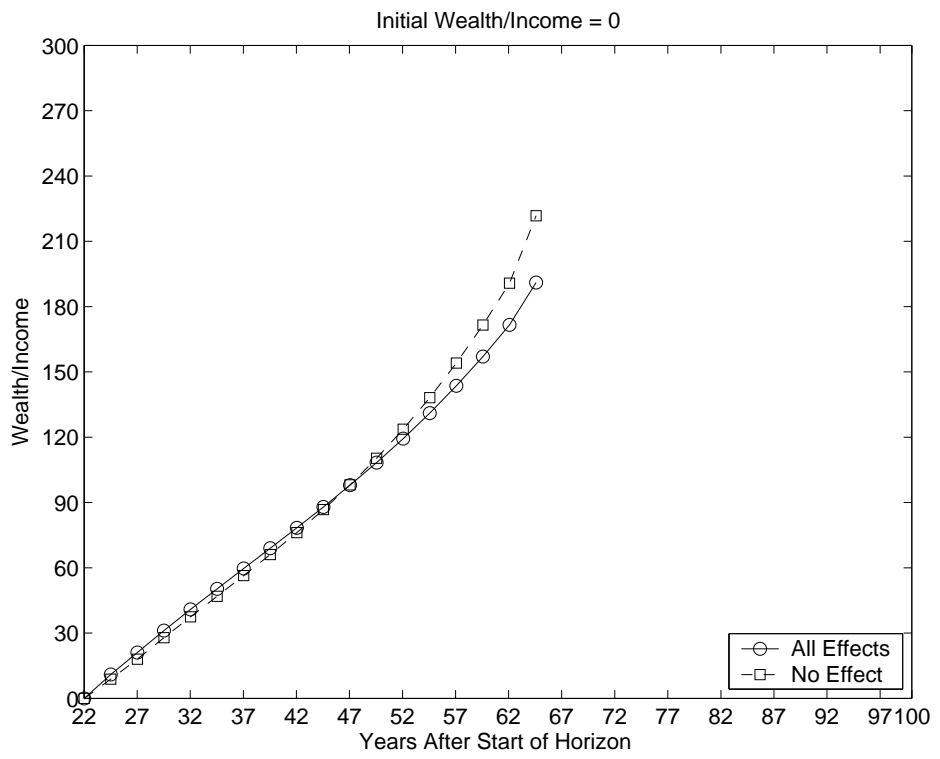

6.c Simulation Wealth/Income Stock

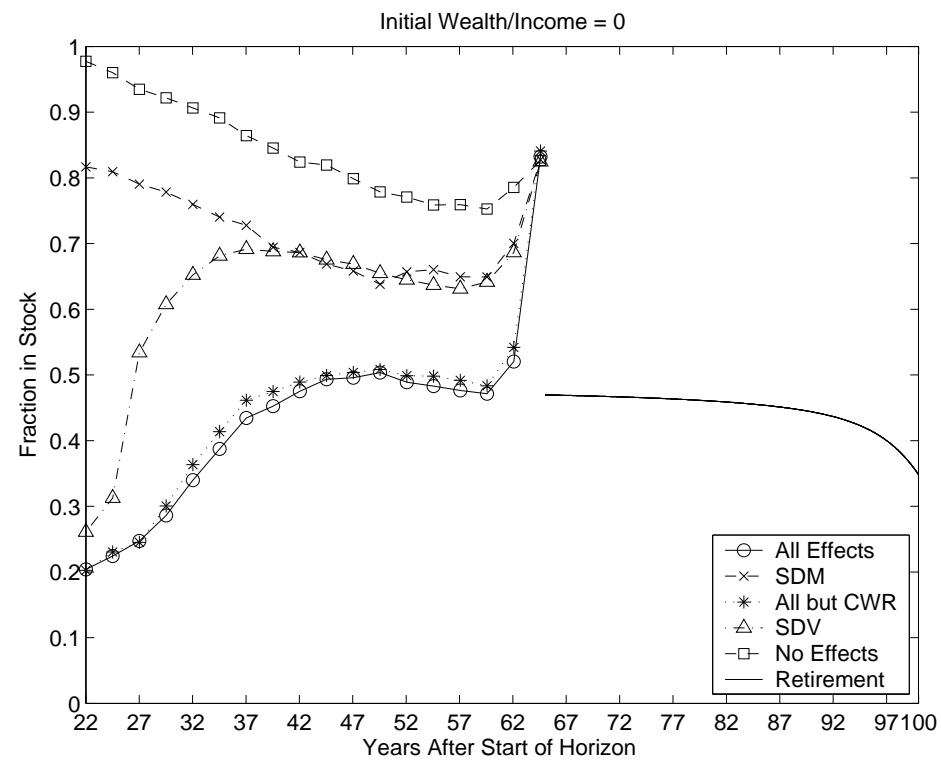

6.b Simulation Fraction in Stock

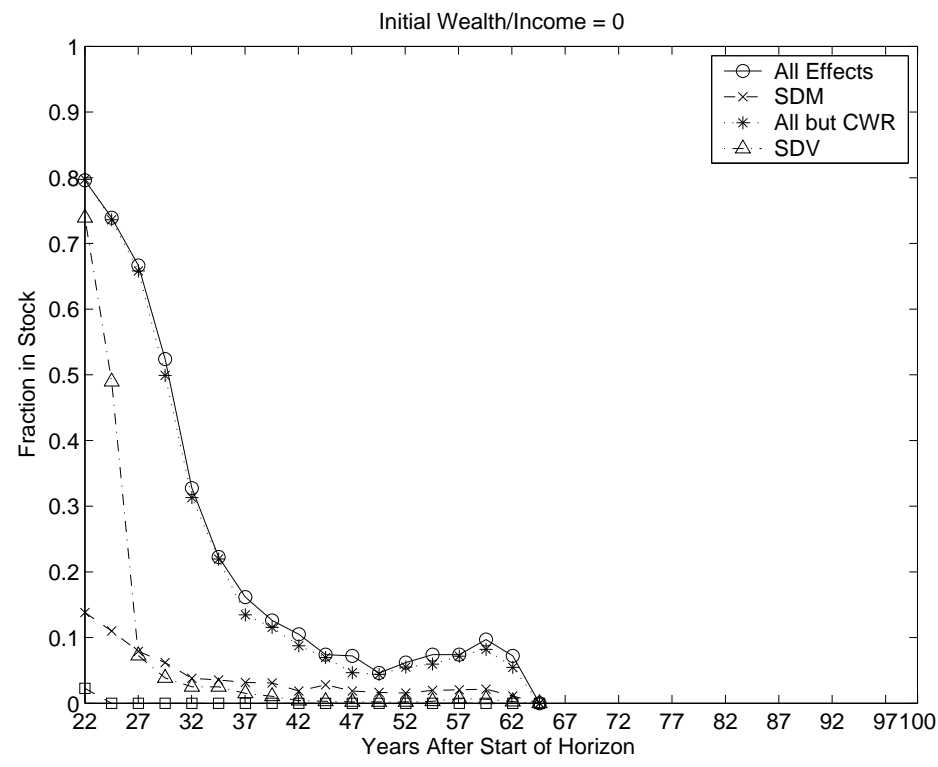

6.d Simulation Probability of Non-participation

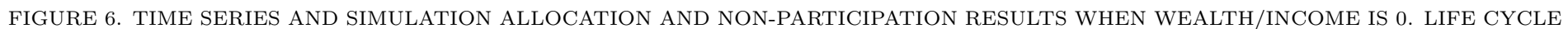

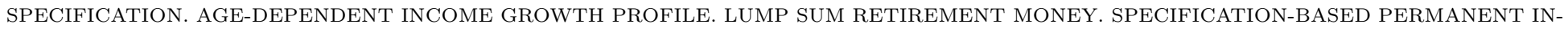

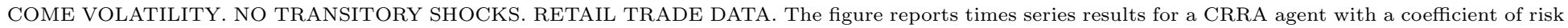

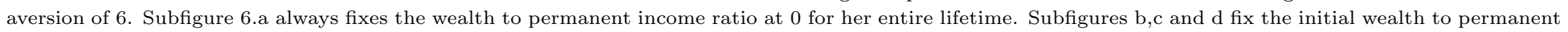

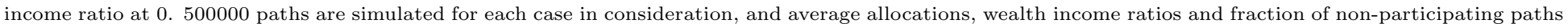

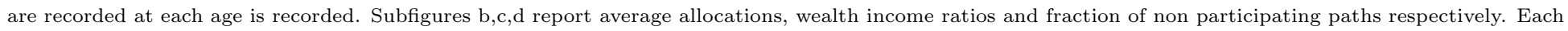

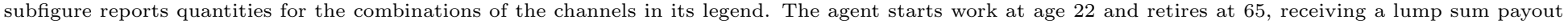

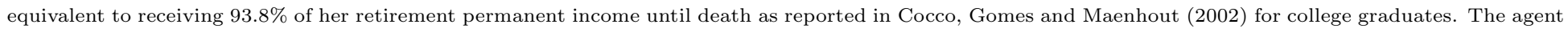

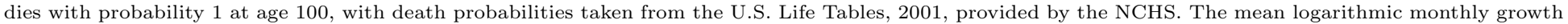

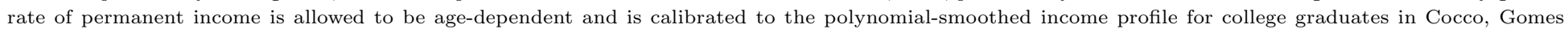

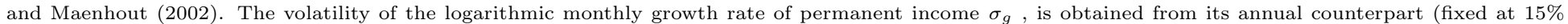

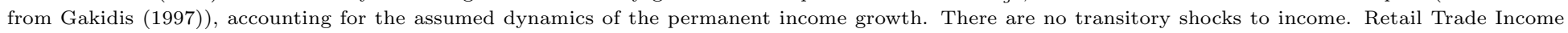

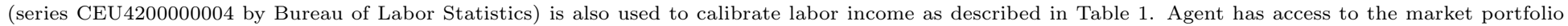

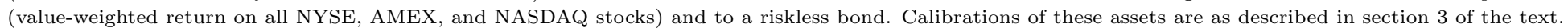

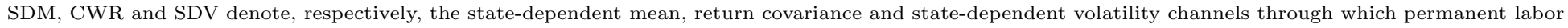

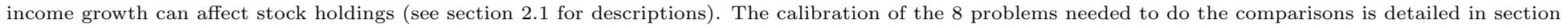
3 of the text. 


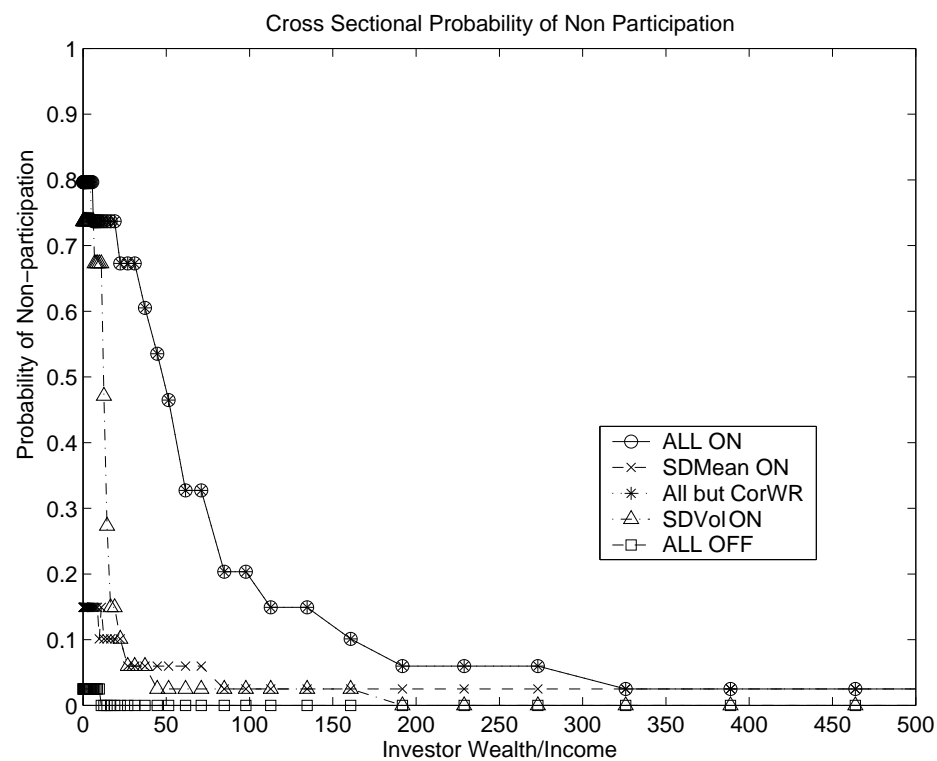

Cross-sectional Non-participation Probabilities

FIGURE 7. FIRST MONTH CROSS-SECTIONAL NON-PARTICIPATION RESULTS. LIFE CYCLE SPECIFICATION. AGE-DEPENDENT INCOME GROWTH PROFILE. LUMP SUM RETIREMENT MONEY. SPECIFICATION-BASED PERMANENT INCOME VOLATILITY. NO TRANSITORY SHOCKS. RETAIL TRADE DATA. The figure reports cross sectional non-participation probabilities for a CRRA agent with a coefficient of risk aversion of 6 for the first month of her 78 year horizon, for a range of wealth to permanent income ratios of 0 to 500 . The agent starts work at age 22 and retires at 65 , receiving a lump sum payout equivalent to receiving $93.8 \%$ of her retirement permanent income until death as reported in Cocco, Gomes and Maenhout (2002) for college graduates. The agent dies with probability 1 at age 100, with death probabilities taken from the U.S. Life Tables, 2001, provided by the NCHS. The mean logarithmic monthly growth rate of permanent income is allowed to be age-dependent and is calibrated to the polynomial-smoothed income profile for college graduates in Cocco, Gomes and Maenhout (2002). The volatility of the logarithmic monthly growth rate of permanent income $\sigma_{g}$, is obtained from its annual counterpart (fixed at $15 \%$ from Gakidis (1997)), accounting for the assumed dynamics of the permanent income growth. There are no transitory shocks to income. Retail Trade Income (series CEU4200000004 by Bureau of Labor Statistics) is also used to calibrate labor income as described in Table 1. Agent has access to the market portfolio (value-weighted return on all NYSE, AMEX, and NASDAQ stocks) and to a riskless bond. Calibrations of these assets are as described in section 3 of the text. SDM, CWR and SDV denote, respectively, the state-dependent mean, return covariance and state-dependent volatility channels through which permanent labor income growth can affect stock holdings (see section 2.1 for descriptions). Figure reports average non-participation probabilities for the combinations of channels indicated in the legend. The calibration of the 8 problems needed to do the comparisons is detailed in section 3 of the text. 


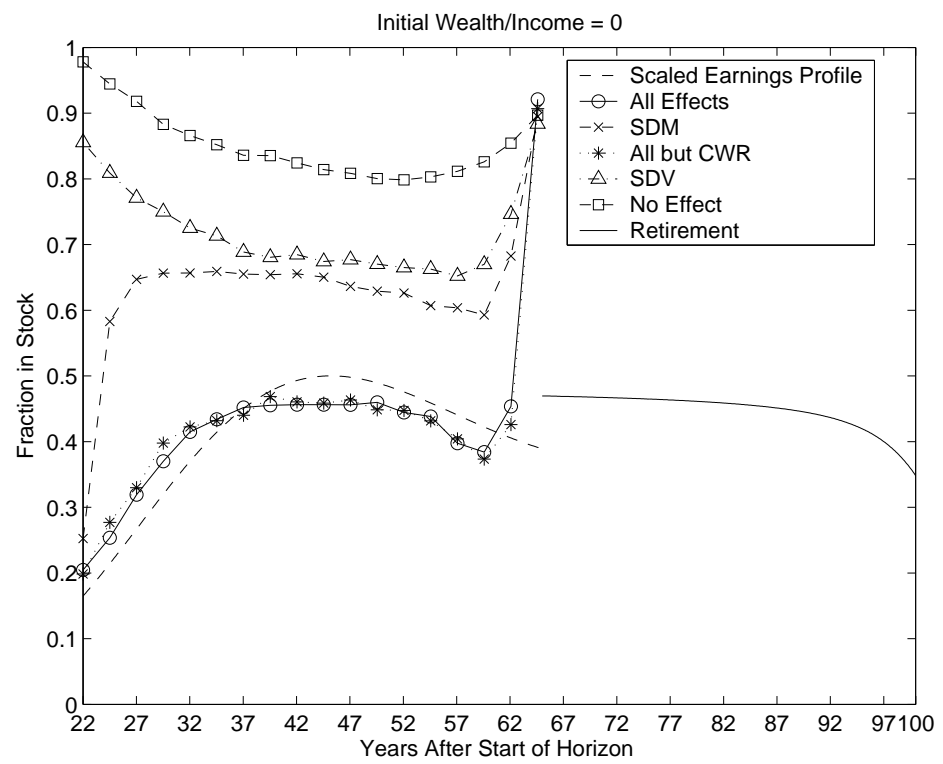

No Earnings Hump

FIGURE 8. SIMULATION ASSET ALLOCATION RESULTS. LIFE CYCLE SPECIFICATION. FLAT INCOME GROWTH PROFILE. LUMP SUM RETIREMENT MONEY. SPECIFICATION-BASED PERMANENT INCOME VOLATILITY. NO TRANSITORY SHOCKS. RETAIL TRADE DATA. The figure reports simulation asset allocation results for a CRRA agent with a coefficient of risk aversion of 6 and always fixing the initial wealth to permanent income ratio at 0.500000 paths are simulated for each case in consideration, and average allocations at each age is recorded.Initial dividend yield states are drawn form their unconditional distribution. The agent starts work at age 22 and retires at 65 ,receiving a lump sum payout equivalent to receiving $93.8 \%$ of her retirement permanent income until death as reported in Cocco, Gomes and Maenhout (2002) for college graduates. The agent dies with probability 1 at age 100, with death probabilities taken from the U.S. Life Tables, 2001, provided by the NCHS. The mean monthly growth rate of permanent income is set to $3 \%$ p.a. based on Gakidis (1997). The volatility of the logarithmic monthly growth rate of permanent income $\sigma_{g}$, is obtained from its annual counterpart (fixed at $15 \%$ from Gakidis (1997)), accounting for the assumed dynamics of the permanent income growth. There are no transitory shocks to income. Retail Trade Income (series CEU4200000004 by Bureau of Labor Statistics) is also used to calibrate labor income as described in Table 1. Agent has access to the market portfolio (value-weighted return on all NYSE, AMEX, and NASDAQ stocks) and to a riskless bond. Calibrations of these assets are as described in section 3 of the text. SDM, CWR and SDV denote, respectively, the state-dependent mean, return covariance and state-dependent volatility channels through which permanent labor income growth can affect stock holdings (see section 2.1 for descriptions). Each subfigure reports average stock holding paths for the combinations of channels indicated in its legend. The calibration of the 8 problems needed to do the comparisons is detailed in section 3 of the text. 


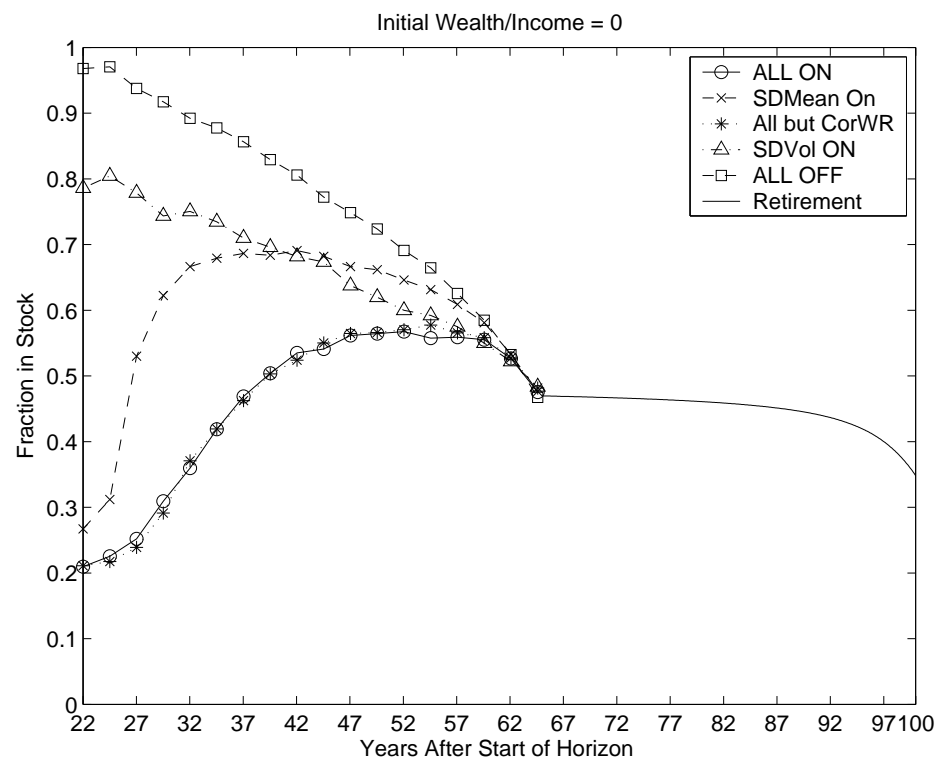

No Retirement Money

FIGURE 9. SIMULATION ASSET ALLOCATION. LIFE CYCLE SPECIFICATION. AGE-DEPENDENT INCOME GROWTH PROFILE. NO RETIREMENT MONEY. SPECIFICATION-BASED PERMANENT INCOME VOLATILITY. NO TRANSITORY SHOCKS. RETAIL TRADE DATA. The figure reports simulation asset allocation results for a CRRA agent with a coefficient of risk aversion of 6 and always fixing the initial wealth to permanent income ratio at 0. 500000 paths are simulated for each case in consideration, and average allocations at each age is recorded.Initial dividend yield states are drawn form their unconditional distribution. The agent starts work at age 22 and retires at 65 . The agent receives no lump sum on retirement. The agent dies with probability 1 at age 100, with death probabilities taken from the U.S. Life Tables, 2001, provided by the NCHS. The mean logarithmic monthly growth rate of permanent income is allowed to be age-dependent and is calibrated to the polynomial-smoothed income profile for college graduates in Cocco, Gomes and Maenhout (2002). The volatility of the logarithmic monthly growth rate of permanent income $\sigma_{g}$, is obtained from its annual counterpart (fixed at $15 \%$ from Gakidis (1997)), accounting for the assumed dynamics of the permanent income growth. There are no transitory shocks to income. Retail Trade Income (series CEU4200000004 by Bureau of Labor Statistics) is also used to calibrate labor income as described in Table 1. Agent has access to the market portfolio (value-weighted return on all NYSE, AMEX, and NASDAQ stocks) and to a riskless bond. Calibrations of these assets are as described in section 3 of the text. SDM, CWR and SDV denote, respectively, the state-dependent mean, return covariance and state-dependent volatility channels through which permanent labor income growth can affect stock holdings (see section 2.1 for descriptions). SDM, CWR and SDV denote, respectively, the state-dependent mean, return covariance and state-dependent volatility channels through which permanent labor income growth can affect stock holdings (see section 2.1 for descriptions). Each subfigure reports average stock holding paths for the combinations of channels indicated in its legend. The calibration of the 8 problems needed to do the comparisons is detailed in section 3 of the text. 